INNOVATIVE COAL-FUELED DIESEL ENGINE INJECTOR

Final Report

By

P. Badgley

D. Doup

May 1991

Work Performed Under Contract No. AC21-88MC25132

For

U.S. Department of Energy Morgantown Energy Technology Center

Morgantown, West Virginia

By

Adlabatics, Inc.

Columbus, Indiana 


\section{DISCLAIMER}

This report was prepared as an account of work sponsored by an agency of the United States Government. Neither the United States Government nor any agency thereof, nor any of their employees, makes any warranty, express or implied, or assumes any legal liability or responsibility for the accuracy, completeness, or usefulness of any information, apparatus, product, or process disclosed, or represents that its use would not infringe privately owned rights. Reference herein to any specific commercial product, process, or service by trade name, trademark, manufacturer, or otherwise does not necessarily constitute or imply its endorsement, recommendation, or favoring by the United States Government or any agency thereof. The views and opinions of authors ex. pressed herein do not necessarily state or reflect those of the United States Government or any agency thereor.

This report has been reproduced directly from the best available copy.

Available to DOE and DOE contractors from the Office of Scientific and Technical Information, P.O. Box 62, Oak Ridge, TN 37831; prices available from (615)576-8401, FTS 626-8401.

Available to the public from the National Technical Information Service, U.S. Department of Commerce, 5285 Port Royal Rd., Springfield, VA 22161. 


\title{
Innovative Coal-Fueled Diesel Engine Injector
}

\author{
Final Report
}

P. Badgley

D. Doup

Work Performed Under Contract No.: DE-AC21-88MC25132

\author{
For \\ U.S. Department of Energy \\ Office of Fossil Energy \\ Morgantown Energy Technology Center \\ P.O. Box 880 \\ Morgantown, West Virginia 26507-0880
}

By

Adiabatics, Inc.

3385 Commerce Drive

Columbus, Indiana 47201

May 1991 
Adlabatics, Inc. would like to acknowledge the following organizations and individuals who have performed specitia key functions in making this project a success.

First and foremost is the help and guidance provided by METC's Contracting Officer's Technical Representative (COTR) Mr. William C. Smith. Adiabatics. Inc. is also appreciative of the encouragement and support of Mr. Michael McMillian, Project Manager, Heat Engines and Dr. Holmes A. Webb, Branch Chiet. Heat Fingines.

The authors would like to thank Adiabatics, Inc personnel: Mr. Michael Baker and Mr. Jerry Harper for contributions in the areas of test engine hardwase and testing: Mr. Michael. Greathouse for the design and drafting work; Mr. Foy Kamo and Mr. David McNulty for technical suggestions during this progrim: Mr. Lloyd Kamo and Ms. Carol Young, for the contract administration; Dr. Rao Mittinti for his assistance in compiling, writing and editing; and Ms. Tina collins for help in preparing, this report. The authors would like to thank Dr. R. M. Kakwani for managerial and design efforts during Phase $I$ of this program. The contributions of Mr. L.K. Ives of the National Institute of Standards and Technology in taking SEM photomicrographs of the nozzle is a]so Eratefully acknowledged. 
ACKNOWLEDGMENTS .

PAGE

LIST OF TABLES

LIST OF FIGURES.

EXECUTIVE SUMMARY.

1.0 INTRODUCTION.

2.0 PURPOSE

3.0 BACKGROUND REVIEW OF CWS INJECTION SYSTEMS. . . . . . . . . . . . 1

3.1 CWS INJECTION SYSTEM BY GE . . . . . . . . . . . . . . . . . 2

3.2 CWS INJECTION SYSTEM BY A.D. LITTLE/COOPER BESSEMER. . . . 2

3.3 TECHNICAL PROBLEMS WITH CWS INJECTORS. . . . . . . . . . . 3

3.4 TICS CONCEPT BY ADIABATICS, INC. . . . . . . . . . . . . . 3

4.0 PROJECT METHODOLOGY . . . . . . . . . . . . . . . . . . . . . . 6

4.1 PROJECT OBJECTIVES . . . . . . . . . . . . . . . . . . . . 6

4.2 TECHNICAL APPROACH .. . . . . . . . . . . . . . . . . . . 6

4.3 INNOVATJVE CWS INJECTOR. . . . . . . . . . . . . . . . . . . . . . . 7

4.4 EXPERIMENTAL SETUP . . . . . . . . . . . . . . . . . . . . 13

4.4.1 Engine and Emissions Systems Setup. . . . . . . . . 13

4.4.2 Types of CWS Fuel................ . 18

5.0 RESULTS AND DISCUSSION. . . . . . . . . . . . . . . . . . 18

5.1 PRELIMINARY ENGINEERING - PHASE I. . . . . . . . . . . . . . . 18

5.1.1 Bench Testing of CWS Injector. . . . . . . . . . . 18

5.1.2 Engine Test Summary and Wear Results. . . . . . . . 21

5.1.3 Performance with CWS, Dry Coal Powder
and Diesel (DF非) Fuels . . . . . . . . . . . . 21.2

5.1.4 Effect of Engine Load... . . . . . . . . . . . . . 31

5.1.5 Effect of Engine Speed. . . . . . . . . . . . . . . 31

5.1.6 Effect of CWS Injection Pressure. . . . . . . . . . 39

5.2 DEVELOPMENT ENGINEERING - PHASE $1 \mathrm{I}$. . . . . . . . . . . . 39

5.2.1 Precombustion Chamber Design. . . . . . . . . . . . 45

5.2.2 Effect of Injection Timing. . . . . . . . . . . . 45

5.2.3 Effect of PCC Temperature ............ . 53

5.2 .4 Effect of PCC Volume. . . . . . . . . . . . . . . . 53

5.2.5 Effect of Injector Orifice Diameter........ . 53

5.2.6 Effect of CWS Injection Pressure. . . . . . . . . . 61

5.2.7 Effect of Exhaust Gas Recirculation.... . . . . . 61

5.2.8 Particulate Measurements. . . . . . . . . . . . . 61

5.2.9 Emissions and Performance Summary. . . . . . . . . 67

5.2.10 Wear Data Summary . . . . . . . . . . . . . . . 67

5.3 TECHNICAL CONCERNS . . . . . . . . . . . . . . . . . . . . . 82

5.3.1 Coal Water Slurry Quality and Handling. . . . . . . $\varepsilon_{2}$

5.3.2 Engine Contamination. . . . . . . . . . . . . . . . \& 2

5.3.3 Deposit Formation In PCC and on Piston. . . . . . . 82

5.3.4 Nozzle Orifice and Cylinder Head Cracking . . . . . 86

6.0 CONCLUSIONS . . . . . . . . . . . . . . . . . . . . . . . . 86

7.0 RECOMMENDATIONS FOR FUTURE WORK . . . . . . . . . . . . . . . . . 88

REFERENCES .... . . . . . . . . . . . . . . . . . . . 89 
Table Ne.

$4.4 .2-1$

$5.1 .2-1$

$5.1 .3-1$

$5.1 .4-1$

$5.1 .5-1$

$5.2 .2-1$

$5 \cdot 2 \cdot 4-1$

$5.2 .8-1$

$5.2 .10-1$

$5 \cdot 2 \cdot 10-2$
Title

Page No.

Analysis of CWS Fuels Used

Summary of Initial CWS-Fueled Engine Tests and Nozzle Hole Wear Data in Phase I (Standard Steel

Nozzle with Single Hole Spray) . . . . . . . . . .

Comparison of CWS, Coal Powder and DF俳 Fueled Englne Performance. . . . . . . . . . . . . . . .

100\% CWS-Fueled Engine Performance at Various Loads. 32

100\% CWS-Fueled Engine Performance at Various Speeds 36 Plot Legend. . . . . . . . . . . . . . . . . . . . . 54 Summary of Prechamber Volumes Tested. . . . . . . . 59 Correlation Between Smoke and Particulates.... . 66

Summary of Phase II CWS-Fueled Engine Tests and Nozzle Hole Wear Data.

Summary of Piston Ring Wear. . . . . . . . . . . . . 80 
Reduction in Fuel Injection Nozzle Pressure as a Function of ' $\mathrm{Time}$ on CWS (GE Data).

Erosive Wear of Orifices by Continuous $27.58 \mathrm{MPa}$ (4,000 psi) CWS Flow (GE Data). . . . . . . . . . . 5

Photographs of CWS injector (with accumulator) and Its Installation on the rest Engine.

Photograph of the Bladder Accumulator and Micromotion Mass Flowmeter Used for the CWS-Injection System. .

Photograph of CWS Handling System Used for the CWS-Injection System . . . . . . . . . . . . . . . plunger) Used for the CWS Injector. . . . . . . .

SEM Photomicrographs of Nozzle Hole After CWS-Fueled Bench and Engine Tests... . . . . . . . . . . .

Photographs of CWS Injector, and Nozzie and Plunger After CWS-Fueled Engine Tests. . . . . . . . . . . . 
Comparison of Cylinder Pressure Data for Coal

Powder, CWS and DF非 2 at 1,000 RPM Engine Speed.

Cylinder Pressure Diagrams for Blue Gem Seam

Cylinder Pressure Data for 100\% Blue Gem Seam

Heat Release Data for 100\% Blue Gem Seam CWS-

Cylinder Pressure Data for CWS-Fueled Engine Tests From 13.8 to $20.7 \mathrm{MPa}$ CWS Injection Pressures. . . 
Elgure No.

$5.2 . ?-2$

$5.2 .2-3$

$5.2 .3-1$

$5.2 .3-2$

$5 \cdot 2 \cdot 3 \cdot 3$

$5.2 .3-4$

$5.2 .3-5$

$5.2 \cdot 3-6$

$5 \cdot 2 \cdot 4-1$

$5 \cdot 2 \cdot 5-1$

$5 \cdot 2 \cdot 6-1$

$5.2 .7-1$

5. $2.8-1$

$5 \cdot 2.9-1$

5. 2.9-2

$5 \cdot 2 \cdot 9 \cdot 3$

$5.2 .9-4$

$5.2 .9-5$

5. $2.9-6$

$5.2 .9-7$

$5.2 .9-8$

$5.2 .9-9$

5. $2.9-10$

$5.2 .9-11$

5. $2.9-12$
Title

Page No.

Beginning of Injection Timing (1,00) RPM). 55 Beginning of Injection Timing (1,400 RPM). . . . . . 55

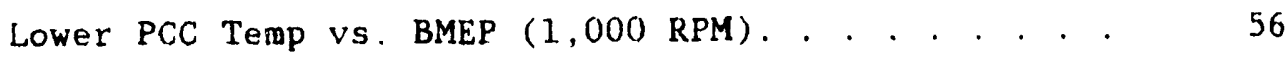

Lower Prechamber Temperature (1,400 RPM) . . . . . . 56

Lower Prechamber Temperature $(1,800$ RPM $) .. . . .957$

Upper vs. Lower PCC Temperature (1,000 RPM). . . . . 57

Upper vs. Lower PCC Temperature (1,400 RPM). . . . . 58

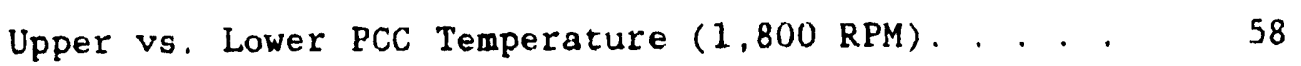

Effect of Prechamber Volume at 1,800 RPM . . . . . . 60

Effect of Nozzle Hole Diameter at 1,800 RPM. . . . . 62

Effect of Injection Pressure at 1,400 RPM. . . . . . 63

Effect of EGR at 1,400 RPM . . . . . . . . . . . . 64

Ceramic Particulate Sampling System. . . . . . . . 65

Brake Specific Fuel Consumption (1,000 RPM). . . . 68

Brake Specific Fuel Consumption (1,400 RPM). . . . . 68

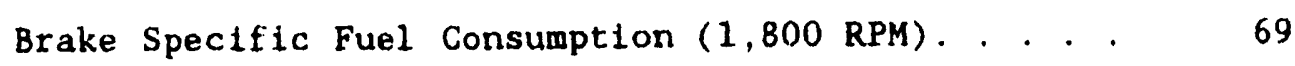

Brake Thermal Efficiency (1,000 RPM) . . . . . . . 69

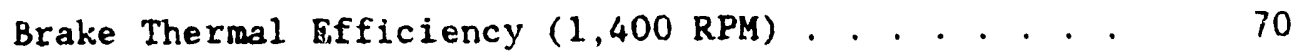

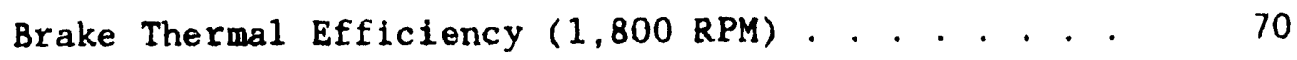

Engine Temperature Rise $(1,000$ RPM ). . . . . . . . . 71

Engine Temperature Rise (1,400 RPM). . . . . . . . . 71

Engine Temperature Rise (1,800 RPM). . . . . . . . . 72

Engine Temperature Rise (A11 Speeds and A11 Loads) . 72

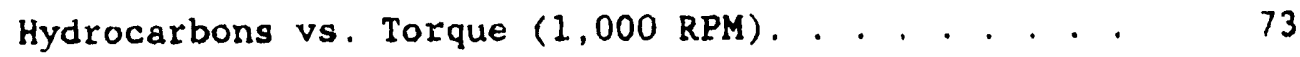

Hydrocarbons vs. Torque $(1,400$ RPM). . . . . . . . 73 


\section{LIST OF FIGURES}

Ei rure No.

Hydrocarbons vs. Torque $(1,800$ RPM $)$. . . . . . . . 74

$5.2 .9-14$

NOx Ernissions (1,000 RPM). . . . . . . . . . . . . . 74

$5.2 .9-15$

N()x Emissions (1,400 RPM). . . . . . . . . . . . . 75

$5.2 .9-16$

NOx Emissions (1,800 RPM). . . . . . . . . . . . . 75

$5.2 .9-17$

Carbon Monoxide Emissions (1,000 RPM). . . . . . . 76

$5.2 .9-18$

Carbnn Monoxide Emissions (1.400 RPM). . . . . . . . 76

$5.2 .9-19$

Carbon Monoxide Emissions (1,800 RPM). . . . . . . . 77

$5.2 .9-20$

Exhaust Smoke (1,000 RPM). . . . . . . . . . . . . 77

$5 \cdot 2 \cdot 9 \cdot 21$

Exhaust Smoke $(1,400 \mathrm{RPM})$. . . . . . . . . . . . . . 78

$5.2 .9-22$

Exhaust Smoke (1,800 RPM). . . . . . . . . . .

Caterpillar Piston After 28.1 Hours of $100 \%$

CWS Engine Operation. . . . . . . . . . . . . . . .

$5.3 .1-1$

Large Particles Filtered Out of CWS Before Testing Began. . . . . . . . . . . . . . . . . . . .

Load Contaminants Collected in Centrifugal Filter After 8 Hours of $100 \%$ CWS Engine Testing . . . . .

$5 \cdot 3 \cdot 3-1$

Pepper Pot Type Prechamber After One Hour of $100 \%$

CWS Engine Testing With Blue Gem Seam Coal.... . 
This report. cntitled "Innovative Coal-Fueled Diesel Engine Injector." describes the progress and tindings of a research program aimed at development of the coal water slury (CWS) injection system in conjunction with the Thermal Ignition Combustion svstem (TICS) concept to achieve autoignition of CWS at various loads and speed ranges (up to $1.800 \mathrm{lpm}$ ) in a single-crlinder diesel engine. This work was performed under the U.S. Department of Energy. Morgantown Energy Technology Center (DOE-METC) contract number DE-AC21-88MC.25132 from September 1988 ro March 1991.

The rest results obtained during this program show the development of an electronically control!ed, hydraulically actuated chs-injection system operating at low injection pressures of 13.8 to 20.7 MPa (2.000 to 3.000 psi) with very low wear of the nozzle spray orifice as compared to the wear data reported for other CWS injectors. Also, the program ibjectives of 100 percent CWS-fueled engine operation with the TICS concept without the use of external Ignition assist sources up to $1.800 \mathrm{rpm}$ were achieved. The high level of: ignition energy in the TICS chamber enabled combustion of CWS fuel in the test engine.

High heat release rates and short combustion durations were observed for the Kentucky Blue Gem seam CWS-fueled engine tests with the TICS concept. The heat release analysis shows a significant portion of the CWS fuel burning in the prenixed combustion mode. An increase in CWS injection pressure from 13.8 to $2.7 \mathrm{MPa}$ increased the peak heat release rate. Performance data for coal powder. CWS and diesel-fueled engine tests show higher cylinder pressure and heat release rates for coal powder and CWS compared to diesel fuel. In the case of 100 percent Cis-fueled operation. test data up to 1,800 rpm speed range shows a maximum brake thermal efficiency of $33 . j$ percent at $1.000 \mathrm{rpm}$ in the single cylinder test engine. However, the brake thermal efficiency in the multi-cylinder CWS-fueled engine will be ever higher. The test engine operation was optimized during 45 hours anri 40 minutes of 100 percent vis engine testing during Phase II of the program with further study of the effects of different parameters on the CWS injection and combustion. Amongst them are included: Improved performance with the swirl type precombustion chamber (PCC) design and larger (47cC) PCC volume. There exist optimum values of PCC temperature $\left(982^{\circ} \mathrm{C}\right)$, nozzle orifice size (imm). injection timing and exhaust gas recirculation (EGR - 10 percent). Further, gaseous emissions, smoke and particulate measurements were made. Based upon the emissions measurements the combustion efflciency (carbon burnout) was of the order of 99 percent.

To date, no emissions standards have been set for stationary coal fueled engines (regarding $\mathrm{NOx}, \mathrm{HC}, \mathrm{CO}$, etc. except in California). The stringent 1394 Federal heavy duty truck emission 1 imits are $6.7 \mathrm{~g} / \mathrm{kW} . \mathrm{h}$ Nox, $1.74 \mathrm{~g} / \mathrm{kW} . \mathrm{h}$ $\mathrm{HC}, 20.8 \mathrm{~g} / \mathrm{kW} . \mathrm{h} \mathrm{CO}$, and $0.13 \mathrm{~g} / \mathrm{kW} . \mathrm{h}$ particulates. The measurements under optimum conditions indicate that the present Caterpillar $1 Y 73$ engine running with CWS and using the TICS combustion system has the potential to meet the 1494 emission standards. Further, it is interesting to note that with the TICS, the temperatures in the combustion chamber could be maintained higher at idle and low loads which could help in lowering HC and CO further. Also, with the CWS operation. the NOx decreased as the load increased which is an added advantage over the diesel and other I.C. engines. 


\subsection{INTRODUCTION}

This report entitled "Innovative Coal-Fueled Diesel Engine Injector." is submitted to the U.S. Department of Energy, Morgantown Energy Technology Center (DOE-METC) per the requirements of their contract number DE-AC21-88MC25132. This report describes the results and findings of a research program aimed at development of an electronically controlled coal water slurry (CWS) injection system in conjunction with the Thermal Ignition Combustion System (TICS) to achieve autoignition of CWS.

During the past several years, the U.S. Department of Energy, Morgantown Energy Technology Center, has sponsored research programs for the development. of coal-fueled diesel engines $[1,2]^{*}$. Most of these programs have used coal water slurry as fuel for the engine. The major coal-fueled reciprocating engine development programs are being conducted by General Electric Company [3,4] and A-D Little/Cooper Bessemer [4,5] which rely on high pressure infection of CWS into a direct injection diesel engine. These CWS-fueled engines require ignition assist devices such as the injection of diesel fuel pilot or a natural gas torch. In some instances, intake air heating was required to improve the combustion of CWS or to allow the engine operation with 100 percent. CWS fuel. The major problem encountered with these engines has been the wear of fuel injection nozzle spray holes, cylinder liners and piston rings. An additional complication of using CWS fuel is that the 50 percent water cont.ht cuts the effective fuel heating value in half and requires the injection capacity to be twice that required with diesel fuel to maintain the same power level.

\subsection{PURPOSE}

The purpose of this research investigation was to develop an electronic coal water slurry injection system in conjunction with the Thermal Ignition Combustion system (TICS) concept to achieve autoignition of CWS at various engine load and speed conditions without external ignition sources. The combination of the new injection system and the TICS is designed to reduce irjector nozzle spray orifice wear by lowering the peak injection pressure requirements.

\subsection{BACKGROUND REVIEW OF CWS INJECTION SYSTEMS}

The development of CWS injection systems has been the focus of recent investigations by many companies e.g. GE, A.D. Little/Cooper Bessemer, and EMD/SwRI. Earlier research and development work by Southwest Research Institute, NIPER, Sulzer, and Energy and Environmental Research Corporation has resulted in considerable progress in fuel injection systems for coal slurries. However, CWS injectors still need $R \& D$ work to achieve the durability required for commercial engine applications.

Numbers in parentheses designate references at the end of the report. 


\subsection{CWS Injection System by GE}

During the investigation of CWS fuel using the GE/7FDL research engine, GE has developed three types of CWS injection systems $[6,7]$ as follows:

- System I fuel injection equipment (FIE) consisted of modified standard size diesel fuel injection equipinent with a CWS isolation pump placed between the high pressure pump and the injector to prevent plunger sticking. Due to the low volumetric energy density of CWS compared to diesel fuel, the engine was operated at only $1 / 3$ of full load with $40 \mathrm{MPa}$ maximum injection pres:ure.

- System II FIE was an up-scaled version of System I fIE capable of supplying CWS for the full load engine operatioli.

- System III FIE consisted of an accumulator based CWS injection system with high injection pressure at the start of the injection cycle and whose operation is fairly independent of engine speed and load. This injection system has been found to improve CWS burnout considerably at both full and part engine loads. In the CWS accumulator infection system, a conventional jerk pump was used to pump diesel oil to a diaphragm pump. The CWS on the opposite slde of the diaphragm was thus pressurized and pushed into the accumulator injector. The accumulator volume of this injector is about $325 \mathrm{cc}$. The system was sized to inject $3 \mathrm{gm}$ of CWS per injection, with the injection pressure falling from 70 to $48 \mathrm{MPa}$ as infection occurred. GE has evaluated a number of different nozzle geometries - 10 to 12 holes and 0.39 to $0.51 \mathrm{~mm}$ hole diameters. The CWS fueled engine test results with the accumulator injector have been presented by Flynn and Hsu [8].

\subsection{WS Injection System bu A,D. Litthe/Cooper Bessemer}

Two different types of CWS injection systems were designed and operated on the Cooper JS1. engine [9]. The first was a jerk pump based system using a unique $A M B A C$ injector design. The jerk pump, which handles only diesel fuel, provides the fuel metering function and hydraulic pressure required for the injection. The AMBAC injector provides a barrier between diesel fuel and CWS and uses a multi-hole nozzle for atomization. CWS fuel was supplied either from a pressurized tank or from a holding tank using a Moyno pump.

The second system was based on the Cooper-Bessemer common rall fuel system. Pressurized CWS was supplied by an accumulator and fuel metering was handled by Cooper-Bessemer's common rail unit. Initial tests with the jerk pump system were plagued by mechanical jamming of the moving farts in contact with CWS. Systematic design modifications during Phase I IS testing have solved early problems and CWS tests were conducted for as long as two hours continuously. Most of the injection system development and Phase 2 testing have been with the jerk pump system, while the common rail system remains the backup system. The injection system parameters of jerk pump CWS injection system arre as follows:

$\begin{array}{llll}\text { - Nozzle hole size } & 0.25-0.5 & \mathrm{~mm} \\ \text { - Injection pressure } & 48.3-103.4 & \mathrm{MPa} \\ \text { - Nozzle opening pressure } & 13.8-34.5 & \mathrm{MPa}\end{array}$




\subsection{Technical Problems with CWS Injectors}

At the present time in the development of CWS injectors, the fuel injection nozzle is the component with the shortest life. In particular, the standard nozzle hole has been found by GE and A.D. Little/Cooper Bessemer. through CWS-fueled engine test results, to have a useful life time of 3 to 5 hours with CWS fuel operation. This short life of the nozzle makes it the most critical component of the CWS-fueled engine. By using wear resistant. materials such as silicon carbide, diamond compact and cubic bocon nitride, the nozzle life was extended to about 100 hours. To obtain 2,000 hours of nozzle life however, will require extensive $R \& D$ on the various aspects of the CWS injection.

A photograph showing the wear of nozzle hole area after 4.5 hours of full load CWS-fueled GE-7FDL engine testing (Figure 3.3-1) shows highest wear at the center and exit of the hole. The original profile of the hole had a single $0.55 \mathrm{~mm}$ diameter, as compared to eroded hole diameters of $0.66 \mathrm{~mm}$ at. the entry and $0.76 \mathrm{~mm}$ at the exit. Due to the nozzle hole wear. the injection pressure fell from about 55 to 47 MPa as shown in Figure 3.3-2. This 15 percent reduction in injection pressure caused unacceptable atomization and combustion characteristics of CWS fuel in the engine. According to GE's wear analysis of nozzles, the wear mechanism of the nozzle hole involves erosion, cavitation and corrosion. $G E$ has used various wear resistant materials to solve the wear problem of the nozzle hole. Figure 3.3-3 shows photographs of single hole orifice through which CWS at $27.6 \mathrm{MPa}$ was continuously flowed. The orifice air erosion tests conducted with different materials show low wear with superhard materials like diamond compact and cubic boron nitride.

\subsection{IICS Concept by Adiabatics. Inc.}

The feasibility of the dry micronized coal powder fueled engine was demonstrated by Adiabatics, Inc. under earlier contracts with the DOE/METC [10,11]. The Thermal Ignition Combustion System (TICS) concept for ignition of fumigated coal powder furl by means of a precombustion chamber operating at high temperatures was discovered during these programs. Single cylinder engine tests achieved uperation with 100 percent coal powder fuel without using external ignition sources. Important features of the coal powder fueled engine test results are as follows $(12,1.3)$ :

A simple and reliable coal powder feed system was developed.

- Ability to burn 100 percent coal powder fuel in the engine without external ignition devices like pilot diesel fuel injection or heated intake air was demonstrated.

- Control of the ignition timing of the fumigated coal powder fuel was accomplished by using exhaust gas recirculation (EGR) and controlled TICS chamber temperature. EGR also lowered the peak cylinder pressure, rate of pressure rise, and NOx emissions.

- Cold starting of the 100 percent coal powder fueled engine with a glow plug was demonstrated.

- Coal-fueled engine operation from 800 to $1,800 \mathrm{rpm}$ speed and idle to

full load with three types of coals was demonstrated:

1. Micronized bituminous coal, 7 microns mean size;

2. Nonbeneficiated 1.6 percent ash content bituminous coal, 21.3 microns mean size; and

3. 7.1 percent ash content North Dakota 1ignite coal, 29 infcrons mean size. 


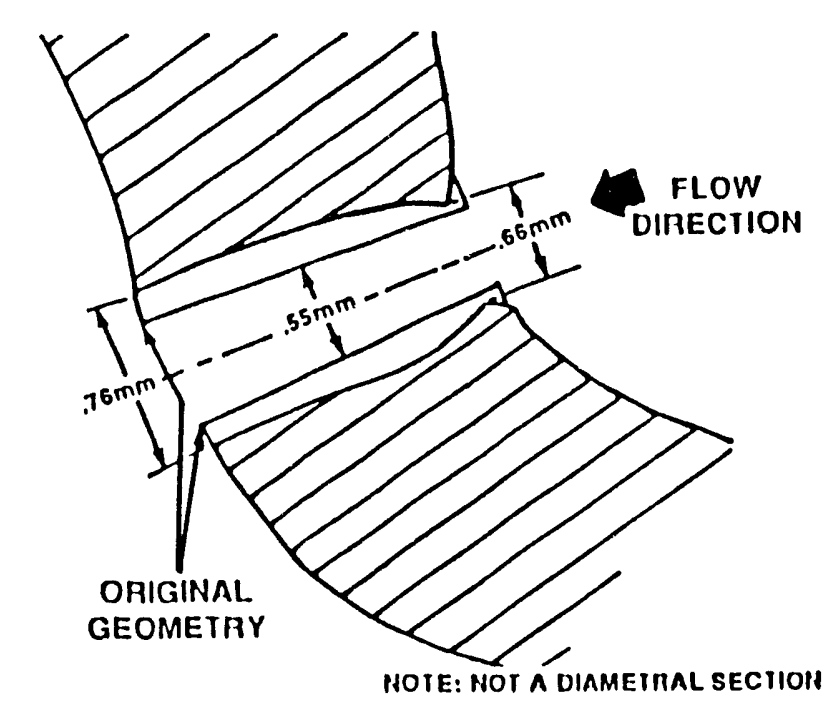

Figure 3.3-1 Cross Section of Steel Nozzle After 4.5 Hours at Full Load on CWS

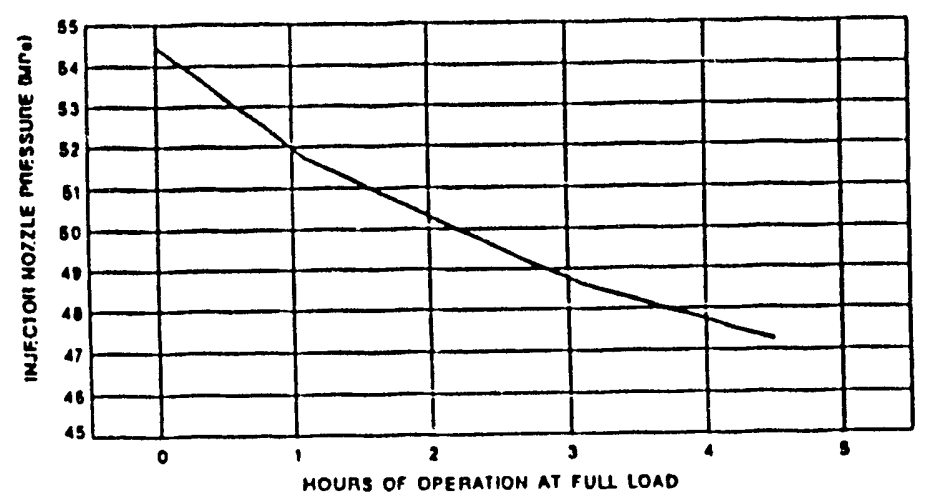

Figure 3.3-2 Reduction in Fuel Injection Nozzle Pressure as a Function of Time on CWS (GE Data) 
SIUCON CARBIDE - NEW

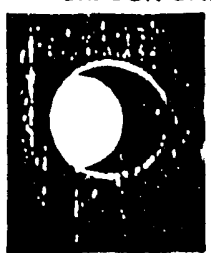

STELUTE -40 MIN.

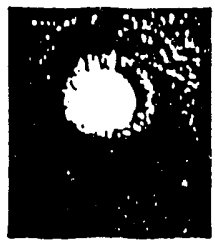

CARBOLOY $883-680$ MIN.
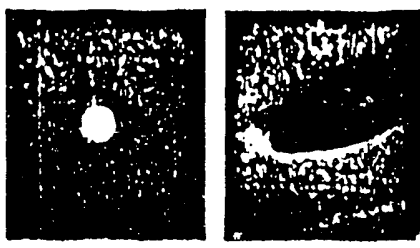

SIUCON CARBIDE - $780 \mathrm{MIII}$
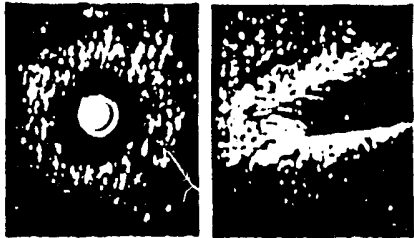

CUBIC BONON PIITIDE- 830 MIR.

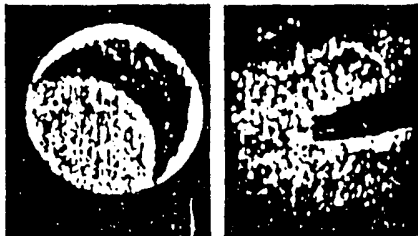

DIAMONO COMPACT. 930 MIN.
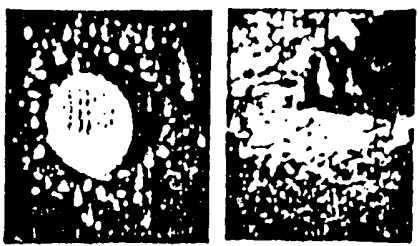

Figure 3.3-3 Erosive Wear of Orifices by Continuous 27.58 MPa (4,000 psi) CWS Flow (GE Data) 
This research investigation on fumigated oal-fueled engines reveaied that the high amolint of igmition energy in the TI S chamber enabled the combustion of even large particle size coal fuel in the test engine. This ignition energ: wis provided by the uricooled TICS chimber which was operating at high will remperatures (up to $900^{\circ} \mathrm{C}$ ). Based on these results a research program wias initiated by Adiabatics. Inc. to develop an electronically ccntrolled chis injection system in conjuncticn with the TICS concept to achieve autoignition of lis at various engine load and speed conditions without employing diesel Filut ignition assist.

\section{SROJECT METHODOLOCY}

This project was intended to develop and demonstrate an Innovative Coal-Fueled Diesel Engine Injector to provide better atomization, less erosion of spray holes, and more durability as compared to the present state-of-the-art CWS injection and the project is described in the following, sections. Section 4.1 outlines the proj:ct objectives and section 4.2 outlines the technical approach with a briet description of the CwS injector and TICS. the new concept developed by Adiabat.cs. Inc.

\section{I Breject Objectives}

The project objectives were as follows:

- To develop an electronically ccitrolled hydraulically actuated coal-water slurry (CWS) injection systern in conjunction with the thermal ignition combustion system (IICS) to achieve the autoignition oi Cirs at various engine load ant speeds without employing any ignition source such as diesel pilot or natural gas torch.

- To optimize the Cris-fueled injection and combustion systems.

- To monitor the combustion and emissions including the smoke and particulates.

- To otrain some qualitative idea or the wear and durability of the injection system.

- To check the ability of the developed injector to burn 101) percent Cris up to $2.800 \mathrm{rpm}$.

- To develor an understanding of the problems with the sustem such as contamination by coal/ash. consistency, and various other maintenance and associated operational problems.

\subsection{Iechnical Approach}

The technical approach taken to accomplish the project goals was to develop an electronically controlled CWS infection system in conjunction with the TiCS concept to achieve auto ignition. of CWS without any external ignition sources. The TICS concept developed by Adiabatics, was utilized to achieve the rapid burning of the ChS fuel. This research program has been carried out in two phases each with a series of suitasks as follows:

\section{PHASE I - PRELIMINARY ENGINEERING}

Technology survey and program plan

Injector design and bench testing

Preliminary engine tests and analysis

Topical report 
PHASE II - DEVELOPMENT ENGINEERING

- Injector/Engine modifications

- Parametric optimlzation studies

- Insulated engine testing and analysis

- Emissions, particulate and smoke ineasurements

- Final report

The key elements of this investigation, namely, the innovative CWS injector and the TICS are described in the following sections:

\subsection{Innovative CWS Injector}

The CWS injection system is an electronically controlled, accumulator system with servo-actuation of the injector valve. A high speed solenoid controlled the CWS injection timing and duration. A schematic of the CWS injection system is shown in Figure 4.3-1. Photographs of the CWS injector with volume type accumulator and its installation on the test engine cylinder head are shown in Figure 4.3-2. Figure 4.3-3 shows photographs of the bladder accumulator used to pressurize CWS up to $20.7 \mathrm{MPa}$ (3,000 psi) pressure and the Micromotion mass flowmeter for measurement of the CWS fuel flow in the engine. The CWS handling system for mixing, storage and filling the bladder accumulator is shown in Figure 4.3-4.

High pressure CWS was provided to the injector at constant pressure from a bladder type accumulator used as a pump. During this test program, CWS pressures ranged from 13.8 to $20.7 \mathrm{MPa}(2,000$ to $3,000 \mathrm{psi})$. In order to reduce CWS pressure drop during the injection period, a volume type accumulator was incorporated into the injector body. The accumulator volume for the injector is approximately $180 \mathrm{cc}$. The CWS injector was sized to inject $0.3 \mathrm{cc}$ of CWS per stroke at the full engine load with the injection pressure falling from 20.7 to $15.5 \mathrm{MPa}$ as injection occurred. Low injection pressures were chosen because CWS was injected directly into the TICS chamber which requires much lower pressure than a direct injection engine and to explore nozzle hole wear at these lower injection pressures.

A standard, water cooled, multi-hole diesel fuel injection nozzle was modified to inject CWS in the test engine, by blocking the existing holes by electron beam welding and then electro-discharge machining (EDM) a single spray hole. Figure 4.3-5 shows a photograph of the modified nozzle and plunger used for the CWS injector. Two different nozzles were made with 0.736 and $0.978 \mathrm{~mm}$ diameter spray hole sizes, respectively. Wear resistant materials were not used for the nozzle in the first phase of this program.

The CWS injection was accomplished in the following manner: A magnetic pickup, mounted on the engine camshaft, provided an electronic timing signal to the high speed solenoid valve, which vented the servo-fluid pressure acting on the end of the injector plunger. As a result of the reduced servo-fluid pressure and upward forces acting on the plunger from the high pressure CWS, the nozzle plunger lifts off the seat, thus allowing CWS injection into the test engine combustion chamber. The injection duration was controlled by an electronic driver for the solenoid valve. The CWS injection event was completed by de-activating the solenoid valve, which quickly raised the servo-fluid pressure and forced the plunger back to its seat. A piezoresistive pressure transducer measured the pressure of the CWS being injected upstream of the nozzle hole. Also, a piezoelectric pressure 


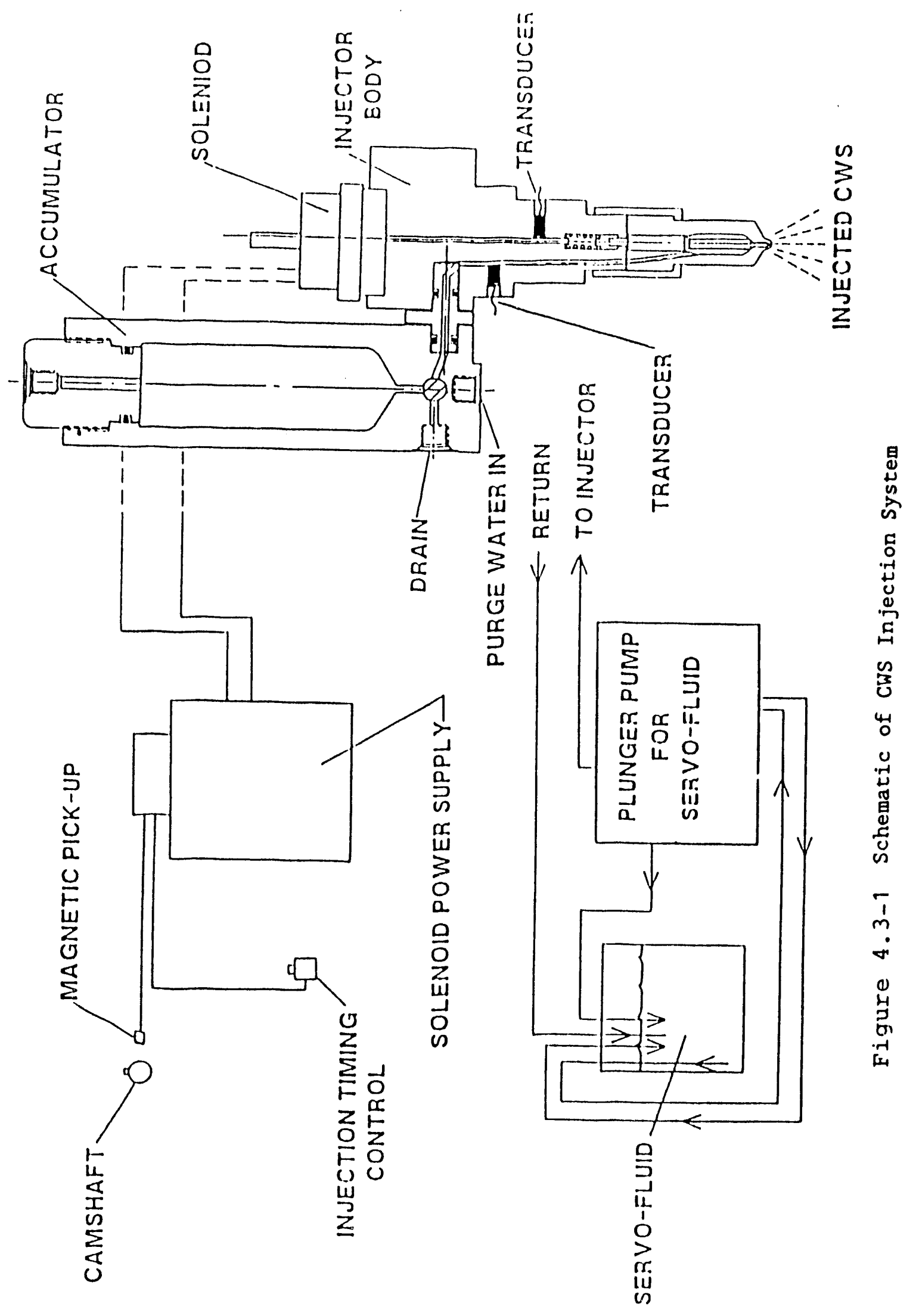




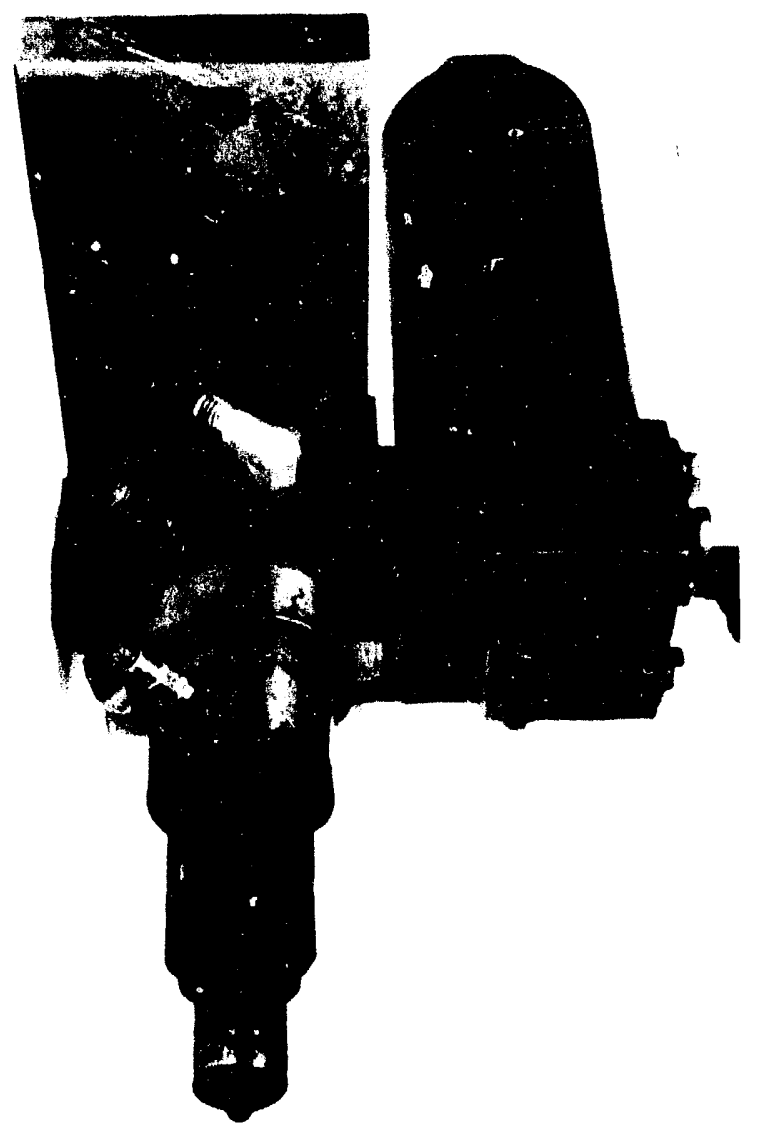

AI - C /182-19

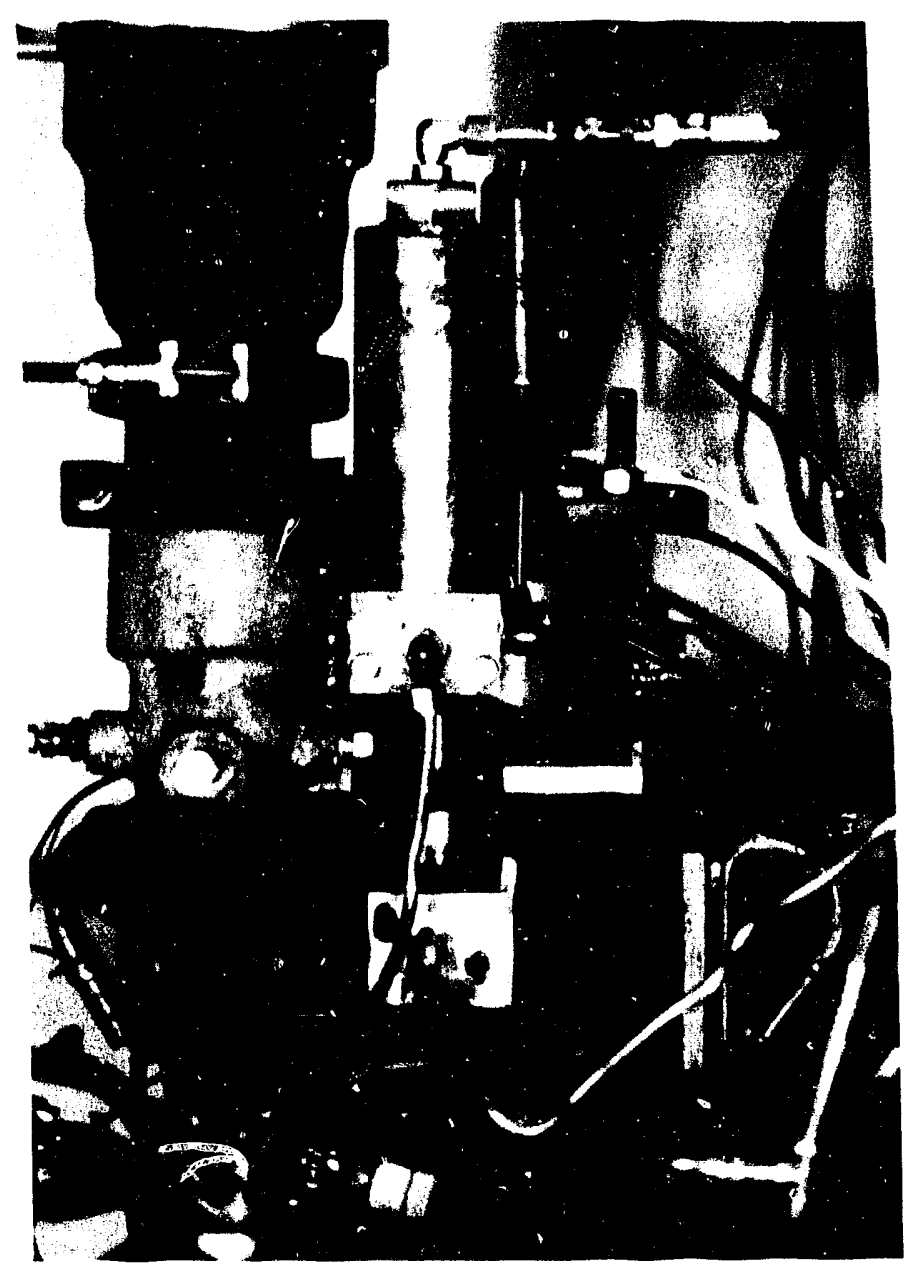

AI $-\mathrm{C} / 179-18$

Figure 4.3-2 Photographs of CWS Injector (with accumulator) and Its Installation on the Test Engine 


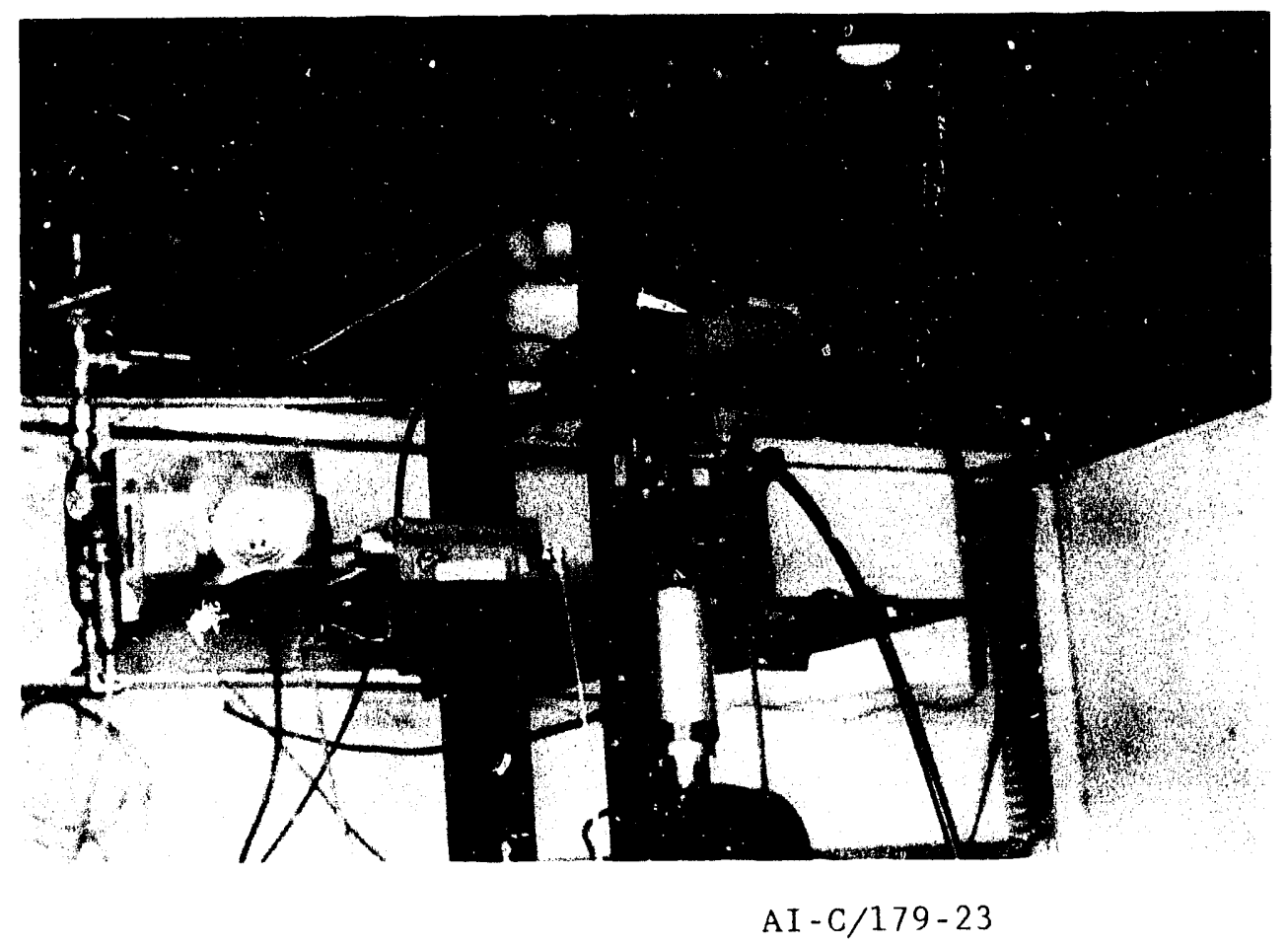

Figure 4.3-3 Photograph of the Bladder Accumulator and Micromotion Mass Flowmeter Used for the CWS-Injection System 


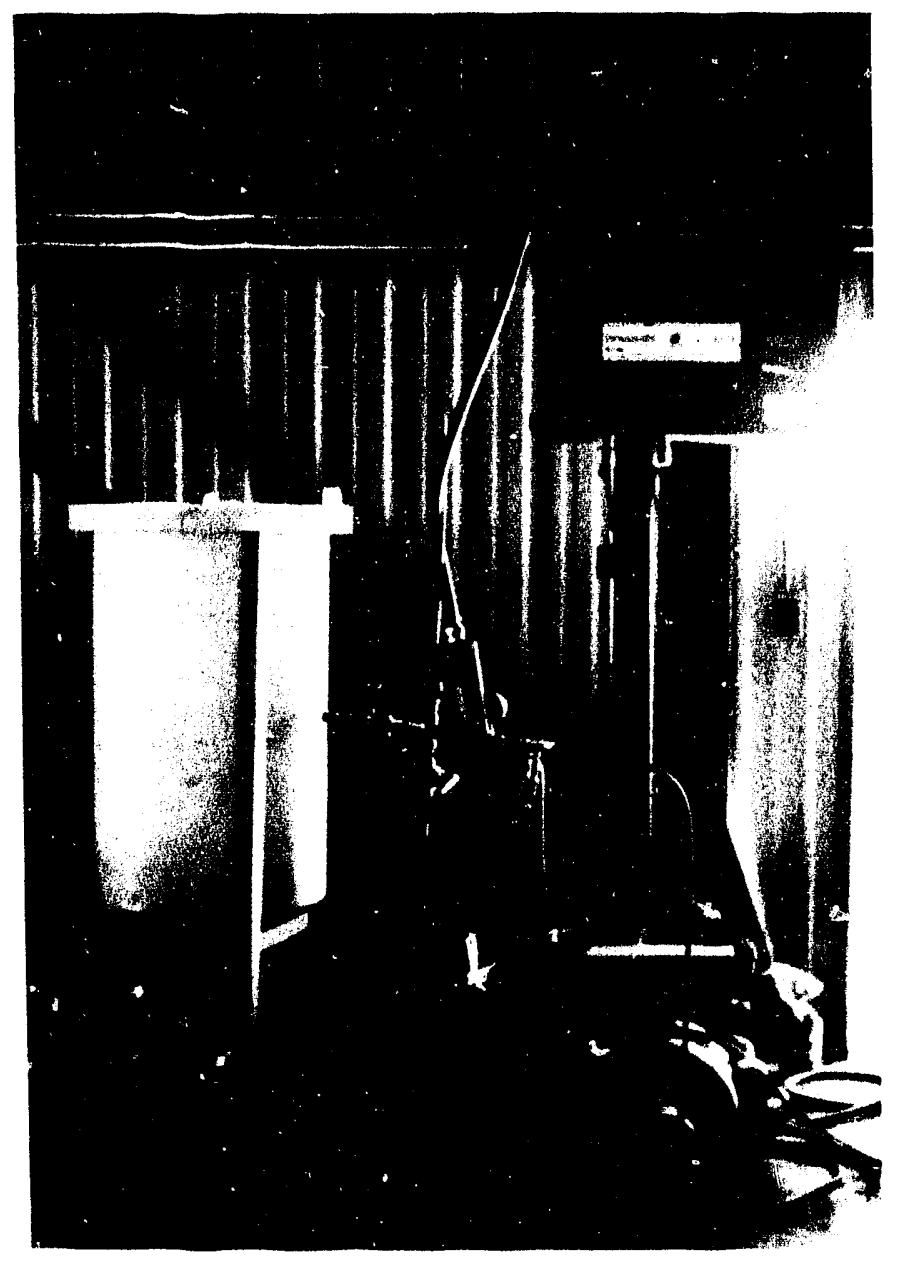

AI -C/188-20

Figure 4.3-4 Photograph of CWS Handling System Used for the CWS-Injection system 


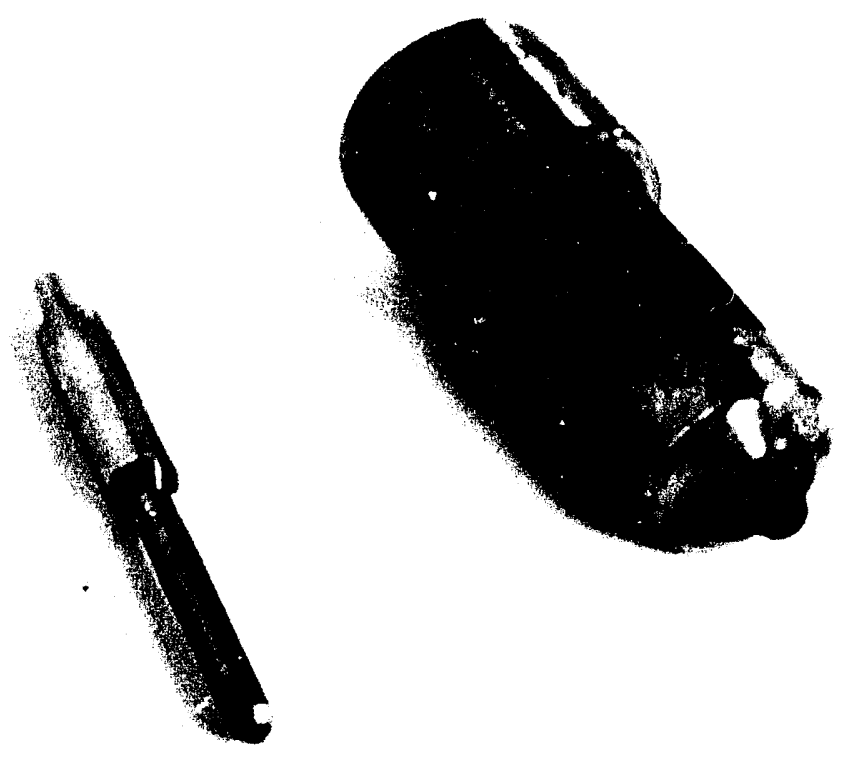

$\mathrm{AI}-\mathrm{C} / 181-11$

Figure 4.3-5 Photograph of Modified Fuel Injection Nozzle (with plunger) Used for the CWS Injector 
transducer was used to measure the se:vo-fluid pressure. During the engine testing with the CWS injector, these pressures were recorded on a computer for later analysis of the CWS infection timing, pressure and duration as the injection occurred.

A high pressure plunger punp was used for supplying the servo-fluid to the injector body at a constant pressure. The servo-fluid was comprised of water with 1 percent soluble oil additive for rust prevention. Since the solevold valve was electrically operated, the CWS injector was quite amenable to electronic controls. A magnetic pickup mounted on the engine camshaft provided an electronic timing signal for the start of injection. This signal was then fed to an adjustable electronic timing delay circuit and the modified timing signal then triggered the electronic solenold driver, thus allowing on-1ine change in the start of injection timing. The amount of fuel injected per cycle was controlled by electrically varying the injection duration.

\subsection{Experinental Setup}

The experimental set-up consisted of a Caterpillar $1 Y 73$ single-cylinder engine and the newly developed injection system. The performance was determined by measuring varlous parameters such as load, speed, air and fuel flows, cylinder pressure and various temperatures. In addition, the gaseous emissions were monitored from the exhaust gas, such as, $\mathrm{HC}, \mathrm{CO}, \mathrm{CO}_{2}, \mathrm{NOx}$ and smoke and particulates as well. The details on the various systems of the experimental set up are as follows:

\subsubsection{ENGINE AND EMISSIONS SYSTEMS SETUP}

\section{Engine Details}

The speciflcations of the Caterpillar $1 Y 73$ single-cylinder engine used for this test program are as follows:

Type :

Number of Cylinders:

Combustion Chamber:

Cycle:

Bore x Stroke:

Engine Speed:

Compression Rat1o:

Air Aspiration:

Piston:

Cylinder Head:

Liner:

Rings :

Injector Orifice

Figure 4.4.1-1 coal-fueled engine shows tests
Caterpillar $1 Y 73$

1

Prechamber-Hastelloy $X$

4 Stroke

$130 \times 165 \mathrm{~mm}$

( $5.125 \times 6.5$ inches)

800 to $1,800 \mathrm{rpm}$

$16.5: 1$

Naturally Aspirated

Aluminum Alloy with PSZ Thermal Barrier Coating

Cast Iron with PSZ Thermal Barrier Coating on Headface.

Cast Iron with Chrome Oxide Wear-Resistant Coating.

Top Ring Coated with Chrome oxide Wear-Resigtant Coating. Intermediate and Oil rings were standard.

M2 Tool Steel

a schematic

of the test engine

used for the which shows

\section{thermal barrier and}

wear-resistant 


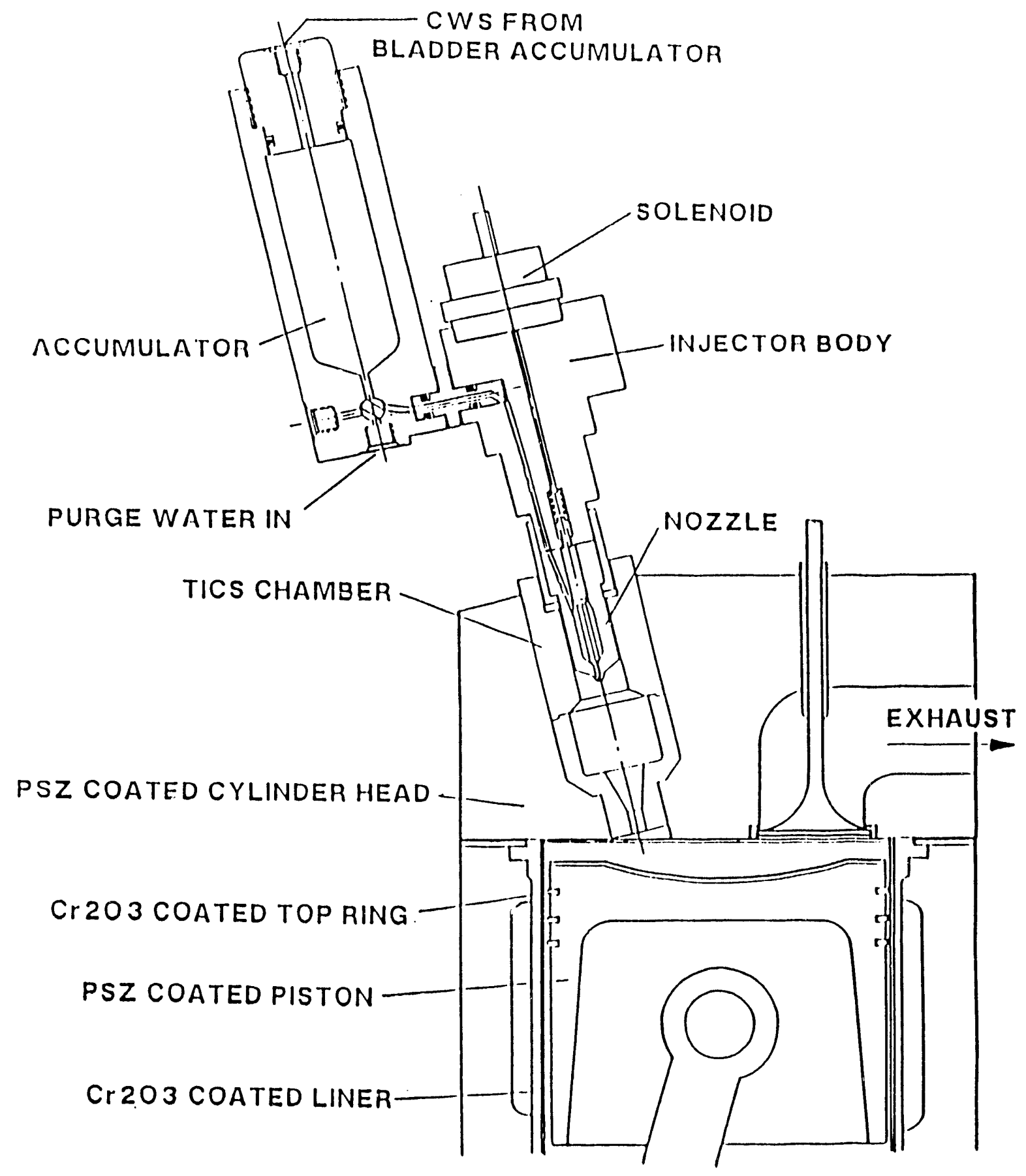

Figure 4.4.1-1 Schematic of Single-Cylinder Test Engine With CWS Injector 
ceramic coated engine components. TICS chamber, and CWS injection system. Photoglaphs of the test engine with CWS injector during the CWS-fueled engine tests are presented in Figure 4.4.1-2.

In order to avoid the difficulties encountered at high temperatures with the standard Caterpillar precombustion chamber, a new TICS chamber was designed and fabricated from Hastelloy $X$, a superalloy material capable of continuously withstanding $1.000^{\circ} \mathrm{C} \quad\left(1,832^{\circ} \mathrm{F}\right)$ temperature. The photograph of the TICS chamber is shown in Flgure 4.4.1-3. The geometry of the TICS chamber was kept similar to the standard Caterpillar preccmbustion chamler. The thermocouples were placed on the outside wall of the lower section of TrCS chamber to measure the wall temperature during the coal-fueled engine testing.

The Caterpillar $1 Y 73$ single cylinder test engine components were modified for two purposes. First, the thermal barrier ceramic coatings were used to reduce heat rejection so that the test engine could be operated at higher temperatures to enhance the corbustion of CWS fuel. The engine components cylinder head face and piston top were coated with partially stabilized plasina spray Zirconia ceramic. These insulated components allowed uncooled engine operation (without cooling water in the cylinder head and block). Second, the cylinder liner surface was coated with a thin coating of wear-resistant chrome oxide to reduce wear of piston rings and cylinder liner by the abrasive coal powder and ash. Also, the top ring design incorporated step gap sealing for reducing blow-by and both plasma spray chrome oxide or chrome carbide coatings for the wear resistance.

The test engine lubrication system consists of a metal wire mesh full flow oil filter, an auxiliary lubricating oil pump, centrifugal by-pass oil filters (capable of separating coal particles down to 0.1 micron size), and an electric oil heater (co preheat the lubricating oil to $90^{\circ} \mathrm{C}$ before the engin? tests). This improved lubrication system proved to be very effect ive duriug the CWS-fueled engine tests and demonstrated effective filtration of the lubricating oil contaminated with unburned coal powder and ash. Also, the engine oil pressure was more stable during the slurry coal-fueled encine testing than in the past coal powder fumigated engine testing.

The test engine was equipped with instrumentation for collecting the following performance data during the coal-fueled engine testing:

- Engine speed and load

- Flow rates

- CWS (Micromotion Mass Flowmeter, model D25)

- Pressures

- Temperatures

- Air (Orifice meter)

- Intake, exhaust, blow-by and oil

- Intake, exhaust, lubricating oil, and wall temperatures of TICS chamber.

- Cylinder pressure

- AVL 8QP500CA pressure transducer, BEI optical encoder, and a high speed data acquisition system.

Emissions System

The gaseous emissions were measured using the following analyzers:

CO: Beckman model 870 NDIR analyzer

$\mathrm{CO}_{2}$ : Beckman model $8 / 0$ NDIR analyzer 

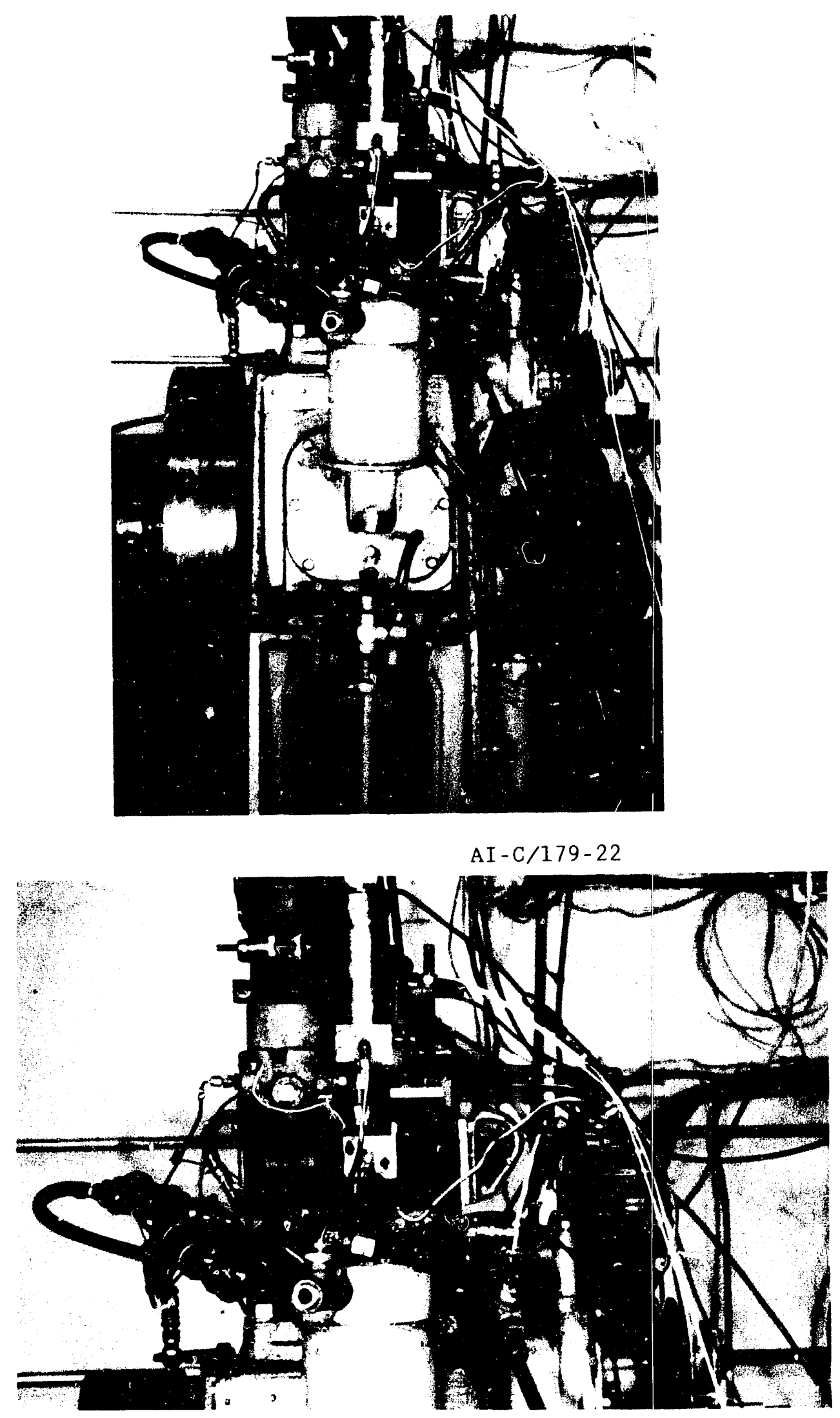

A I - C $/ 179-20$

Figure 4.4.1-2 Photographs of the Single Cylinder Test Engine With the CWS Injector 


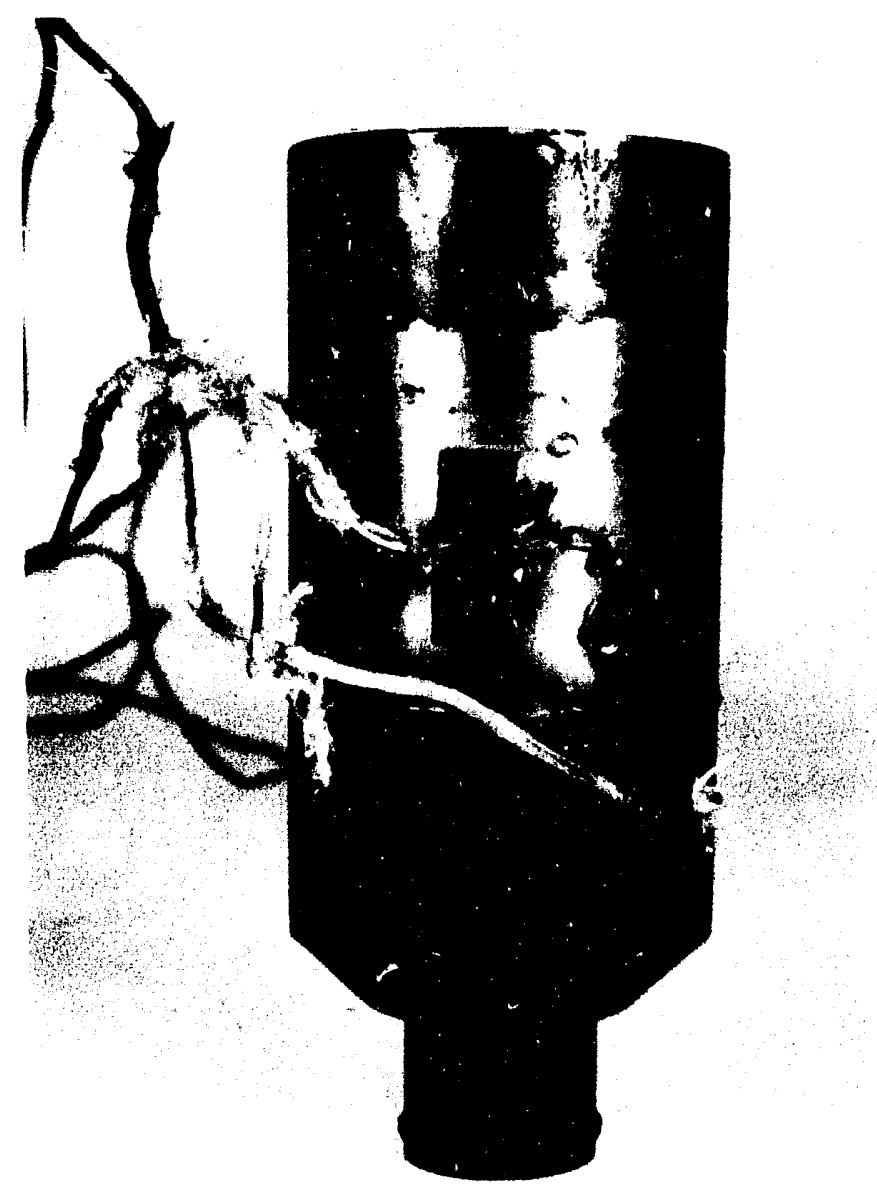

AI - C / 183-11

Figure 4.4.1-3 Photograph of TICS Chamber Made From Hastelloy X 
HC: $\quad$ Beckman model 400A FID analyzer

NOx: Beckman model 955 Chemiluminescent analyzer

Further, the smoke was measured with an AVL model 409 smokemeter and particulates were measured at selected times with a full flow ceramic foam filter made up of Lithium and Aluminum Silicate with 2.56 pores per millimeter.

The emission sample tube which transports the exhaust gas from the engine to the emissions analyzers was unheated throughout all engine testing.

The engine test data was acquired by two separate data acquisition systems. First, a micro-computer based slow speed system acquired the engine speed, load, flow rates and temperatures at 20 second intervals. Second, a high speed ( $100 \mathrm{kHz}$ ) systern was used to acquire and analyze the cylinder pressure data. An average of 100 engine cycles was computed to obtain cylinder pressure vs. crank angle, rate of pressure rise vs. crank angle, pressure-volume, and heat release diagrams.

\section{4 .2 TYPES OF CWS FUEL}

The CWS fuel, procured from Otisca Industries, was prepared from Kentucky Blue Gem seam and Taggert seam bituminous coals. The specifications of these CWS fuels are presented in Table 4.4.2-1. Taggert seam CWS was used for the CWS injector bench testing and the initial engine testing. However, Blue Gern seam CWS was used for all the subsequent engine testing because of its better burning.

\subsection{RESULTS AND RISCUSSION}

The results obtalned during Phases $I$ and $I$ of the investigation are presented as follows:

\subsection{Preliminary Engineering - PHASE I}

This section presents the program results and discussion for the bench and preliminary engine testing of the CWS injector. Also, the performance obtained with various other fuels such as dry coal powder [12.13] and diesel fuel (DF 非) using the innovative CWS infector is presented.

\subsubsection{Bench Testing of CWS Injector}

The bench testing of CWS infector with accumulator was conducted with the Taggert seam CWS. The CWS injector was bench tested over an equivalent engine speed range of 440 to $1,800 \mathrm{rpm}$ by injecting CWS outside the engine while the test engine was operating on diesel fuel No. 2. An external trigger from the test engine camshaft provided the timing signals for the injection of CWS. A standard steel fuel infector nozzle with a single $0.97 \mathrm{~mm}$ diameter nozzle spray hole was bench tested with CWS from 13.8 to $20.7 \mathrm{MPa}$ pressure (2,000 to 3,000 psi) for a total duration of 4.5 hours. Nozzle hole wear was negligible and could not be measured during this bench testing. Figure 5.1.1-1 shows photographs of the CWS injector on the test bench and an injection event for the CWS at $20.7 \mathrm{MPa}(3,000 \mathrm{psi})$ pressure.

CWS injector bench test results showed excellent operation as per design 
Table $4.4 .2-1$

\section{ANALYSIS OF CWS FUEIS USED}

$\begin{array}{lll}\text { Coal type: } & \text { Blue Gem seam } & \text { laggert seam } \\ \text { Beneficiated: } & \text { Yes } & \text { Yes } \\ \text { Solids loading: } & 49 \% & 50 \% \\ \text { Viscosity: } & 170 \mathrm{cp} & 41 \mathrm{cp} \\ \quad \text { (at } 112 \text { per sec.) } & & 32,564 \mathrm{~kJ} / \mathrm{kg} \\ \text { Lower Heating Value: } & 32,797 \mathrm{~kJ} / \mathrm{kg} & (14,000 \mathrm{Btu} / \mathrm{lb}) \\ & (14,100 \mathrm{Btu} / \mathrm{lb}) & \\ \text { Particle Size at } & & 2.9 \mathrm{microns} \\ 50 \text { Mass Percent: } & 3.3 \mathrm{microns} \\ \quad \text { Maximum: } & 11.5 \mathrm{microns} & 9.5 \mathrm{microns} \\ \text { Proximate Analysis: } & & 0.83 \\ \text { Ash \% } & 0.85 & 0.69 \\ \text { Total Sulfur \% } & 0.95 & 35.58 \\ \text { Volatile \% } & 40.11 & 63.59 \\ \text { Fixed Carbon \% } & 59.04 & \end{array}$




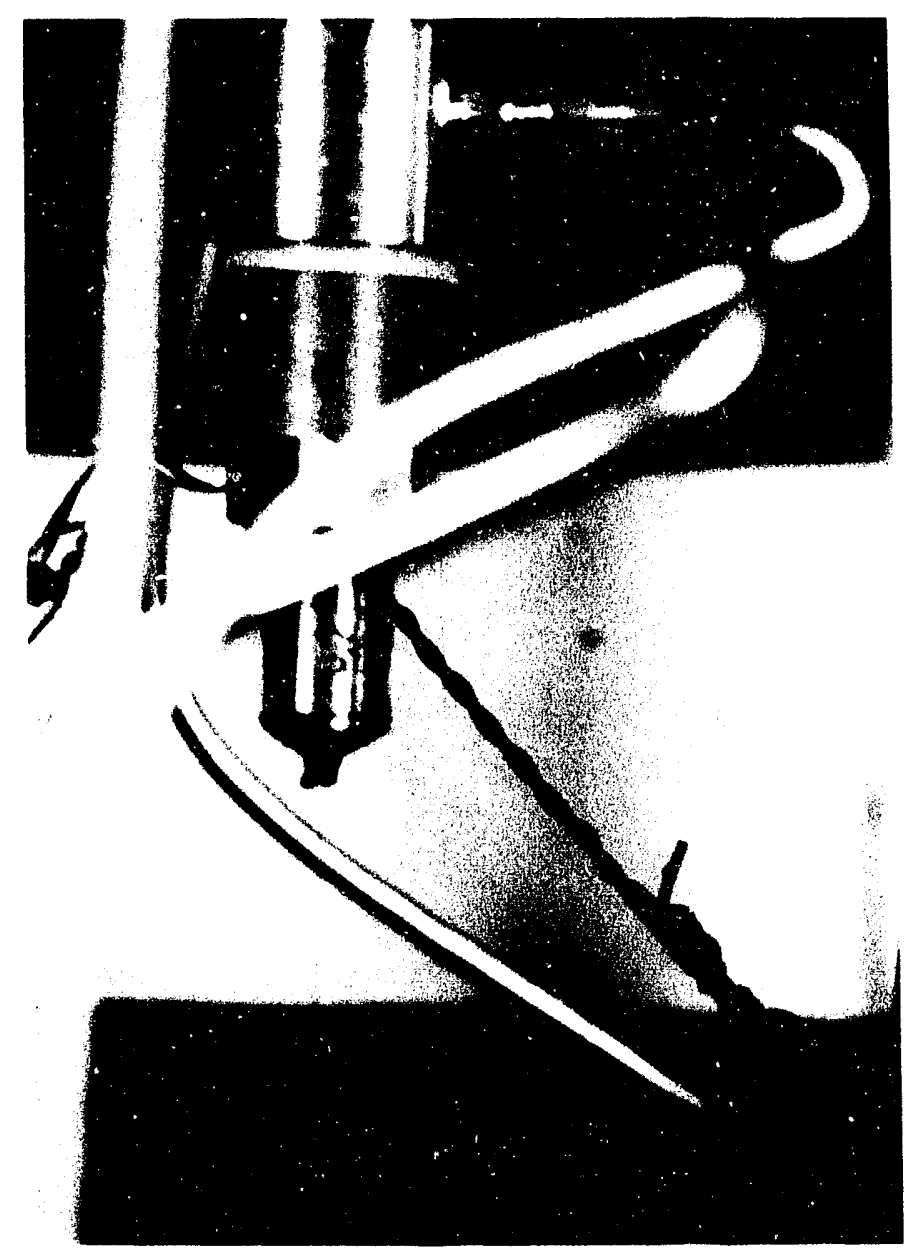

AI - C/179-10

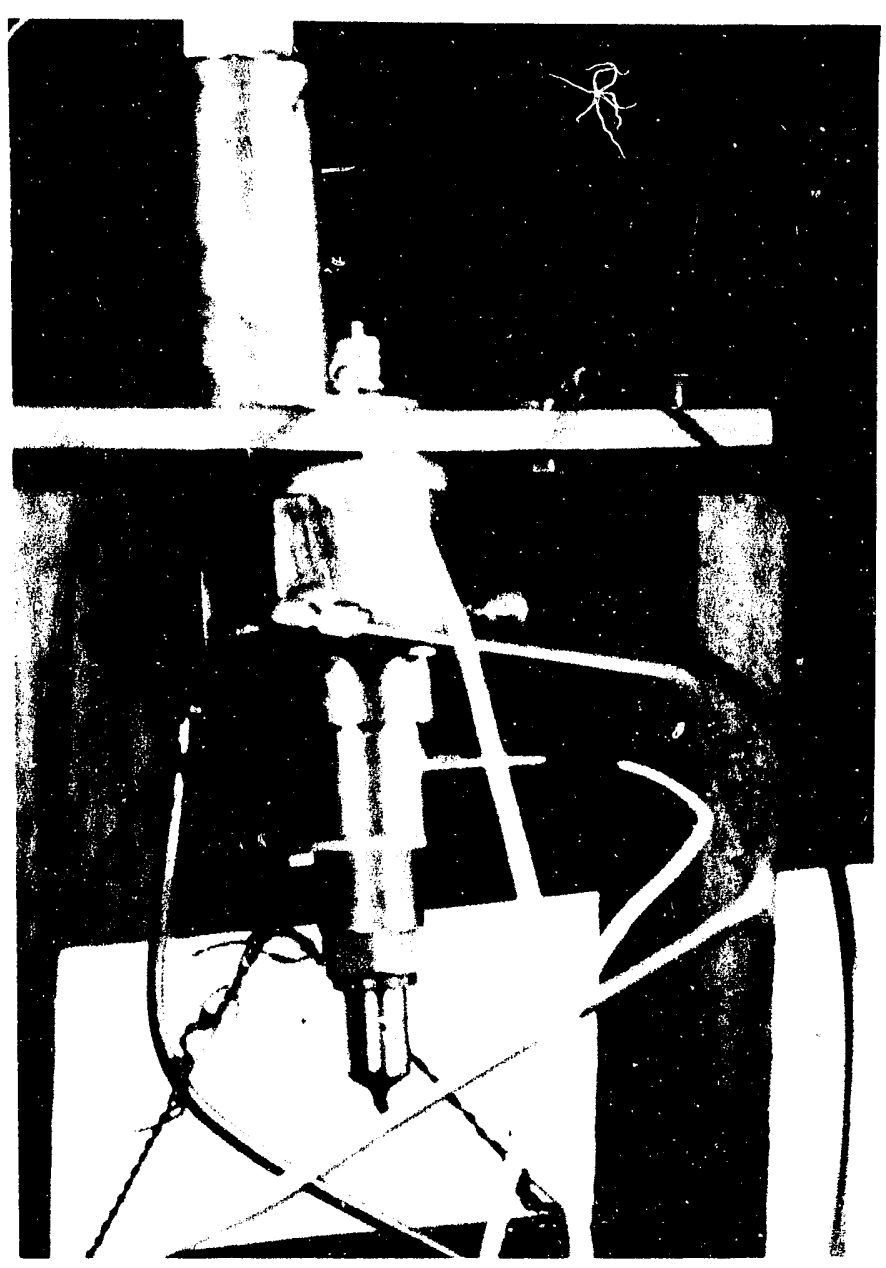

A I - C / 179-4

Figure 5.1.1-1 Photographs of CWS Injector During Bench Testing With the Taggert Seam CWS 
spectfications at various engine speeds, CWS pressure and $f l$ ow rates were based upon visual observations and CWS injection pressure vs. time during the injection period. The analysis of CWS infection pressure vs time (crank angle) measurements indicated a maxinum of 20 percent drop in the CWS pressure during the injection period at higher CWS flow rates. However, the CWS pressure drop was only 5 to 15 percent at lower CWS flow rates. The CWS injector with $0.97 \mathrm{~mm}$ nozzle hole was capable of injecting from 30 to more than $300 \mathrm{~mm}^{3}$ slurry per stroke. Thus, the CWS-fueled engine operation would be possible from idle to full load engine condition at various engine speeds. The slurry injection duration was adjustable from $1.5 \mathrm{~ms}$ to about $10 \mathrm{~ms}$ ( 9 to 60 degrees crankangle at $1,000 \mathrm{rpm}$ engine speed). Also, the start of injection timing was varied from 100 degree BTDC to TDC with a resolution of 0.1 degree interval with the electronic iniming device. This on line change in the injection timing was found to be useful during the later CWS-fueled engine testing. The CWS fuel injection pressure was varied from 13.8 to $20.7 \mathrm{MPa}$ by applying different air pressure to the bladder accumulator.

The CWS and servo-fluid pressures diagrams recorded during the bench testing with Taggert seam CWS at $20.7 \mathrm{MPa}$ pressure are presented in Figures 5.1.1-2 and 5.1.1-3. These pressure diagrams provide valuable information about the CWS injection pressure vs. timing (crank angle), start and end of injection and injection duration. As shown in Figures 5.1.1-2 and 5.1.1-3, CWS injection durations are 2.52 and $4.52 \mathrm{~ms}$ for the two cases, respectively.

\section{1 .2 Engine Test Summary and Wear Results}

Table 5.1.2-1 presents a summary of the CWS-fueled engine tests conducted and the nozzle hole wear data. The last 1 ine of data presented in the table shows a high wear rate of the injector nozzle hole which was the result of testing at high engine speeds (up to $1,800 \mathrm{rpm}$ ). As mentioned before, a standard steel nozzle without wear-resistant materials or coatings was used for the CWS-fueled engine tests. Figure 5.1.2-1 shows scanning electron microscope photomicrographs of the $1 \mathrm{~mm}$ nozzle hole after 4.5 hours bench test with Taggert seam CWS, and 9.25 hours engine test with Taggert seam and Blue Gem seam CWS. The nozzle hole appears to have retained 1 ts original cylindrical shape and the diameter seems to be uniform along the length of the hole. Figure 5.1.2-2 presents photographs of the CWS injector, and the nozzle seat and plunger after CWS-fueled engine tests. No wear was observed on the nozzle seat or plunger during this program. Leakage of the servo-fluid past the plunger into the CWS probably was beneficial. in avoiding the upward flow of CWS in the nozzle. Because of this fact, the CWS did not cause wear of the plunger.

The test engine teardown after the CWS-fueled tests did not reveal any problems or deposits on the engine components. Figures 5.1.2-3 and 5.1.2-4 show photographs of the piston, cylinder liner, cylinder headface, and intake and exhaust valves after CWS-fueled englne testing.

\subsubsection{Performance with CWS, Dry Coal Powder and Diesel (DF非) Fuels}

The preliminary test results obtained with CWS fuels were compared with the engine test results for combustion of dry coal powder and diesel fuel No. 2 (DF非) in Table 5.1.3-1 and Figures 5.1.3-1 and 5.1.3-2. The results indicate much higher heat release rates and shorter combustion duration for the coal powder fuel. The coal powder fuel, fumigated with the intake air, was ignited by the TICS chamber and exhaust gas recirculation was used to 


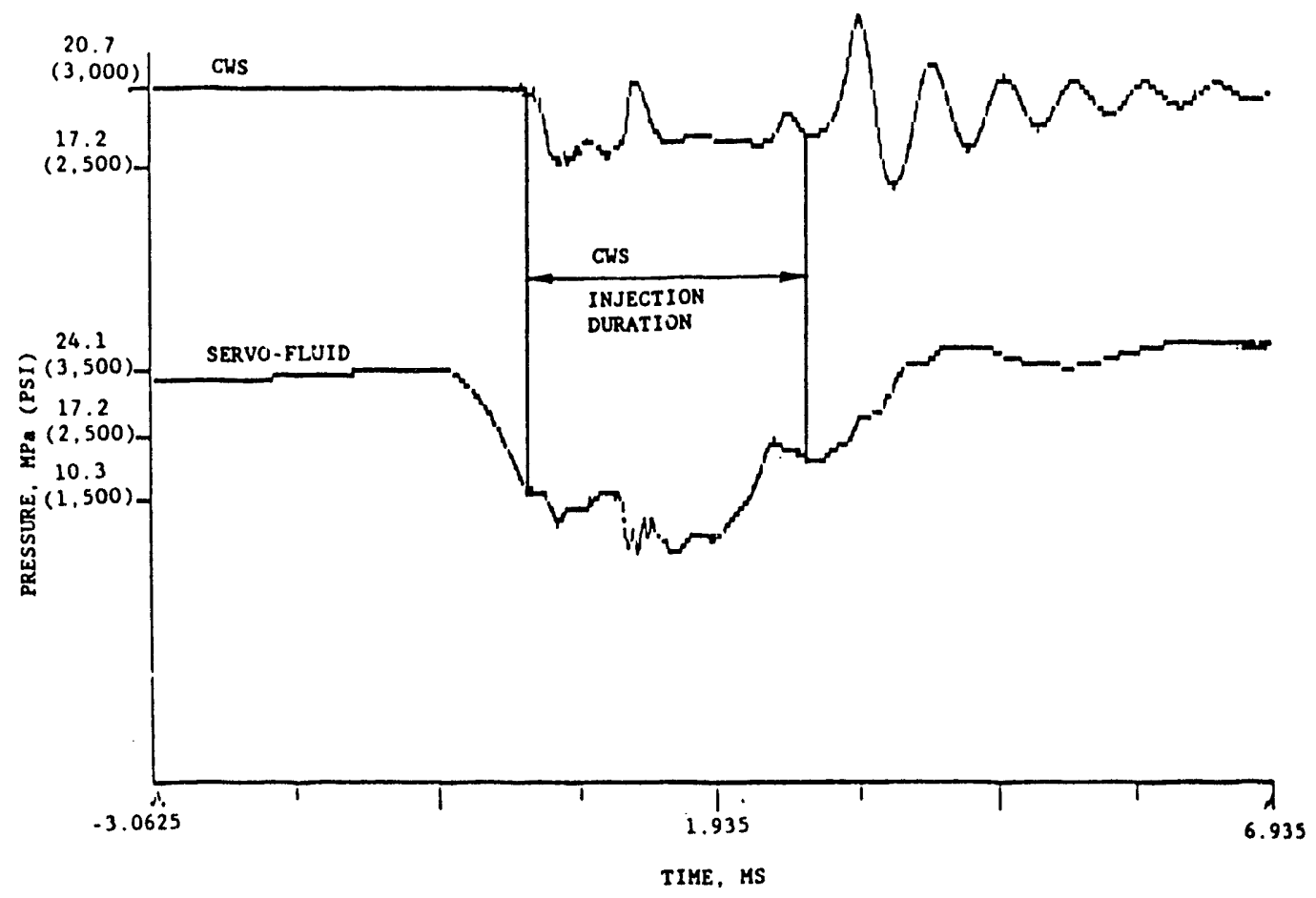

Figure 5.1.1-2 CWS and Servo-fluid pressures vs. Time during the Bench Testing with Taggert Seam CWS

Injections Per Minute $=500$

Injection Duration $-2.52 \mathrm{~ms}$

CWS Injected $-196 \mathrm{~mm}^{3} /$ stroke

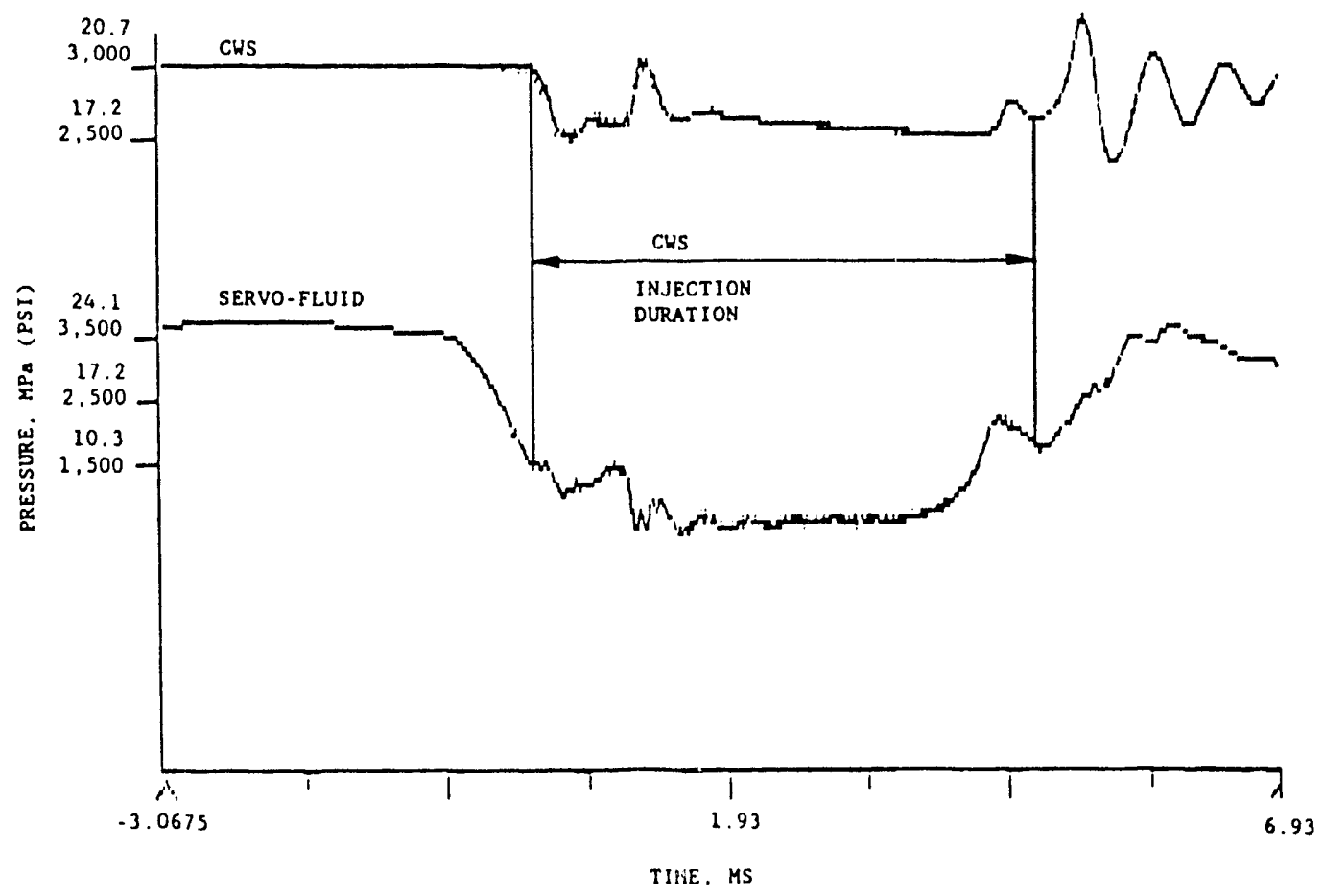

Figure 5.1.1-3 CWS and Servo-fluid pressures vs Time during the Bench Testing with Taggert Seam CWS

Injection Duration $=4.52 \mathrm{~ms}$

CWS Injected $=358 \mathrm{~mm}^{3} / \mathrm{stroke}$ 


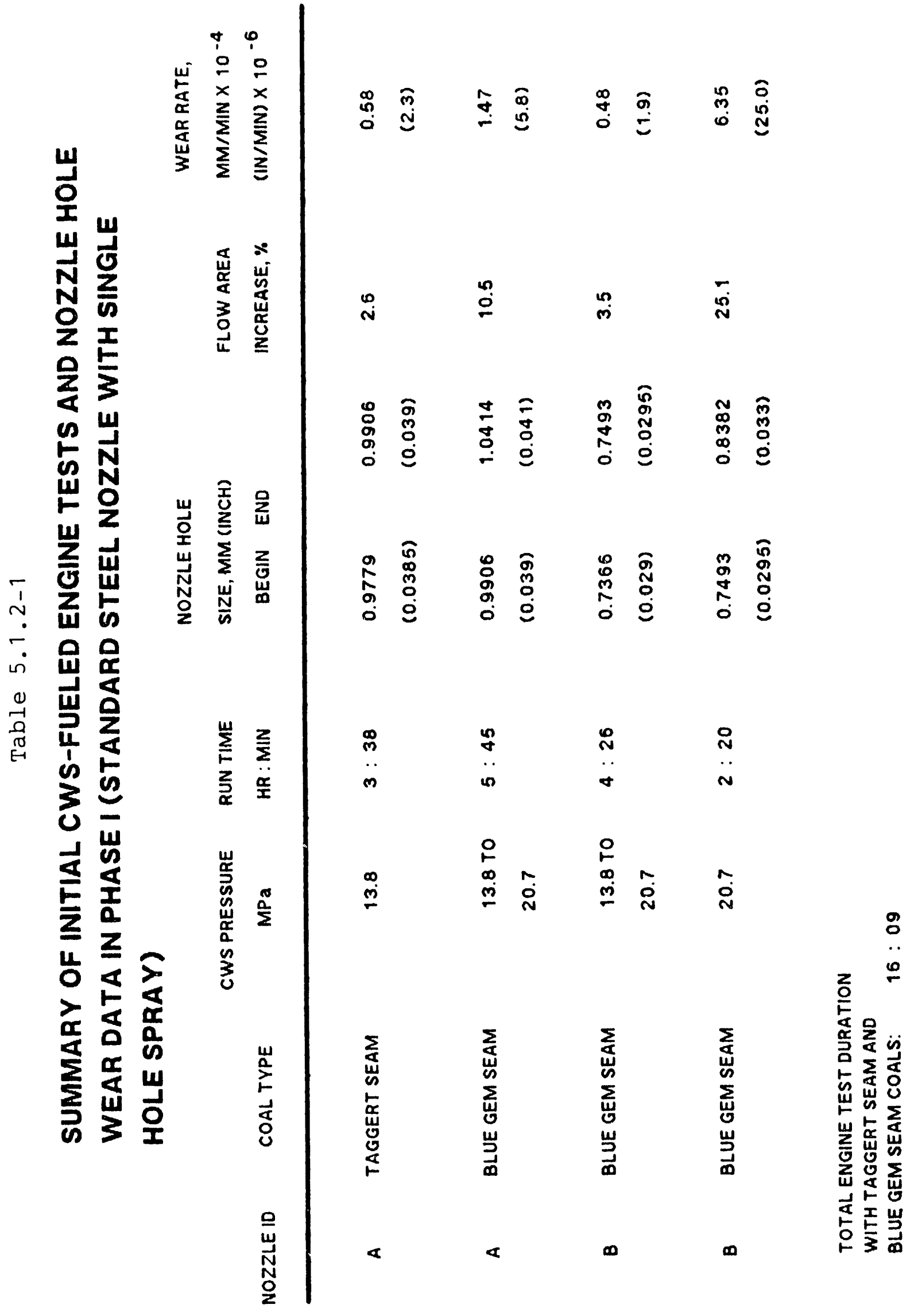



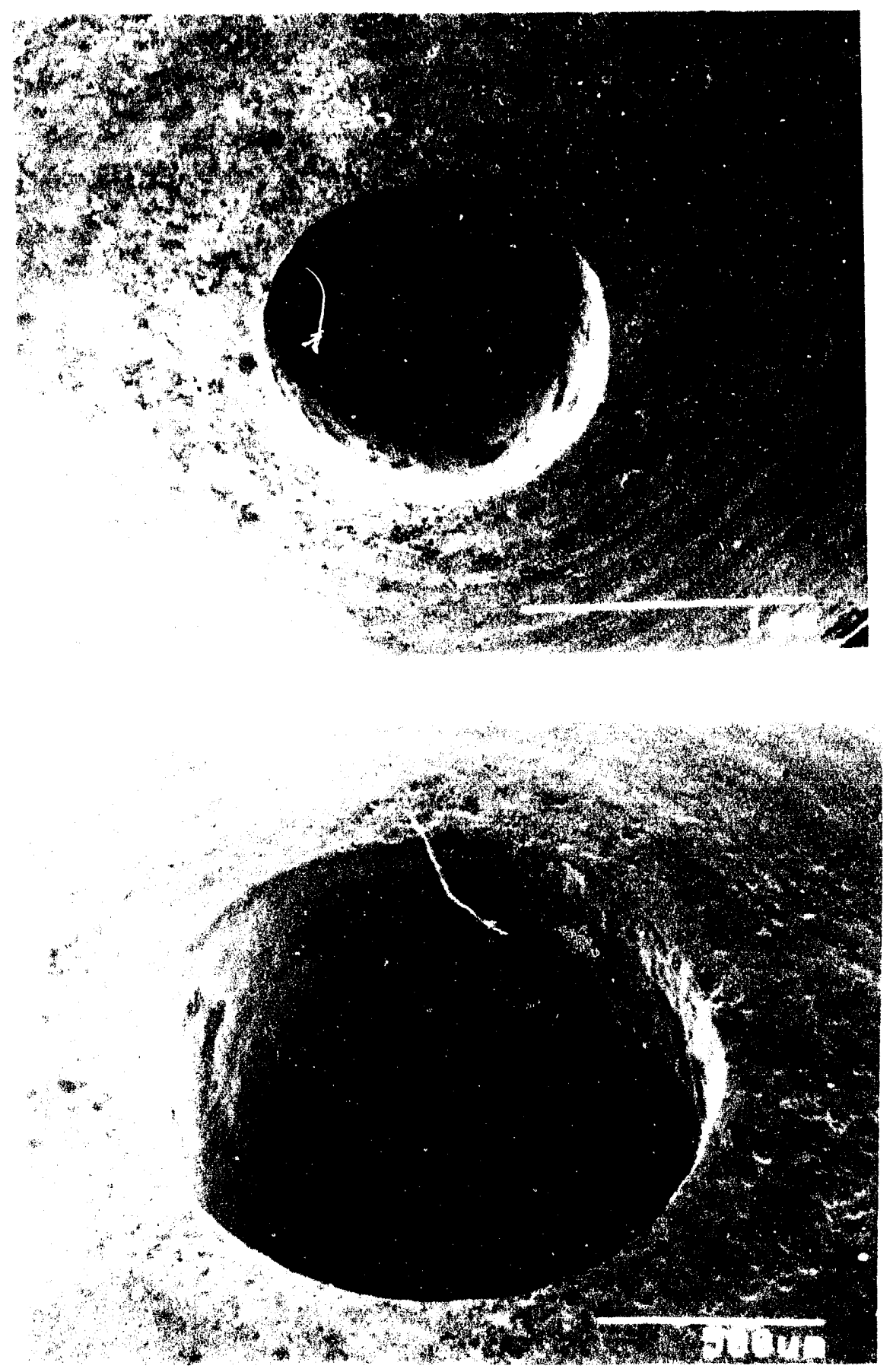

Figure 5.1.2-1 SEM Photomicrographs of Nozzle Hole after

CWS-Fueled Bench and Engine Tests (Nozzle ID = A, see Table 5.1.2-1 for data) 


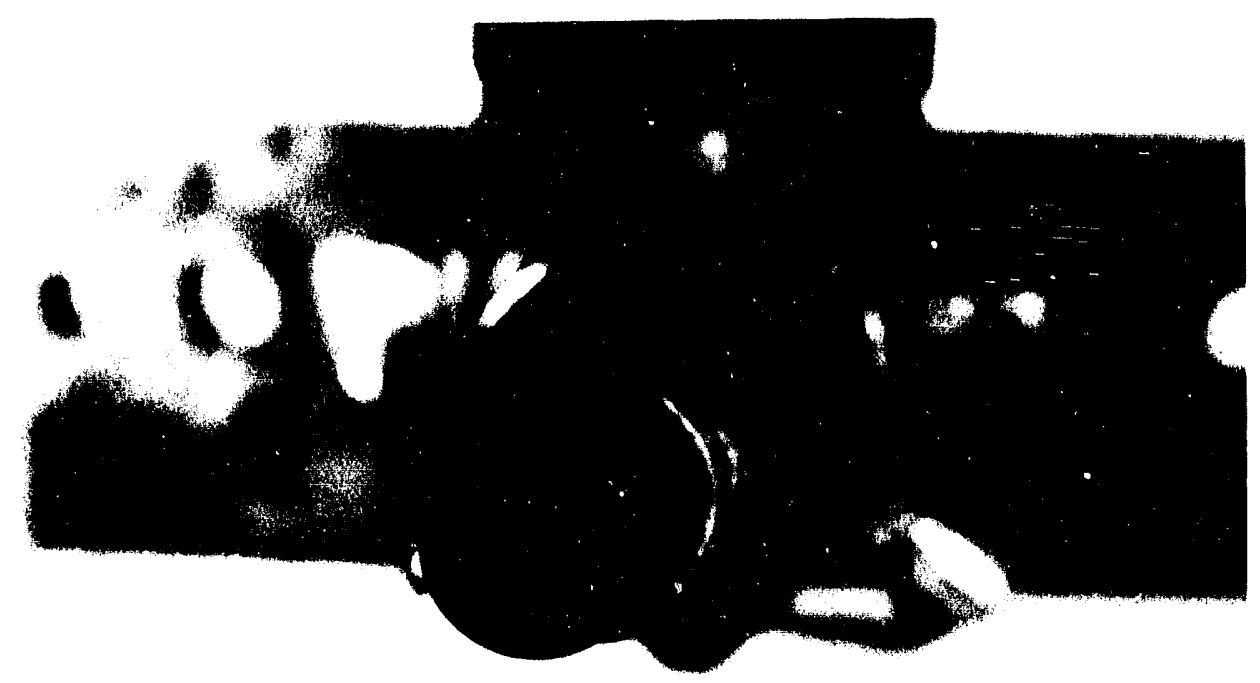

$\mathrm{AI}-\mathrm{C} / 182-21$
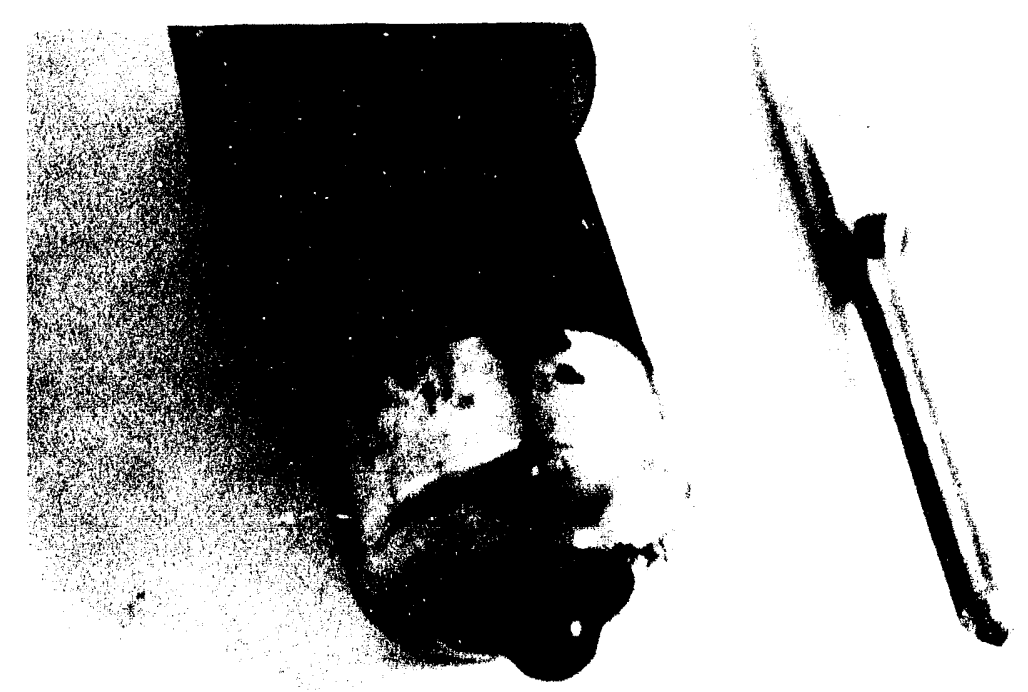

AI $-\mathrm{C} / 181-13$

Figure 5.1.2-2 Photographs of CWS Injector, and Nozzle and Plunger After CWS-Fueled Engine Tests 


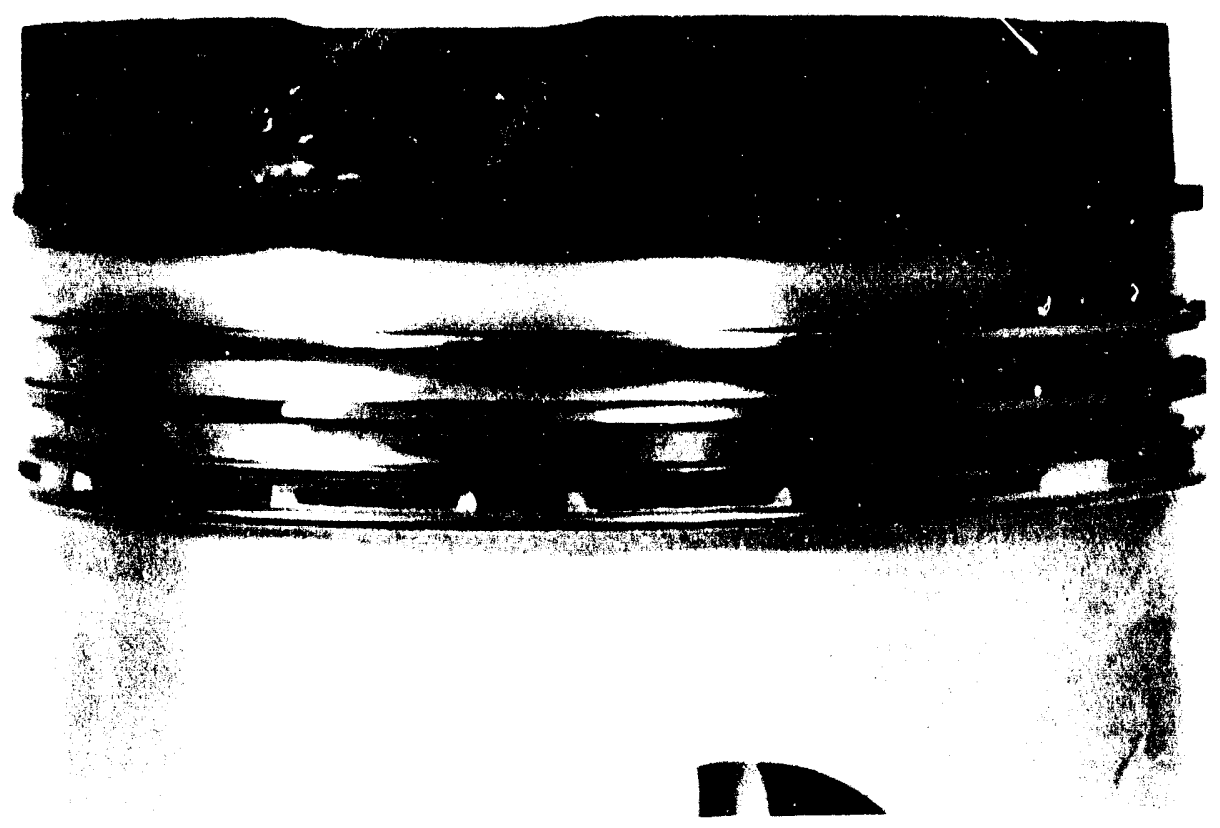

AI $-\mathrm{C} / 180-2$

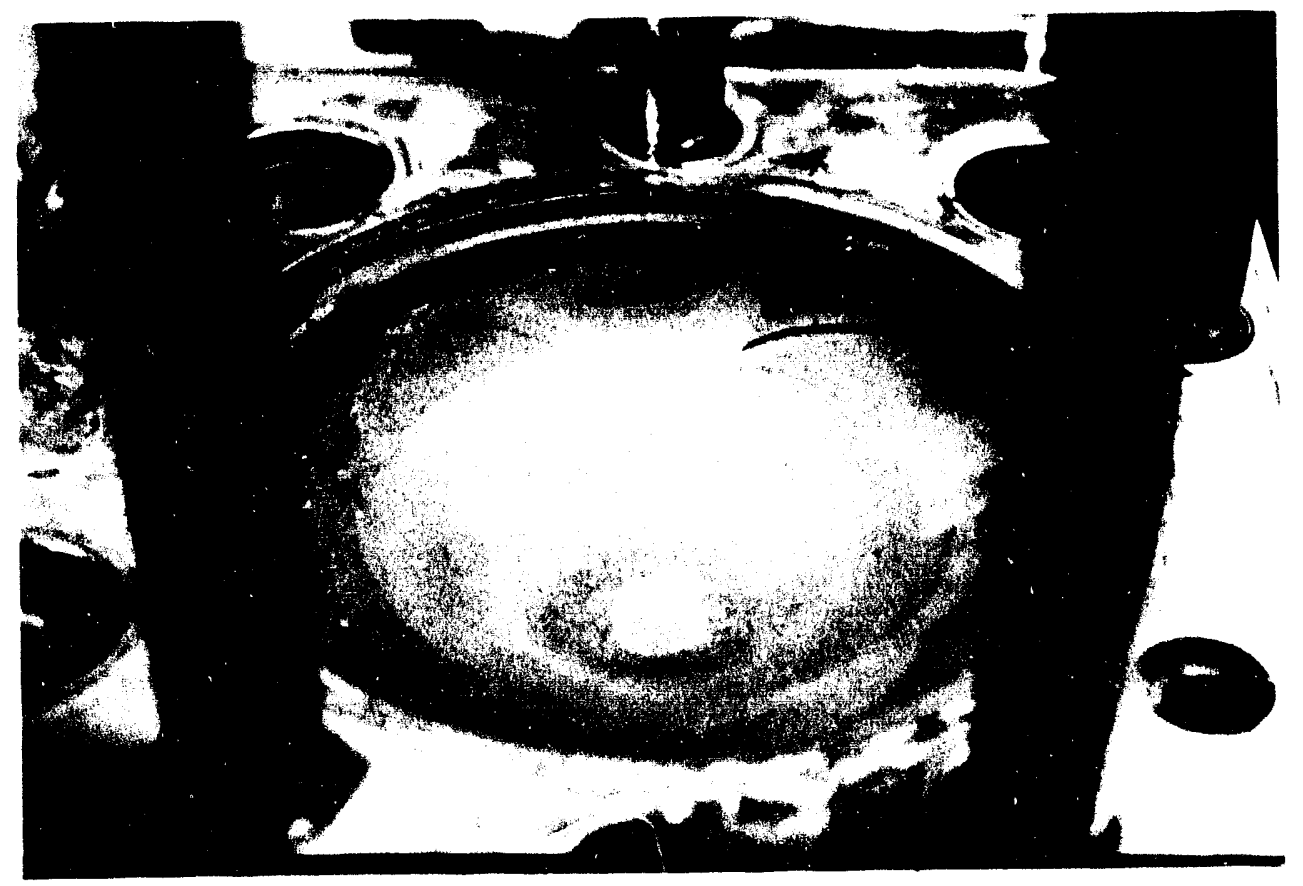

AI - C/181-14

Figure 5.1.2-3 Photographs of Piston After CWS-Fueled Engine Tests 


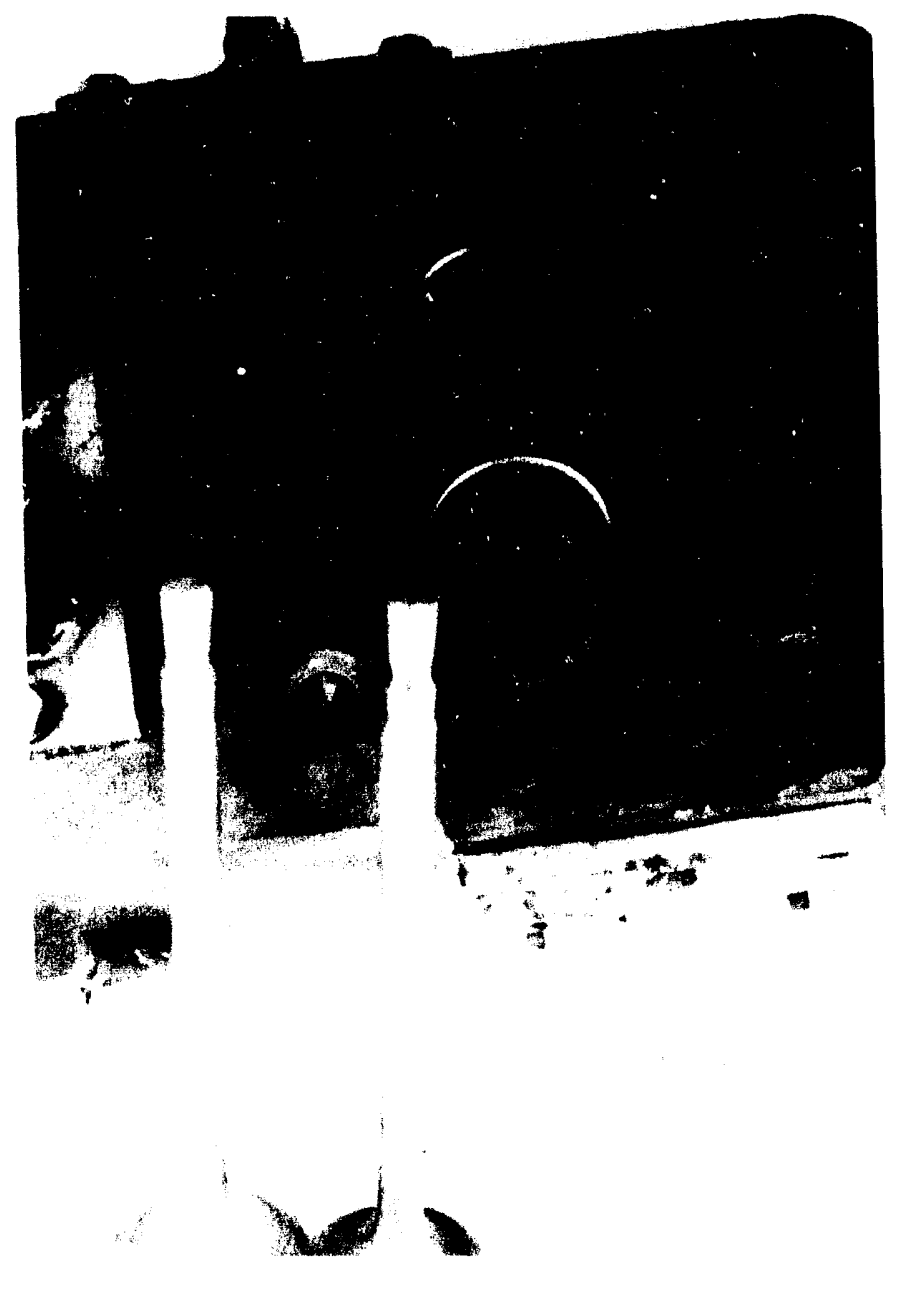

$\mathrm{AI}-\mathrm{C} / 182-24 \mathrm{~A}$
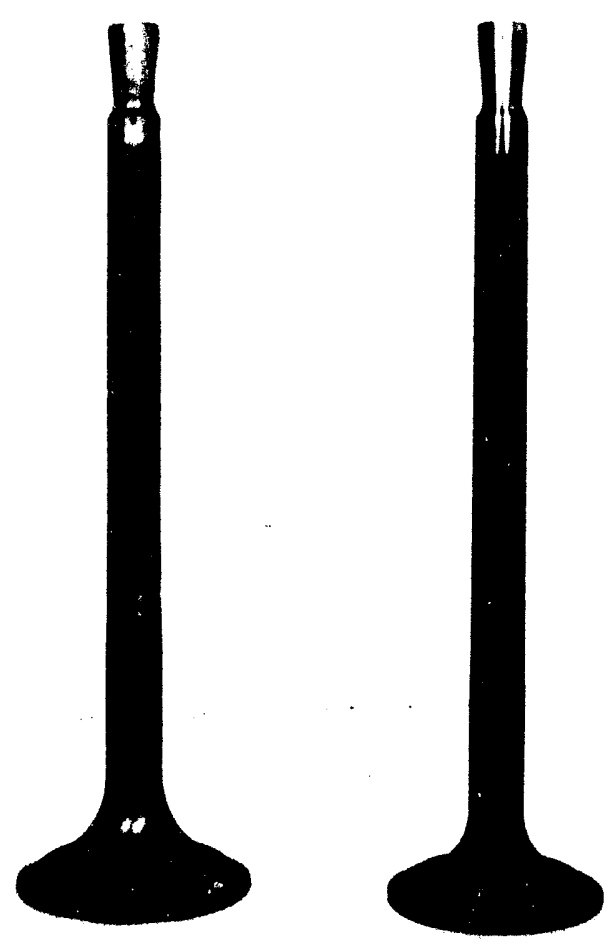

$\mathrm{AI}-\mathrm{C} / 181-0$

Figure 5.1.2-4 Photographs of Cylinder Head, and Intake and Exhaust Valves After CWS-Fueled Engine Tests 


\section{Table $5 \cdot 1 \cdot 3-1$ \\ COMPARISON OF CWS, COAL POWDER and DF-2 \\ FUELED ENGINE PERFORMLANCE}

\begin{tabular}{|c|c|c|c|}
\hline FUEL & CWS & COAL POWDER & DF -2 \\
\hline TEST NUMBER & $0824 \mathrm{GCL}$ & $0819 \mathrm{KCL}$ & $0902 \mathrm{CDF}$ \\
\hline ENGINE SPEED, $\quad$ rpW & 1,000 & 1,000 & 1,000 \\
\hline INJ. TIMING, deg BTDC & 29 & Fumlgated & 8 \\
\hline \% EGR & 0 & 26.0 & 0 \\
\hline BRAKE POWER, $\mathrm{kW}$ & 7.8 & 7.5 & 7.7 \\
\hline INDICATED POWER, $\mathrm{kW}$ & 9.2 & 11.7 & 10.4 \\
\hline IMEP, $\mathrm{kPa}$ & 500 & 640 & 569 \\
\hline $\begin{array}{l}\text { PEAK CYLINDER } \\
\text { PRESSURE, MPa } \\
\text { (al deg ATDC) }\end{array}$ & $\begin{array}{l}5.32 \\
(7)\end{array}$ & $\begin{array}{l}7.12 \\
(8)\end{array}$ & $\begin{array}{l}4.38 \\
(12)\end{array}$ \\
\hline $\begin{array}{l}\text { PEAK RATE OF } \\
\text { PRESSURE RISE, MPa/deg } \\
\text { (at deg ATDC) }\end{array}$ & $\begin{array}{c}0.285 \\
(3)\end{array}$ & $\begin{array}{r}0.48 \\
(4)\end{array}$ & $\begin{array}{c}0.069 \\
(9)\end{array}$ \\
\hline
\end{tabular}

EMISSIONS

\begin{tabular}{|c|c|c|c|}
\hline Co, $\begin{array}{l}g / b h p-h x \\
(1 \mathrm{l} / \mathrm{MMB}(\mathrm{L} u)\end{array}$ & $\begin{array}{l}18.1 \\
(4.41)\end{array}$ & NM & $\begin{array}{l}1.1 \\
(0.28)\end{array}$ \\
\hline $\mathrm{CO}_{2}, \%$ & 12.4 & 17.0 & 6.3 \\
\hline $\begin{aligned} & H C, g / b h p-h r \\
&(1 \mathrm{~b} / \mathrm{MMBLu})\end{aligned}$ & $\begin{array}{l}0.3 \\
(0.07)\end{array}$ & $\begin{array}{l}2.0 \\
(0.26)\end{array}$ & $\begin{array}{l}0.2 \\
(0.04)\end{array}$ \\
\hline $\begin{array}{l}\text { Nox, } g / \text { bhp-hr } \\
(1 \mathrm{~L} / \mathrm{MMBLu})\end{array}$ & $\begin{array}{l}3.1 \\
(0.76)\end{array}$ & $\begin{array}{l}5.0 \\
(0.65)\end{array}$ & $\begin{array}{l}3.7 \\
(0.96)\end{array}$ \\
\hline SMOKE, BOSch & NM & NM & NM \\
\hline
\end{tabular}




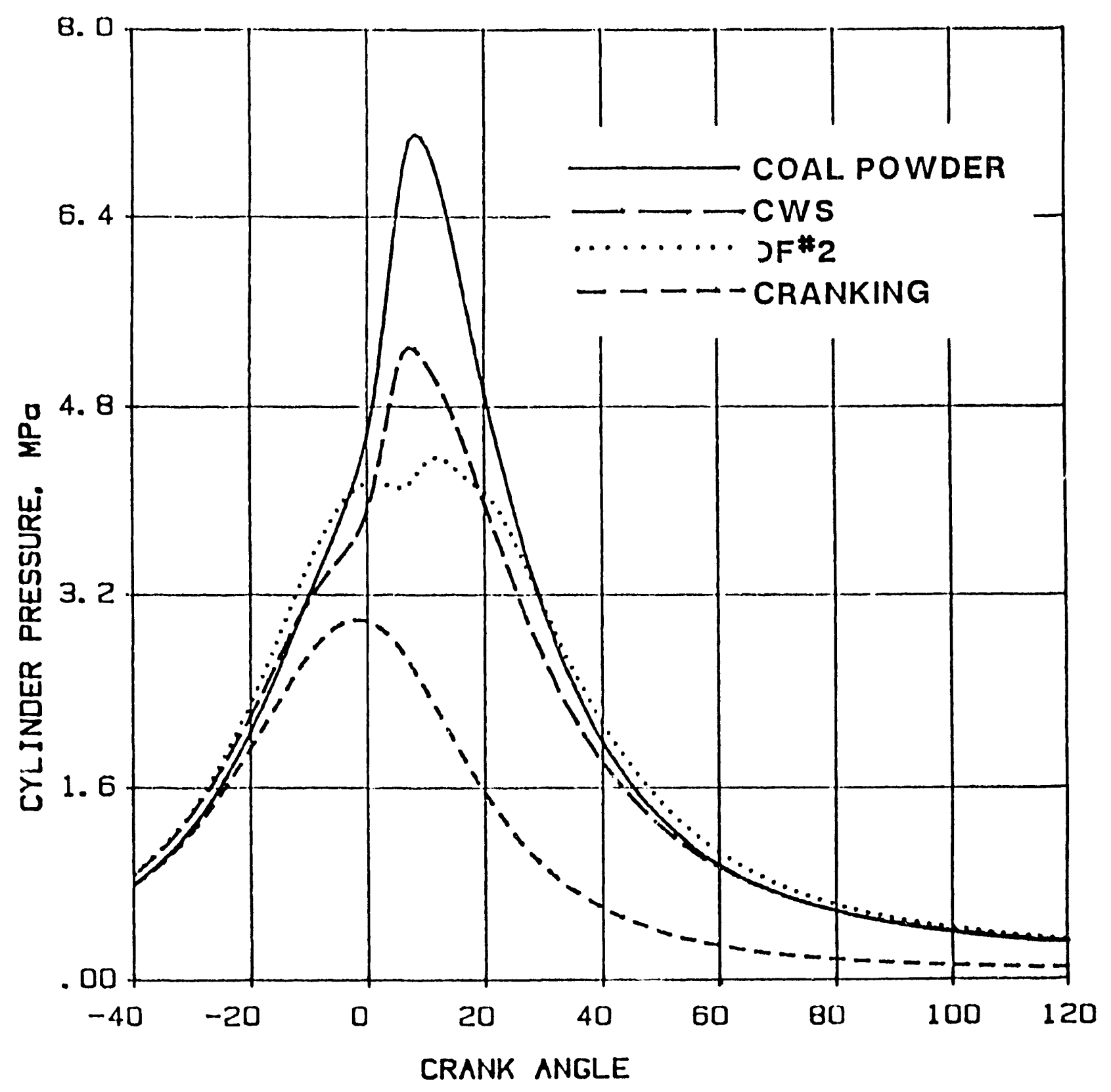

Figure 5.1.3-1 Comparison of Cylinder Pressure Data for Coal Powder, CWS and DF非 at 1,000 RPM Englne Speed 


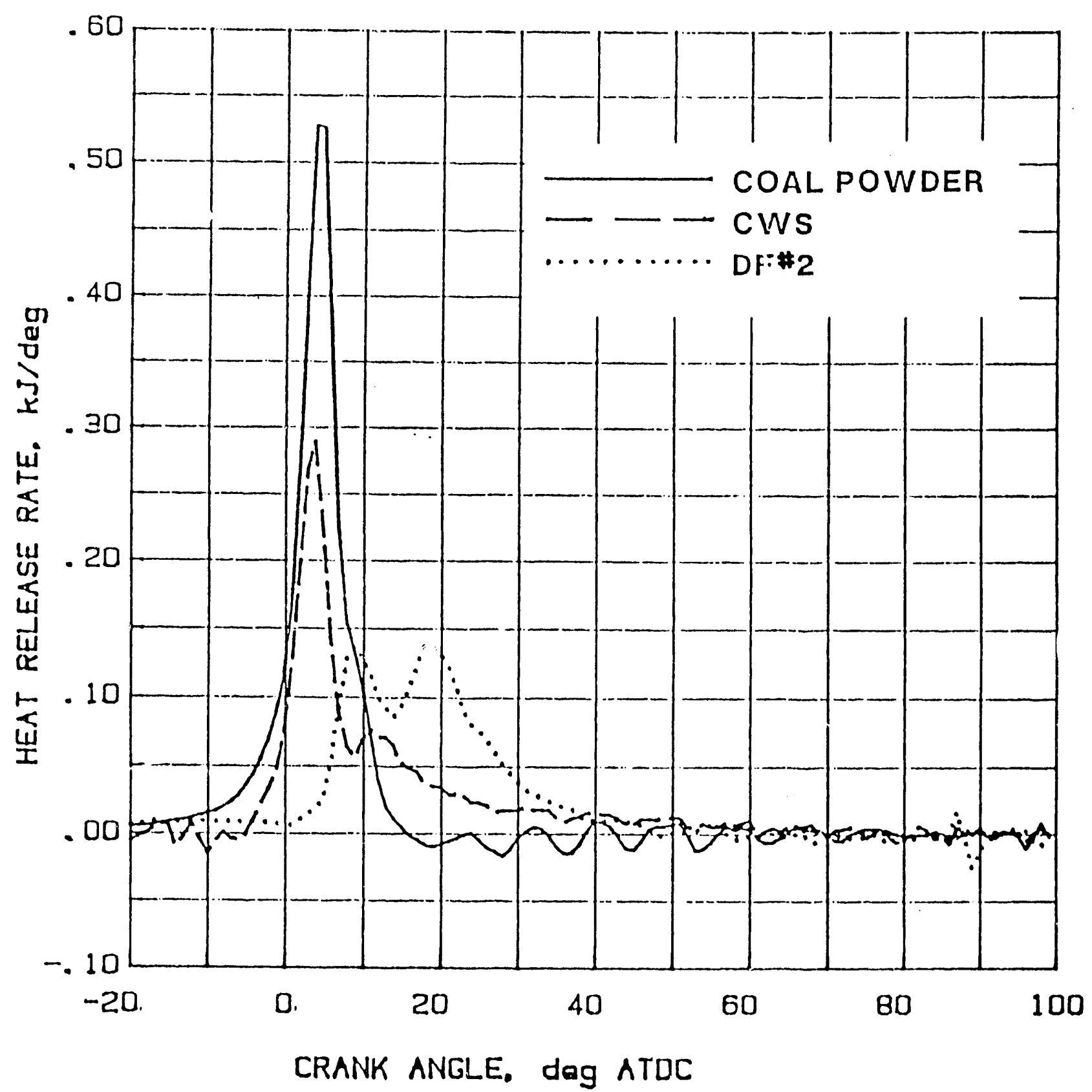

Figure 5.1.3-2 Comparison of Heat Release Data for Coal Powder, CWS and DF非 2 at 1,000 RPM Engine Speed 
control the ignition timing [13]. The engine testing with DF非 was carried out using the standard Caterpillar diesel fuel injector (13), while the CWS-fueled engine tests were carried out with the CWS injector developed in this program. The CWS injection pressure and nozzle hole diameter were 20.7 $\mathrm{MPa}$ and $1.016 \mathrm{~mm}$, respectively. TICS chamber made from Hastelloy X was used for all three fuels discussed here.

A comparison of the cylinder pressure data shows highest peak cylinder pressure and peak rate of pressure rise for the coal powder combustion. The peak cylinder pressure for coal powder, CWS and DF非 were 7.12, 5.32 and 4.38 $\mathrm{MPa}$, respectively. Also, the heat release analysis results in Figure 5.1.3-2 show highest peak heat release rate for the coal powder and lowest peak heat release rate for the DF非. For coal powder and CWS combustion, a major portion of the heat release was seen to be during the premixed combustion mode, whereas DF非 heat release results show a significant portion of the heat release during the diffusion combustion mode. Also, the shapes of coal powder and CWS heat release rates were more concentrated near TDC.

The NOx level for the CWS was the lowest, followed closely by the DF非. The peak cylinder temperature, one of the primary causes of thermal generated NOx, was reduced by the additional heat required to vaporize the water in the CWS. Coal powder fuel gave the highest NOx emissions because of higher peak cylinder temperature. However, the CO for the CWS was much higher, which suggests that there was still optimization of the test engine parameters to be carried.

\subsubsection{Effect of Engine Load}

The engine test results for the part to full 1 oad 100 percent CWS-fueled engine operation at $1,000 \mathrm{rpm}$ engine speed are presented in Table 5.1.4-1. These engine tests were conducted with Blue Gem seam coal using nozzle B. $0.7366 \mathrm{~mm}$ hole diameter, and $20.7 \mathrm{MPa}$ CWS injection pressure. A comparison of the cylinder pressure and heat release data presented in Figures $5.1 .4-1$ and 5.1.4-2, shows rapid heat release rates and shorter combustion duration at various engine loads.

The cylinder pressure and the rate of pressure rise values refer to the main combustion chamber. The heat release model was used to compute the gross heat release rate (including heat transfer to combustion chamber walls and crevice volume) from the cylinder pressure data. The heat release data for the lower engine loads, 272 and $340 \mathrm{kPa}$ IMEP, show that most of the burning was in the premixed combustion mode, whereas $500 \mathrm{kPa}$ IMEP data show both premixed and diffusion combustion modes. As expected the peak heat release rate increases with the engine load. The pressure-volume diagram shows effectively constant volume combustion for the CWS (see Figure 5.1.4-3).

\subsubsection{Effect of Engine Speed}

Preliminary engine test results from 1,200 to $1,800 \mathrm{rpm}$ speed range are presented in Table 5.1.5-1 and Figures 5.1.5-1 and 5.1.5-2. These 100 percent CWS-fueled engine tests were conducted without external ignition assist with nozzle B (0.7493 mm hole diameter) and $20.7 \mathrm{MPa}$ CWS injection pressure. The data shows maximum brake thermal efficiency of 27.9 percent and maximum peak cylinder pressure of $5.4 \mathrm{MPa}(783 \mathrm{psi})$ at 1,400 rpm engine speed. The test data at 1,600 and $1,800 \mathrm{rpm}$ engine speeds shows lower peak cylinder pressures 
TABLE $5 \cdot 1 \cdot 4-1$

$100 \%$ CWS-FUELED ENGINE PERFORMANCE AT VARIOUS LOADS

Otisca Blue Gem Coal

Hastelloy $X$ chamber temp $=730$ to $760+C$

Intake air temp $=71 \mathrm{C}$

CWS Injection Pressure (at begin) $=20.7 \mathrm{MPa}$

Nozzle Hole Diameter $=0.7366 \mathrm{~mm}(0.029$ inch)

TEST NUMBER

0824 ICL

$0824 \mathrm{HCL}$

$0824 G C L$

ENGINE SPEED, rpm

1,000

1,000

1,000

LOAD, ft.Ib

26.0

34.4

55.1

$(N \cdot m)$

(35.3)

$(46.6)$

(74.7)

INJ. TIMING, deg BTDC

32

30

29

FUEL FLOW, kg/mm

0.055

0.066

0.105

AIR/DRY FUEL RATIO

33.2

27.7

17.4

BRAKE POWER, $\mathrm{KW}$

3.7

4.9

7.8

BRAKE THERMAL EFF. , \&

$25 . \dddot{2}$

27.8

28.2

INDICATED POWER, kW

5.0

6.2

9.2

IMEP, $\mathrm{kPa}$

272

340

500

PEAK CYLINDER PRESSURE, MPa (at deg ATDC)

4.96

5.21

5.32

(8)

PEAK RATE OF

PRESSURE RISE, MPa/deg (at deg A'TDC)

0.221

0.244

(3)

0.285

PEAK hEAT RELEASE RATE, $\mathrm{kJ} / \mathrm{deg}$

0.192

0.252

(4)

0.291

EMISSIONS

Co, g/bhp-hr

17.6

(lb/MMBtu)

(3.84)

11.1

(2.67)

18.1

$(4.41)$

$\mathrm{CO}_{2}$, \&

5.7

7.6

12.4

HC, g/bhp-hr

(Ib/MMBtu)

NOx, g/bhp-hr

0.4

$(0.09)$

0.2

0.3

$(0.06)$

$(0.07)$

5.6

6.8

(1.23)

(1.63)

3.1

$(0.76)$

SMOKE, BOSCh

NM

NM

NM

NM $=$ Not Measured

Emissions measurement was not certified 


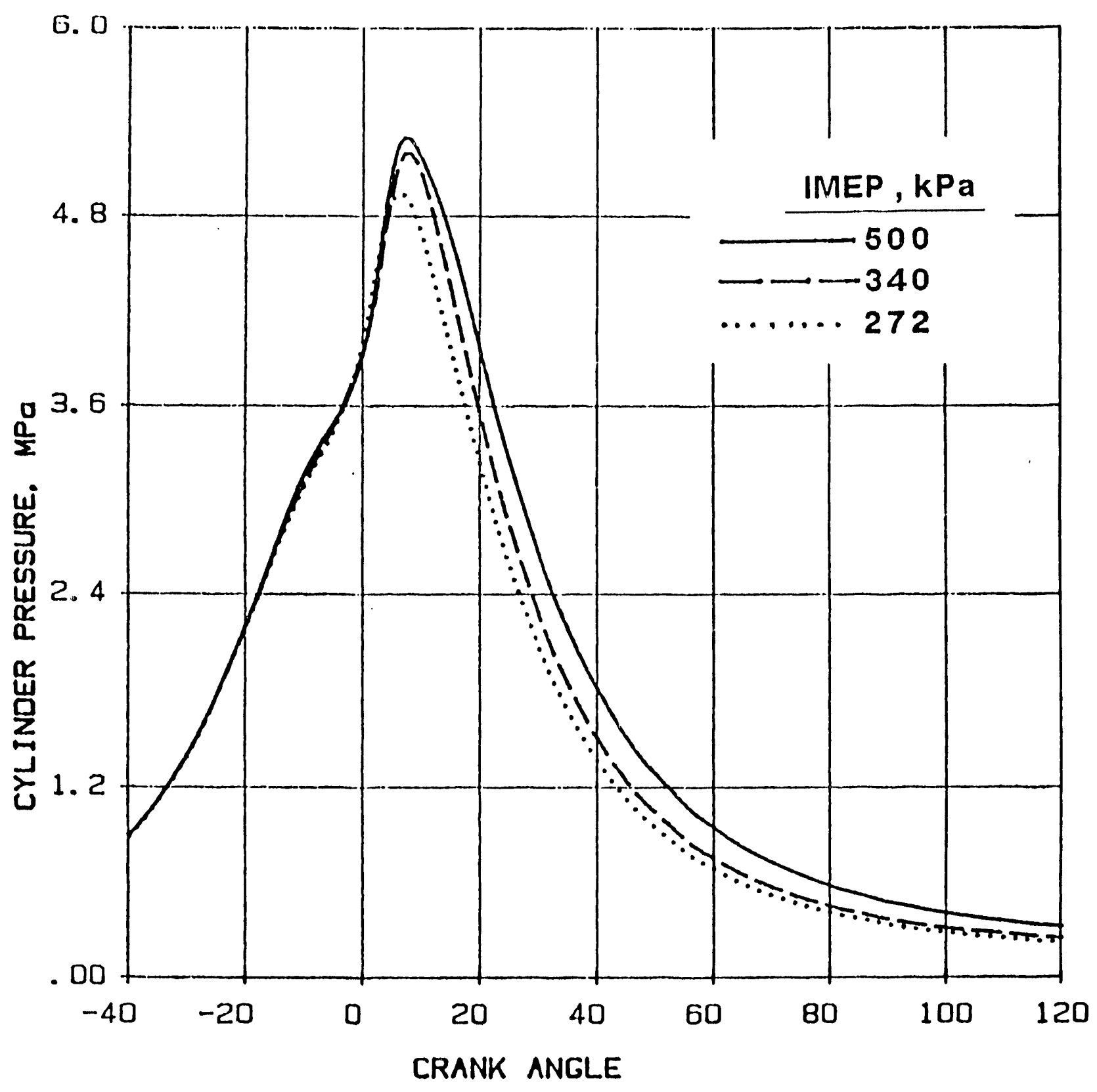

Figure 5.1.4-1 Cylinder Pressure Diagrams for Blue Gem Seam CWS-Fueled Engine Tests at Different-Loads (see Table 5.1.4-1)

Engine Speed - 1,000 RPM 


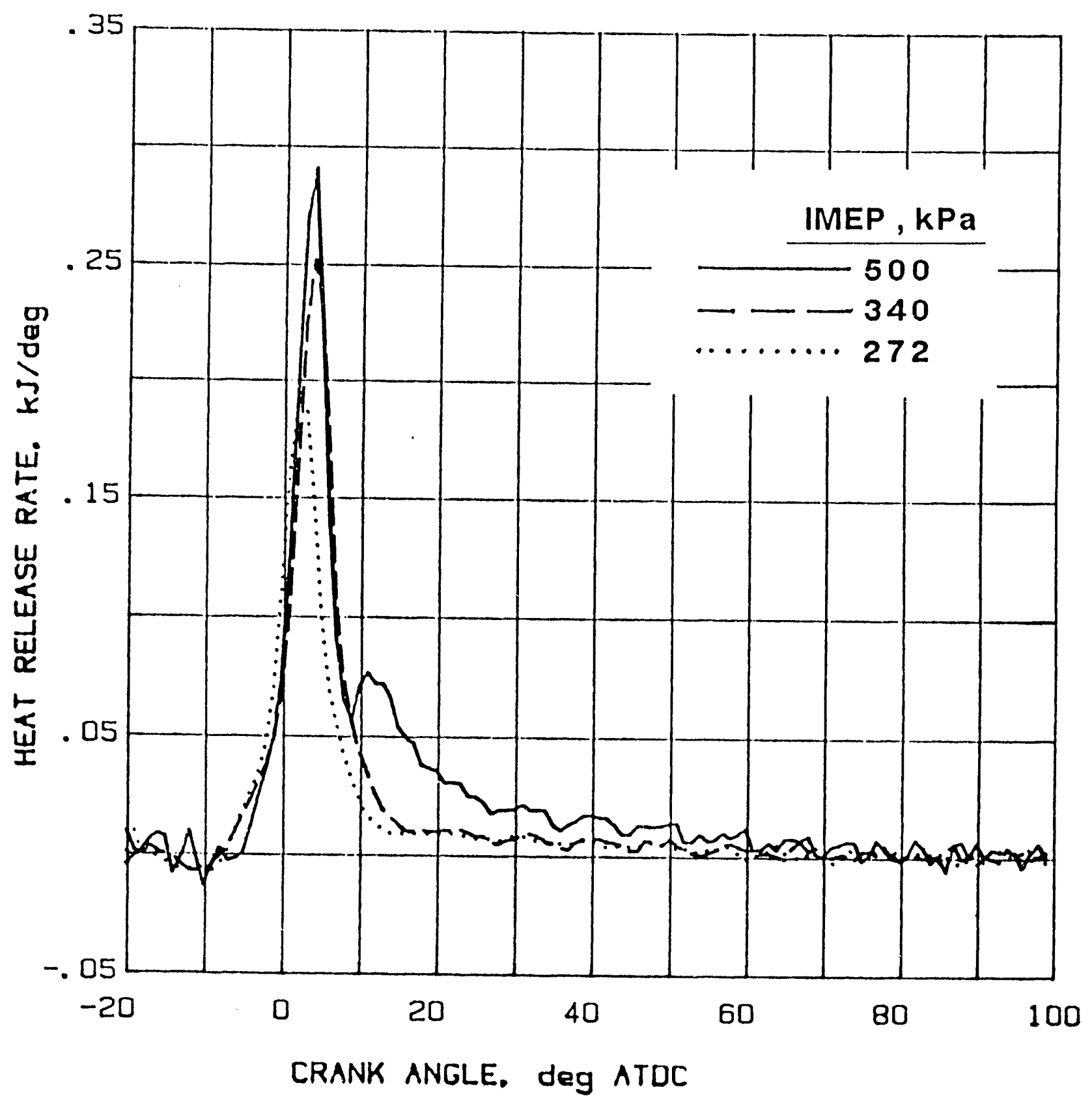

Figure 5.1.4-2 Heat Release Diagrams for Blue Gem Seam CWS-Fueled Engine Tests at Different-Loads

(see Table 5.1.4-1)

Engine Speed $=1,000$ RPM 


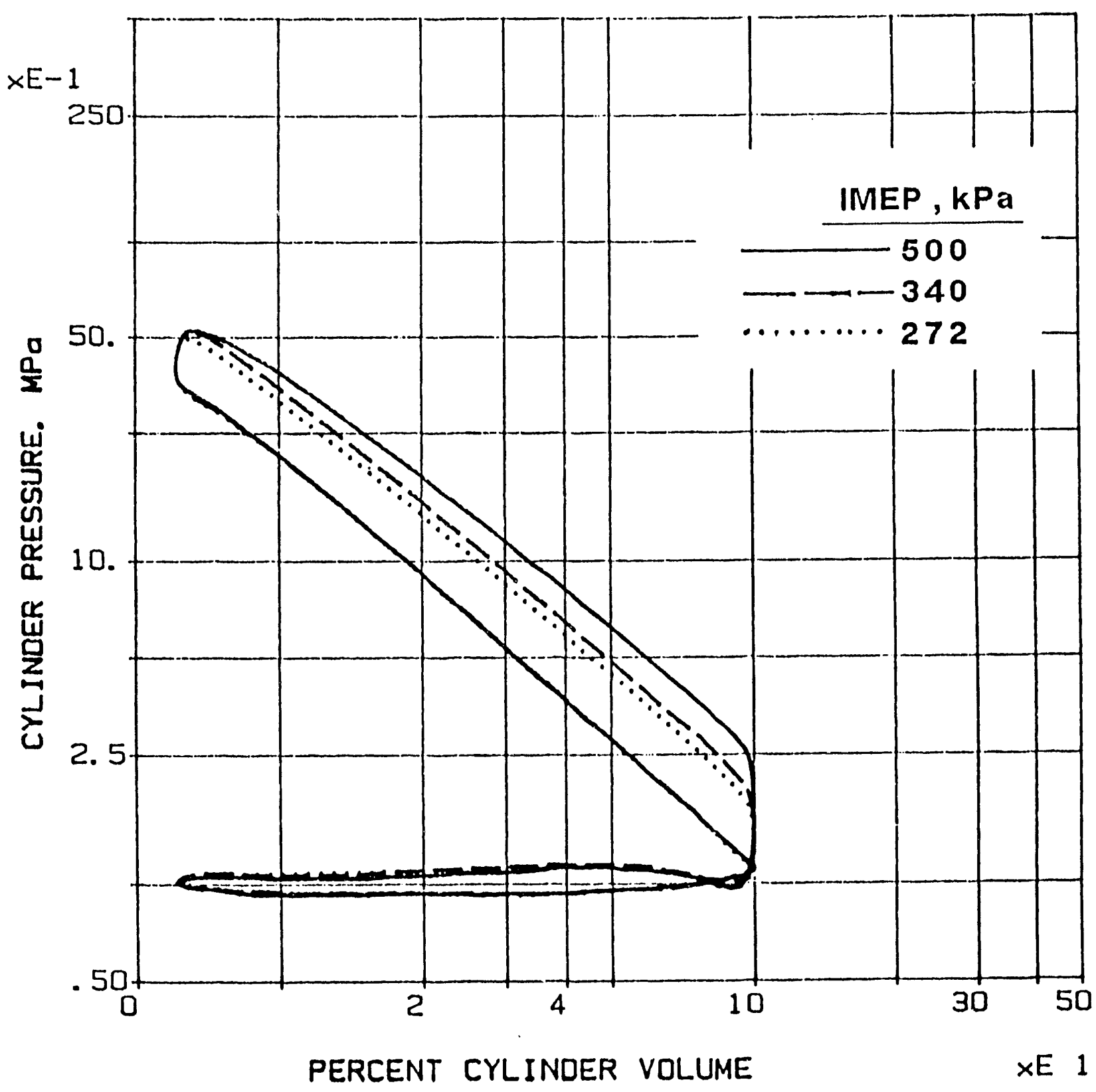

Figure 5.1.4-3 Pressure Volume Diagrams for Blue Gem Seam CWS-Fueled Engine Tests at Different-Loads (see Table 5.1.4-1)

Engine Speed $=1,000$ RPM 
otisca Blue Gem Coal

Hastelloy $X$ chamber temp $=752$ to $856^{\circ} \mathrm{C}$

Intake air temp $=56$ to $77^{\circ} \mathrm{C}$

CWS Injection Pressure (at begin) $=20.7 \mathrm{MPa}$

Nozzle Hole Diameter $=0.7493 \mathrm{~mm}(0.0295 \mathrm{inch})$

TEST NUMBER

$0929 \mathrm{FCL}$

$0929 \mathrm{HCL}$

$0929 \mathrm{KCL}$

0929ICL

ENGINE SPEED, rpm

1,200

1,400

1,600

1,800

LOAD, ft. Ib

24.1

34.9

39.0

29.1

(N.m)

(32.7)

$(47.3)$

(52.9)

$(39.5)$

INJ. TIM., deg BTDC

30

30

30

30

START OF COMBUSTION, $\operatorname{deg} B T D C$

$$
3
$$

0.072

5

7

4

FUEL FLOW, $\mathrm{kg} / \mathrm{mm}$

30.7

0.0948

0.138

0.138

AIR/DRY FUEL RATIO

\section{1}

28.0

22.6

25.6

BRAKE POWER, $\mathrm{KW}$

6.9

8.9

7.4

BRAKE THER. EFF., 8

21.7

27.9

24.4

20.6

IHD. POWER, KW

$$
6.4
$$

9.4

12.0

12.4

IMEP, kPa

292

368

409

376

PEAK CYLINDER

PRESSURE， MPa

(at deg ATDC)

5.36
$(7)$

0.281

(3)

RISE, MPa/deg

(at deg ATDC)

PEAK HEAT RELEASE

RA'TE, KJ/deg

(at deg ATDC)

EMISSIONS

Co, g/bhp-hr (Ib/MMBtu)

0.292

(4)

5.42

(7)

0.241

(3)

0.243

(3)

10.9

(2.06)

5.4

(1.32)

6.8

$\mathrm{CO}_{2}$, ?

HC, g/bhp-hr

(1b, MMBtu)

NOx, g/bhp-hr

(1b/MMBtu)

10.6

0.2
$(0.04)$

7.4

0.1

$(0.03)$

5.04

(5)

4.69

(7)

0.10

(1)

0.078

0.082

(1)

0.091

SMOKE, BOSch
7.8

(1.88)
10.9

(2.30)

15.5

(2.78)

8.8

0.3

$(0.06)$

9.3

0.4

$(0.08)$

6.1

(1.29)

9.5

(1.70)
NM

NM

NM

NM

NM $=$ Not Measured

Emissions measurement was not certified 


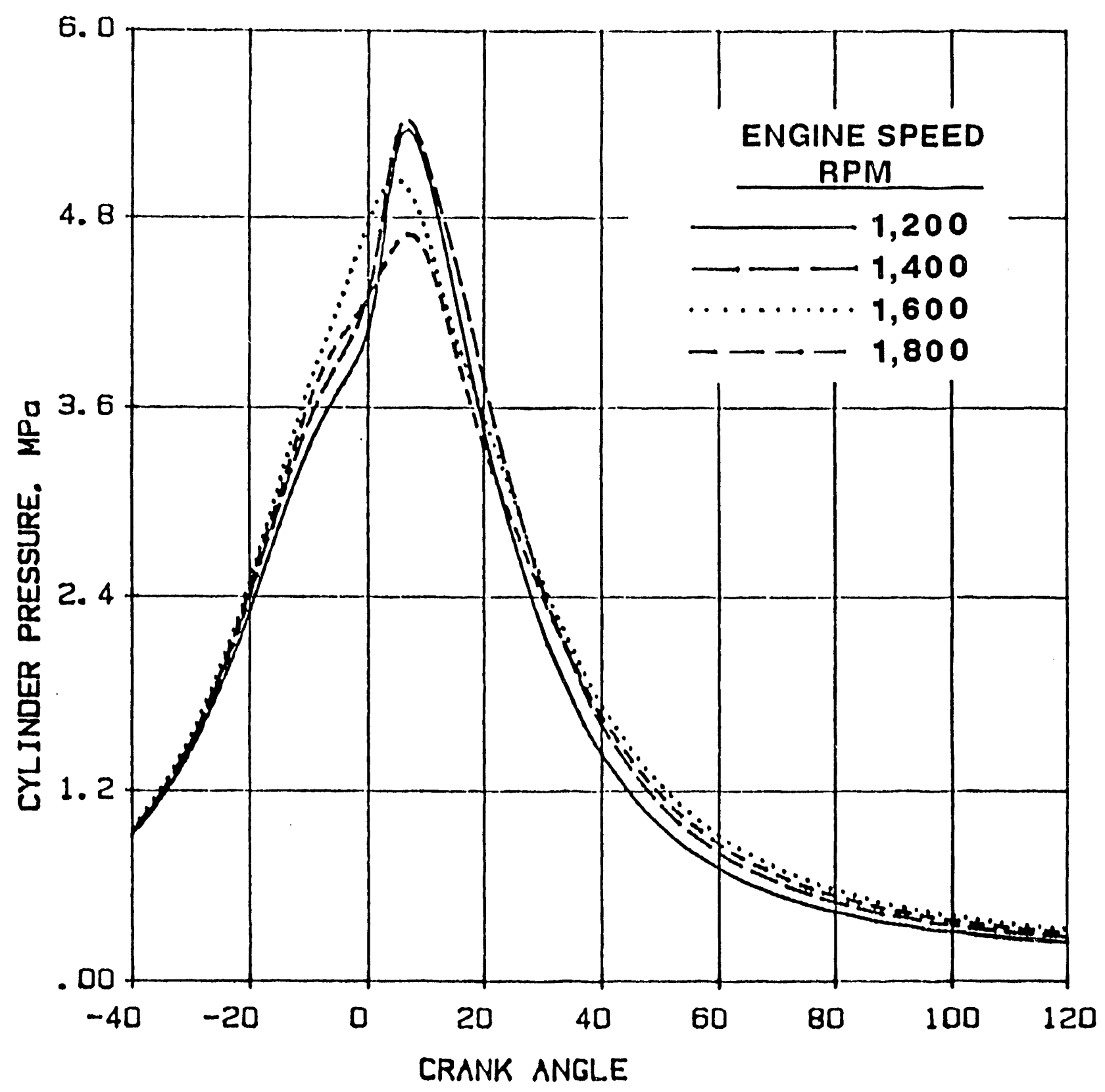

Figure 5.1.5-1 Cylinder Pressure Data for 100\% Blue Gem Seam CWS-Fueled Engine Tests at Different Speeds 


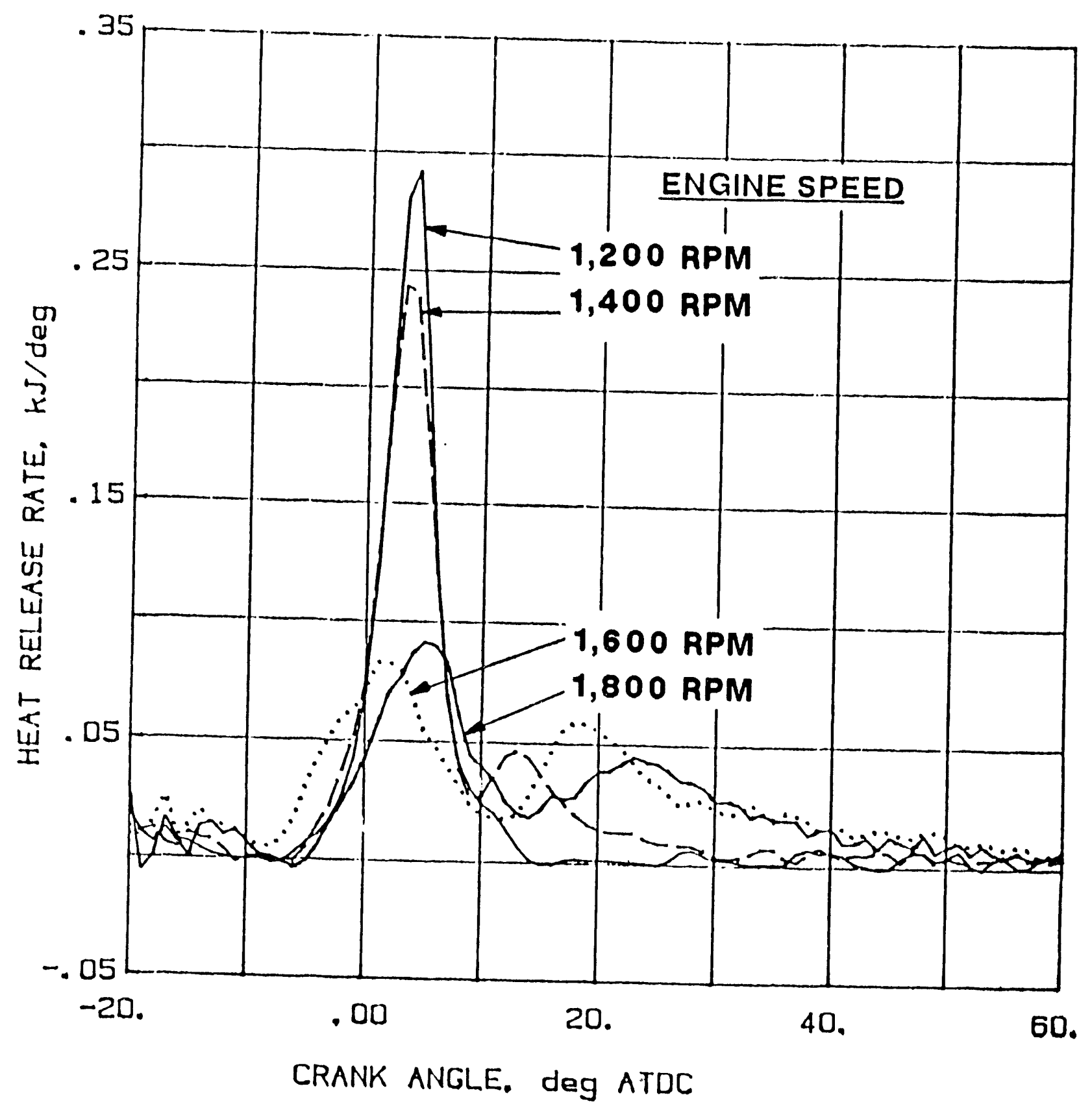

Figure 5.1.5-2 Heat Release Data for 100\% Blue Gem Sean CWS-Fueled Engine Tests at Different Speeds 
and brake thermal efficlency because of lower intake air temperature and non-optimized CWS injection timing.

These results demonstrate the feasiblity of CWS-fueled engine operation up to $1,800 \mathrm{rpm}$. This speed range is typical of many current heavy duty diesel engines.

\subsubsection{Effect of CWS Infection Pressure}

The effect of CWS injection pressure on the cylinder pressure and heat release rate data in Figures 5.1.6-1 and 5.1.6-2 shows an increase in the peak heat release rate with an increase in the injection pressure from 13.8 to 20.7 $\mathrm{MPa}$. This behavior was expected because of better CWS atomization and lower Sauter mean diameter at the higher injection pressures [14]. The lower infection pressures resulted in lower wear of the nozzle hole and a less complicated CWS injection system when compared to data reported for other CWS injectors.

\subsection{Develepment Englneering - PHASE II}

During Phase II, both the CWS injector and prechamber designs were rodifled in an attempt to optimize the infector and engine performance.

In order to provide a more durable injector spray hole, and to facilitate measurement of the spray hole wear, the fuel injector has been modified to incorporate a replaceable spray orifice insert (shown in Figure 5.2-1). The orifice insert is a simple flat disk with a hole in its center which is clamped to the infector. Disks were fabricated from tungsten carbide, silicon nitride and M2 tool steel. Of the three disk materials, only the M2 tool steel disk was engine tested.

Engine testing was performed with three different nozzle hole diameters (1, 0.91 and $0.76 \mathrm{~mm}$ ). The predicted performance of these three nozzle hole diameters are shown in Figure 5.2-2 which plots injection duration at 1,800 $\mathrm{rpm}$ versus hole diameter at constant infection pressure for the maximum flowrate required by the engine.

The one piece Hastelloy $X$ prechamber used during Phase I was modified to enable the configuration to bo easily changed. First, the prechamber was made into two parts (a top half and a bottom half). The prechamber halves were clamped together and sealed with a gasket. The two plece prechamber greatly reduced machining costs since one top half was used with different bottom halves. The second prechamber modification was a machining change to accommodate the new CWS injector nozzle cap which housed the replaceable spray insert orifice. A photograph of the modified CWS injector and prechamber is shown in Figure 5.2-3.

For each injector and prechamber configuration, engine data was obtained at each of the following test conditions: 


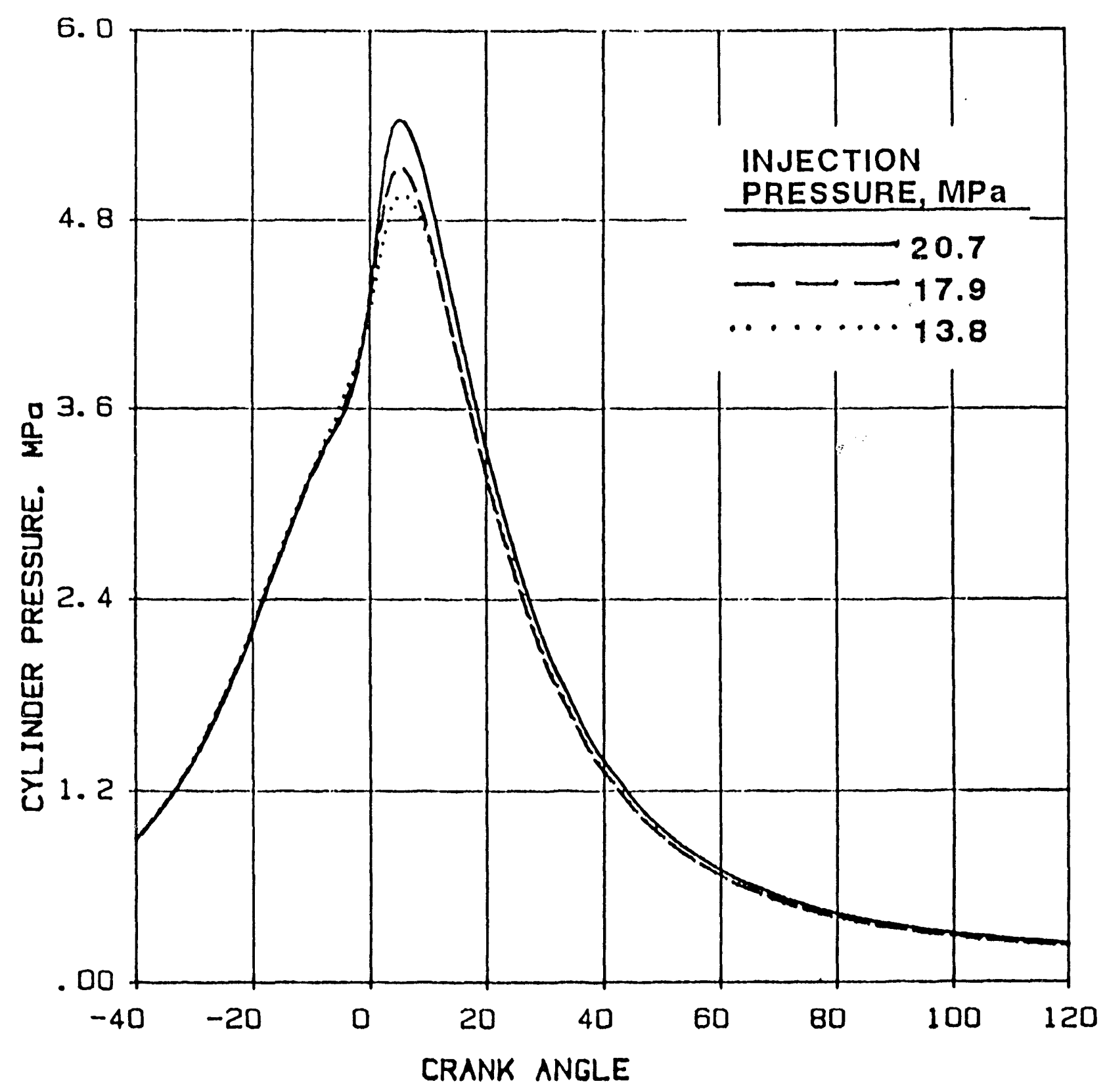

Figure 5.1.6-1 Cylinder Pressure Data for CWS-Fueled Engine Tests From 13.8 to $20.7 \mathrm{MPa}$ CWS Injection Pressures (Engine Speed $=1,000 \mathrm{RPM}$ ) 


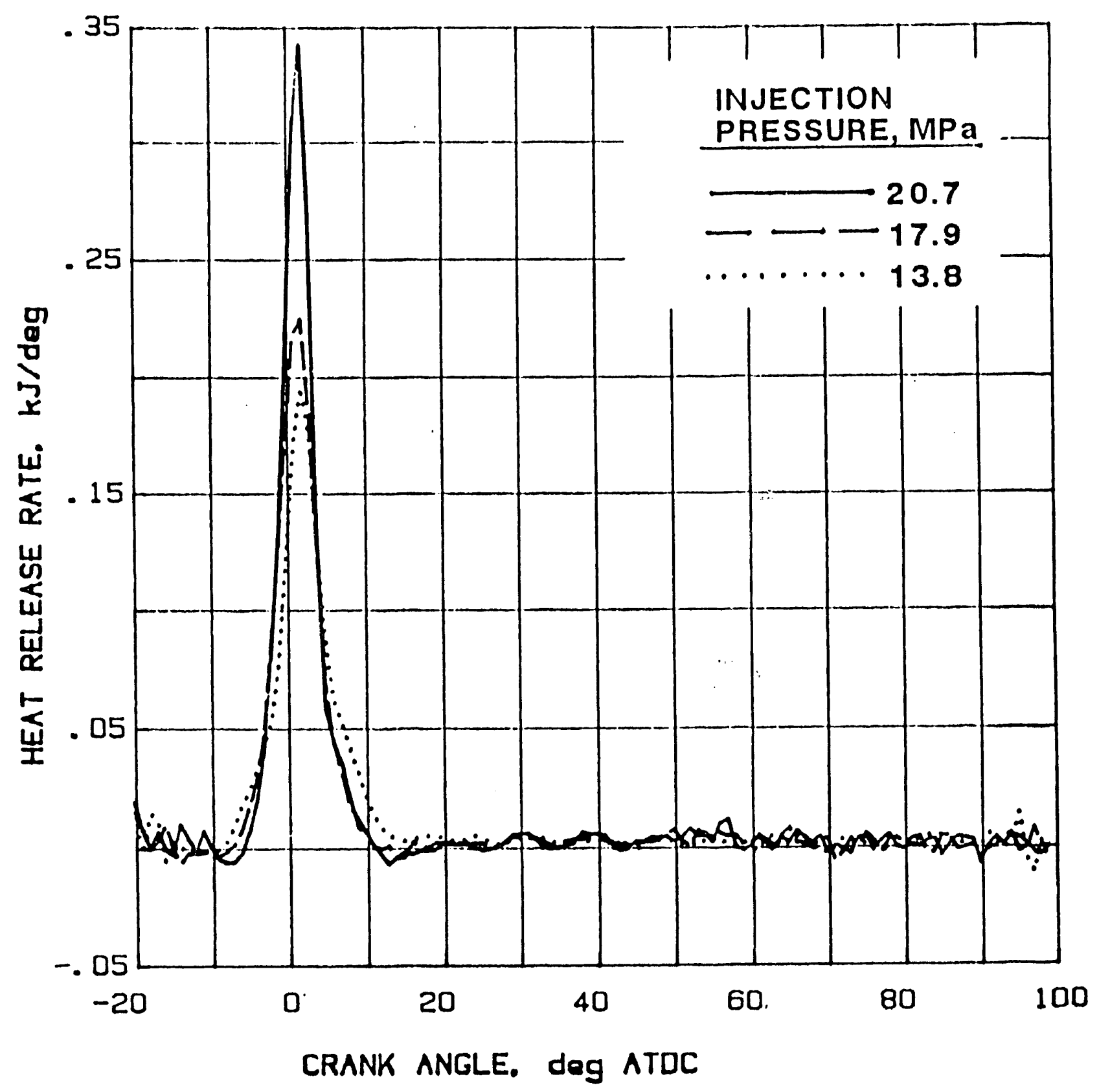

Figure 5.1.6-2 Heat Release Data for CWS-Fueled Engine Tests From 13.8 to $20.7 \mathrm{MPa}$ CWS Injection Pressures

(Engine Speed $=1,000 \mathrm{RPM}$ ) 


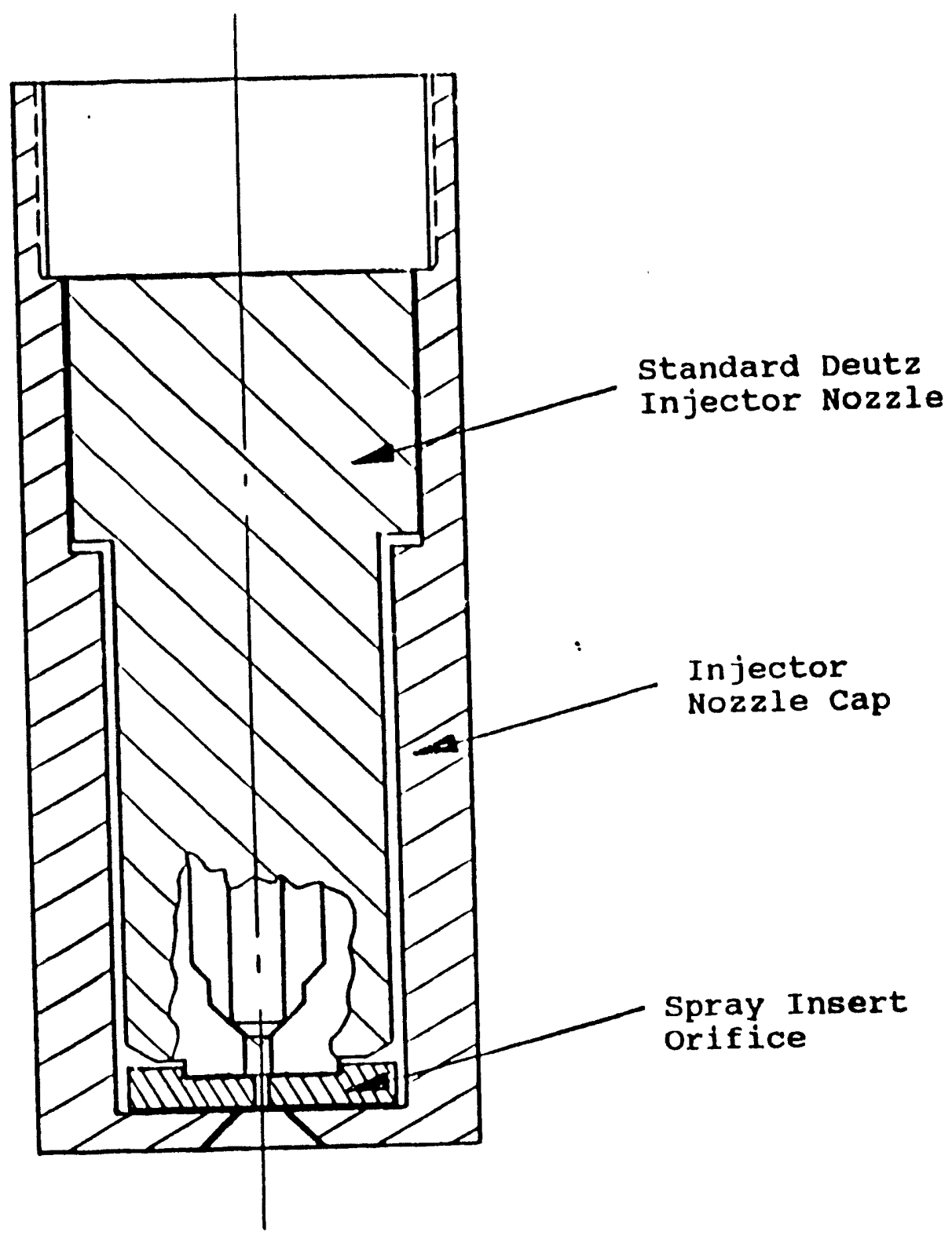

Figure 5.2-1 CWS Injector Nozzle Assembly 


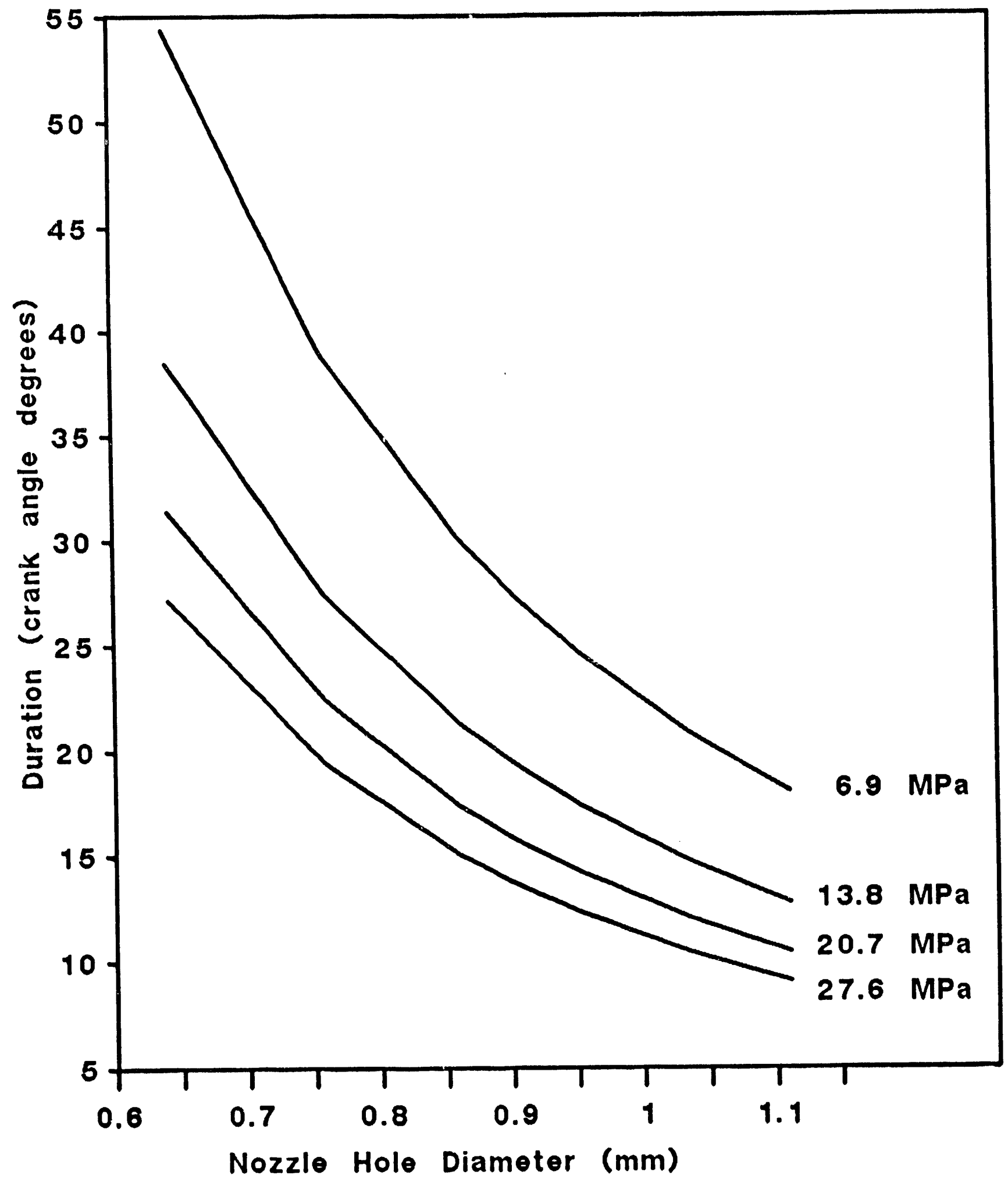

Figure 5.2-2

\section{INJECTION DURATION VS NOZZLE DIAMETER and MEAN INJECTION PRESSURE}




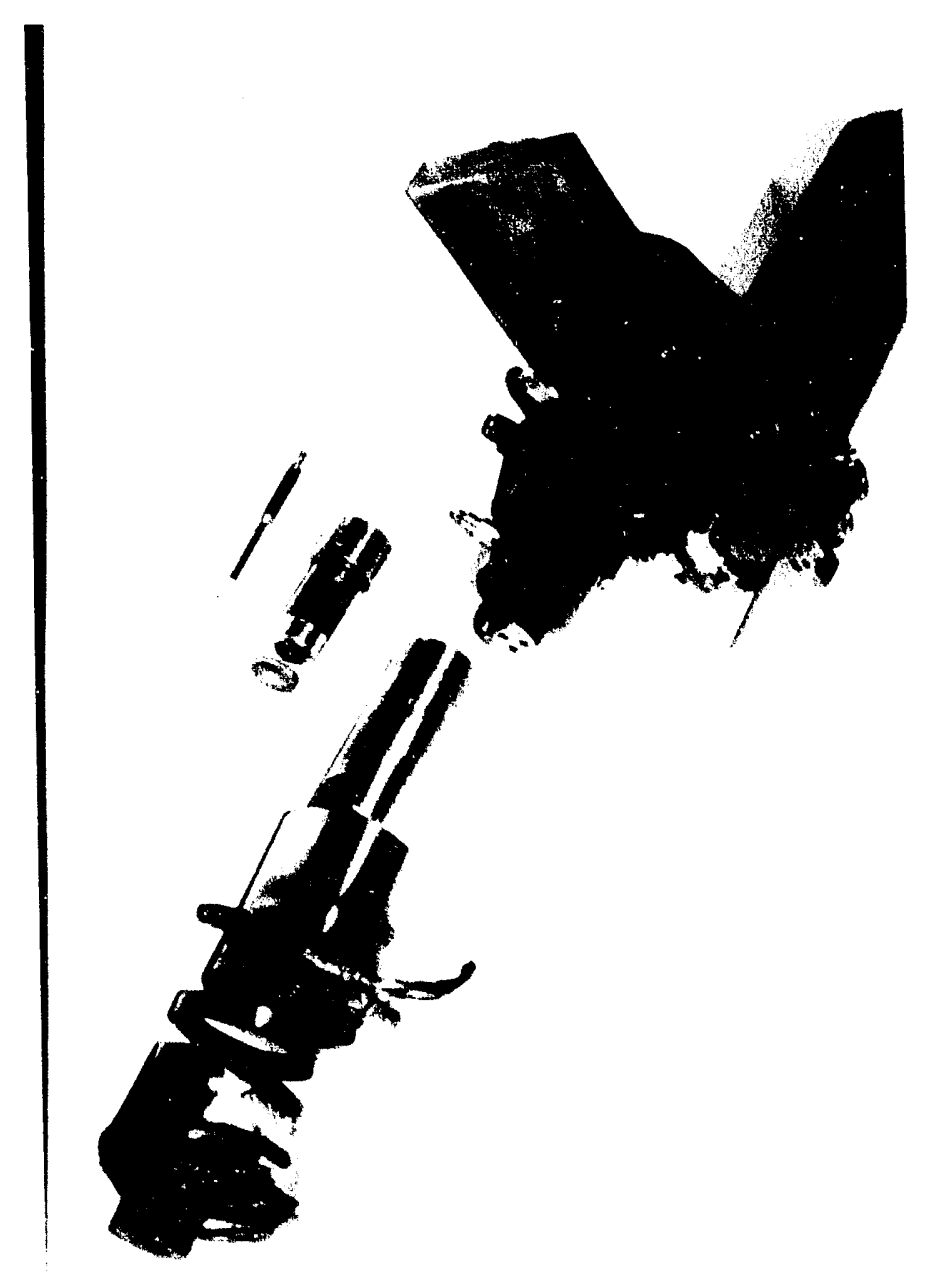

AI $-233-9 A$

Figure 5.2-3 Modirisd CWS Injector and Prechamber 


\begin{tabular}{|c|c|c|c|c|}
\hline & \multicolumn{4}{|c|}{ Engine Test Matrix } \\
\hline & & $\begin{array}{l}n g i \\
00 \\
\end{array}$ & $\begin{array}{l}\text { e Speed, } \\
1,400 \\
\end{array}$ & $\begin{array}{l}\text { rpm } \\
1.800 \\
\end{array}$ \\
\hline & Idle & $\mathrm{X}$ & $\mathrm{X}$ & $x$ \\
\hline & $50 \%$ & $\mathrm{x}$ & $\mathrm{X}$ & $\mathrm{x}$ \\
\hline & Ful 1 & $\mathrm{x}$ & $\mathrm{x}$ & $\mathrm{x}$ \\
\hline
\end{tabular}

A summary of various optimization studies as well as wear data are presented in the sections that follow. All of the testing during Phase Il was carried out with Otisca Blue Gem seam CWS.

\subsubsection{Precombustion Chamber Design}

In order to improve the performance from the baseline (straight round throat) CWS precombustion chamber (PCC) design, two additional throat concepts were explored. The concepts were a multi-hole throat called the "pepper pot" (Figure 5.2.1-1) and a single hole throat machined to induce swirl (Figure 5.2.1-2). Figure 5.2.1.3 is a drawing of the pepper pot design prechamber which shows the cylinder and piston crown (shown with the piston at 30 degrees before top dead center).

While testing the three prechamber design concepts, prechamber volumes were held constant at $47 \mathrm{cc}$. The $47 \mathrm{cc}$ prechamber volume accounted for 31.4 percent of the total clearance volume and produced a 15.7:1 compression ratio. The injector nozzle hole diameter was about $1 \mathrm{~mm}$. Timing of the CWS injection was optimized for maximum power at each test point.

The comparison of the overall performance with the baseline, swirl and pepper pot prechamber tests are presented in Figures 5.2.1-4 through 5.2.1-6 for a range of loads from 100 to $500 \mathrm{kPa}$ BMEP at $1,000,1,400$ and $1,800 \mathrm{rpm}$. In all cases, the injection pressure was maintained at $20.7 \mathrm{MPa}$. Initial running with the pepper pot PCC design showed extremely poor performance and very high precombustion chamber temperatures. The pepper pot chamber was modified to add one additional $5 \mathrm{~mm}$ hole along the centerline axis of the chamber. This modification improved the engine performance. All of the test data shown for the pepper pot chamber was taken after this modification. It can be seen that at $1,000 \mathrm{rpm}$, both the new designs (swirl and pepper pot) have shown improvement as compared to the baseline and the pepper pot gives the highest efficiency. This may be attributed to the better atomization and mixing of the fuel and air. The higher NOx in the case of pepper pot could be attributed to the higher flame temperature presumably due to the better burning achieved with improved mixing.

However, at 1,400 and $1,800 \mathrm{rpm}$, the swirl chamber has shown the highest thermal effictency. Further, the performance improvements were reflected in lower BSFC, $C O$ and smolse level in the case of swirl chamber. At 1,400 rpm, the pepper pot temperatures were found to be very high and the power was 1 ow. The pepper pot PCC could not be run at $1,800 \mathrm{rpm}$ as the PCC temperatures exceeded the preset limit of $982^{\circ} \mathrm{C}\left(1,800^{\circ} \mathrm{F}\right)$.

\section{2 .2 Effect of Injection Timing}

The effect of CWS infection timing is shown in Figure 5.2.2-1. The data points were taken at $1,400 \mathrm{rpm}$ with a $1 \mathrm{~mm}$ injector nozzle hole diameter, the 

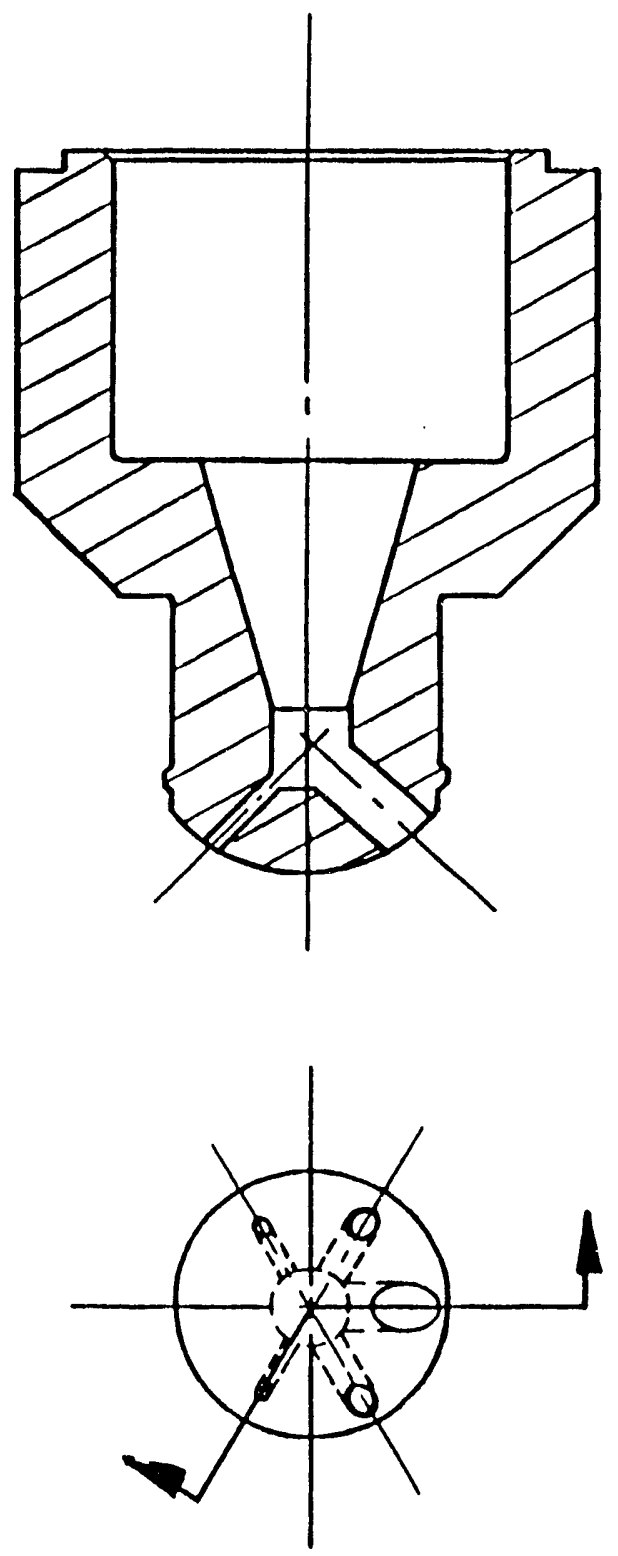

Figure 5.2.1-1 Pepper Pot Prechamber Design Made From Haste1loy X

AI - 900135

46 

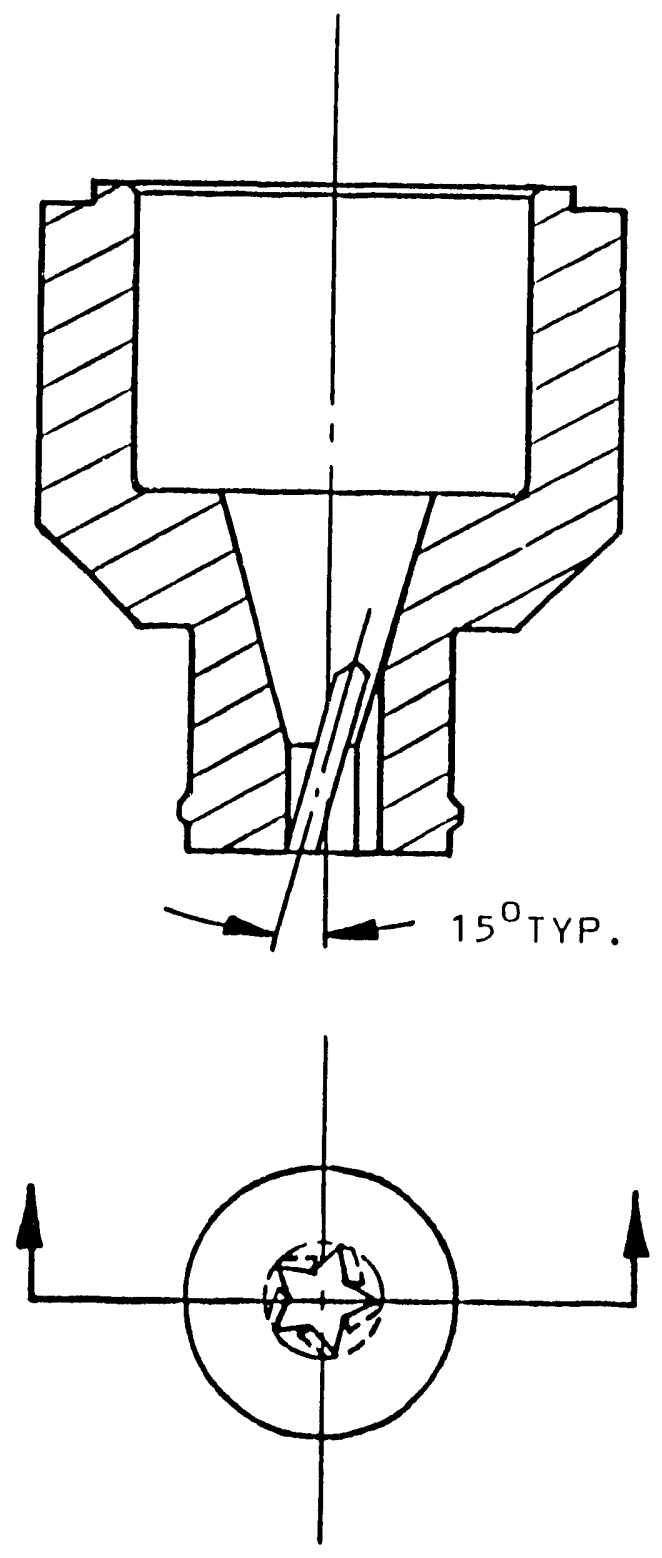

Figure 5.2.1-2 Swirl Prechamber Design Made From Hastelloy X

$$
\text { AI }-900136
$$

47 


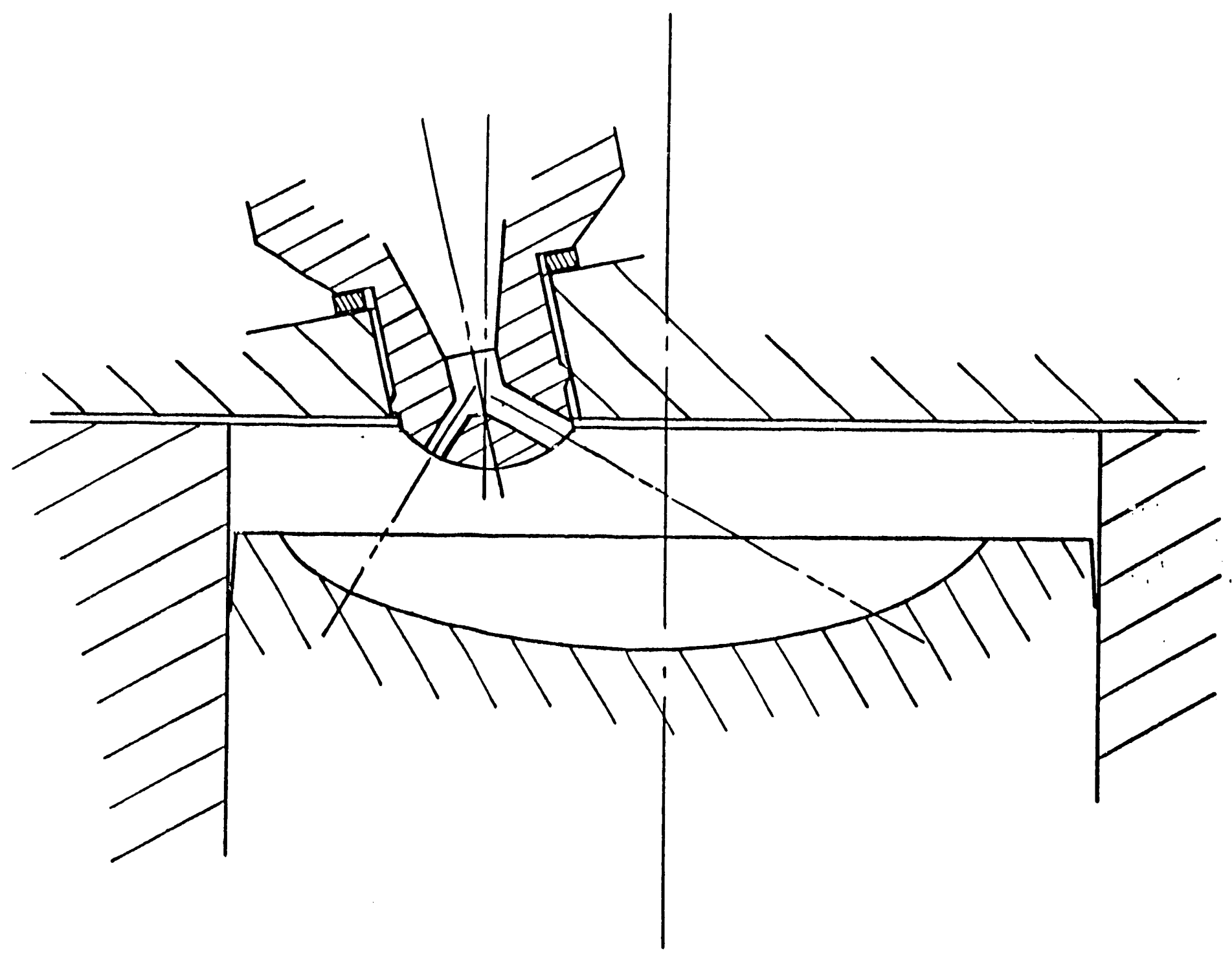

$\begin{aligned} \text { Figure 5.2.1-3 } & \text { Pepper Pot Prechamber Combustion Gas Flow } \\ & \text { at } 30^{\circ} \text { BTDC }\end{aligned}$ AI - 900137 


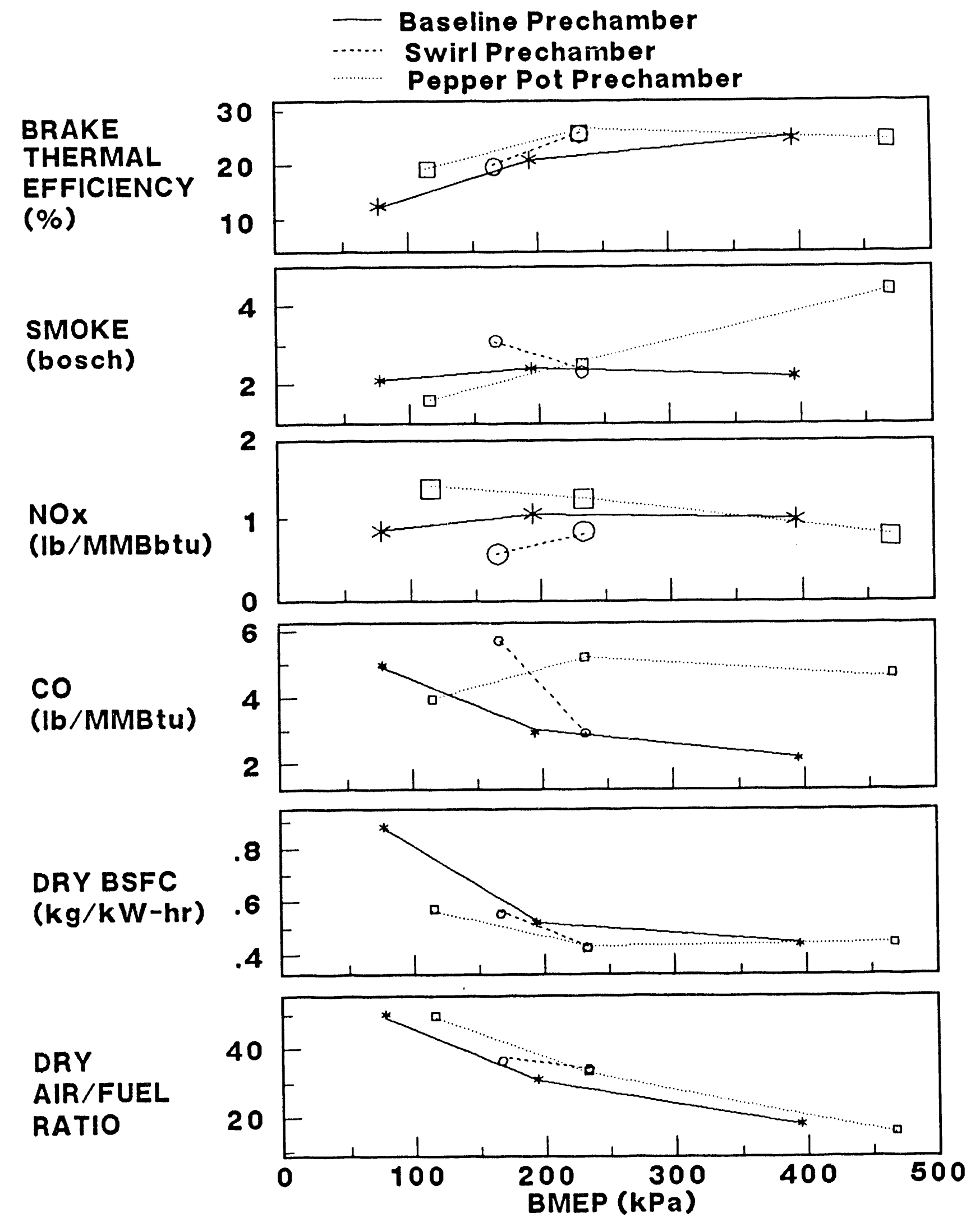

Figure 5.2.1-4 Innovative Coal-Fueled Diesel Engine at 1,000 RPM and 20.7 MPa Injection Pressure 


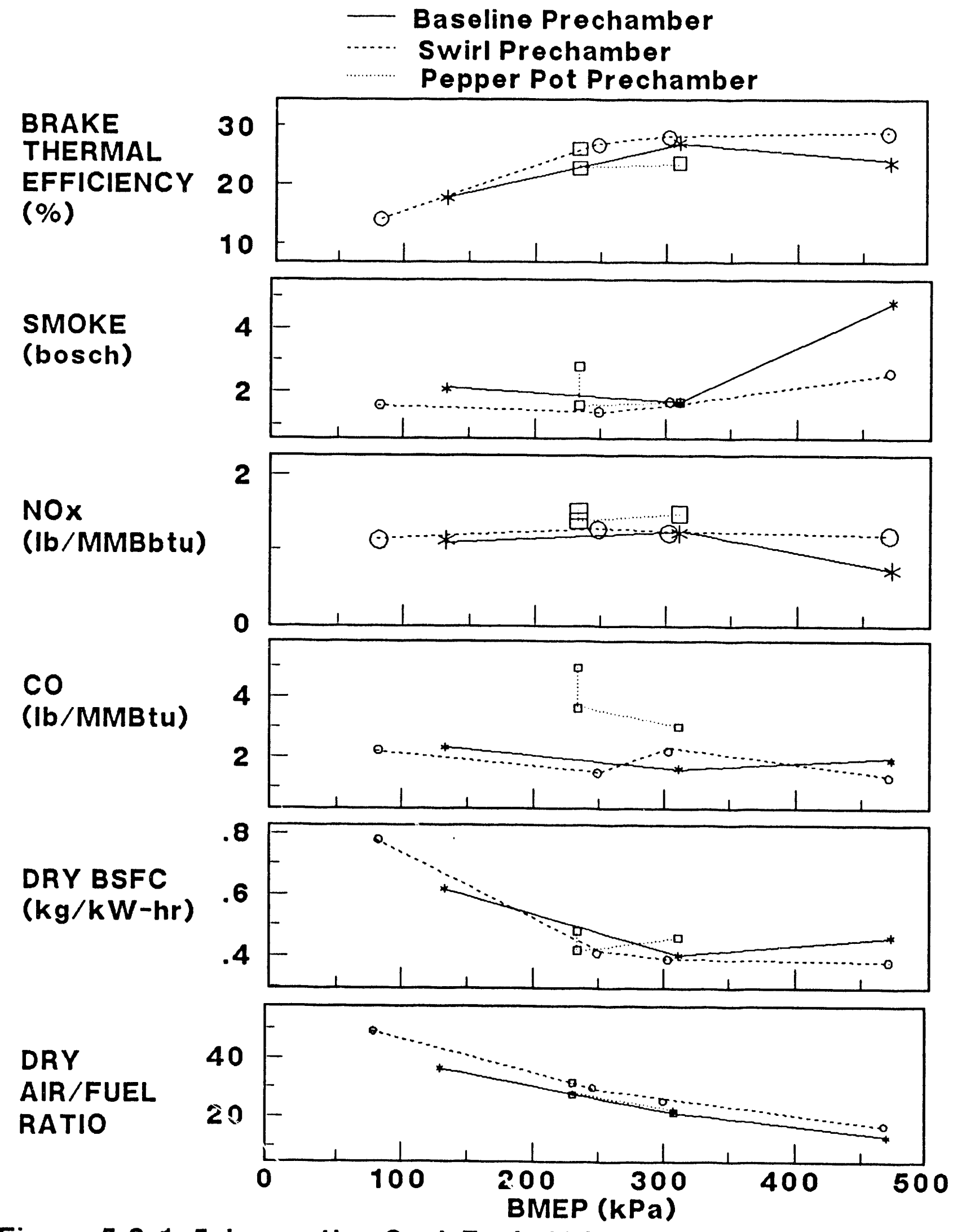

Figure 5.2.1-5 Innovative Coal-Fueled Diesel Engine at 1,400 RPM and 20.7 MPa Injection Pressure 


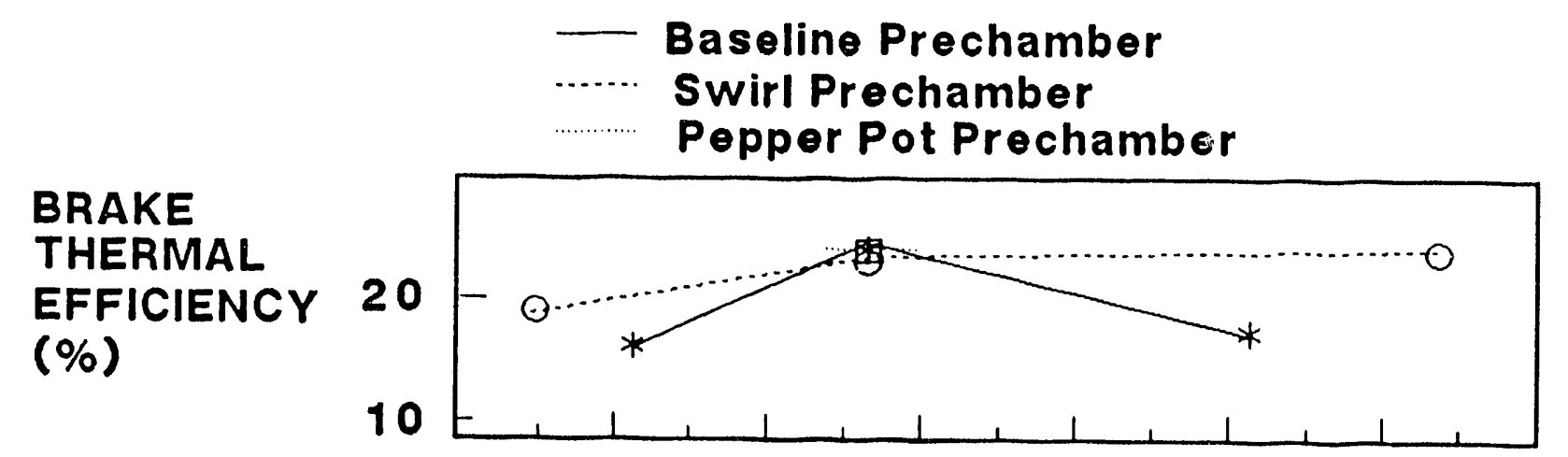

\section{SMOKE (bosch)}

NOX

(Ib/MMBbtu)

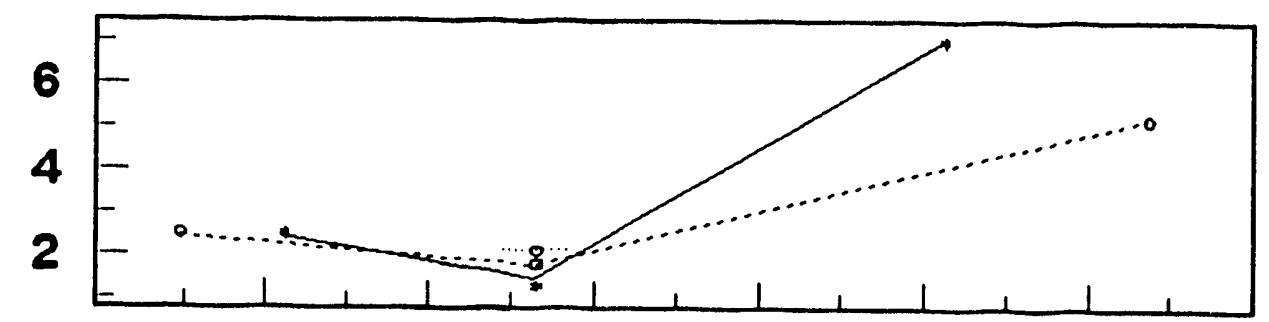

CO

(Ib/MMBtu)

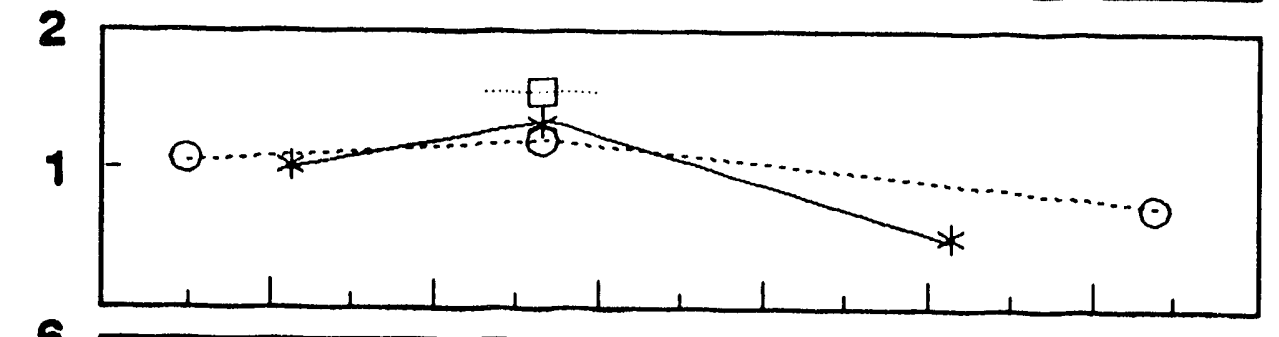

DRY BSFC (kg/kW-hr)

DRY

AIR/FUEL RATIO
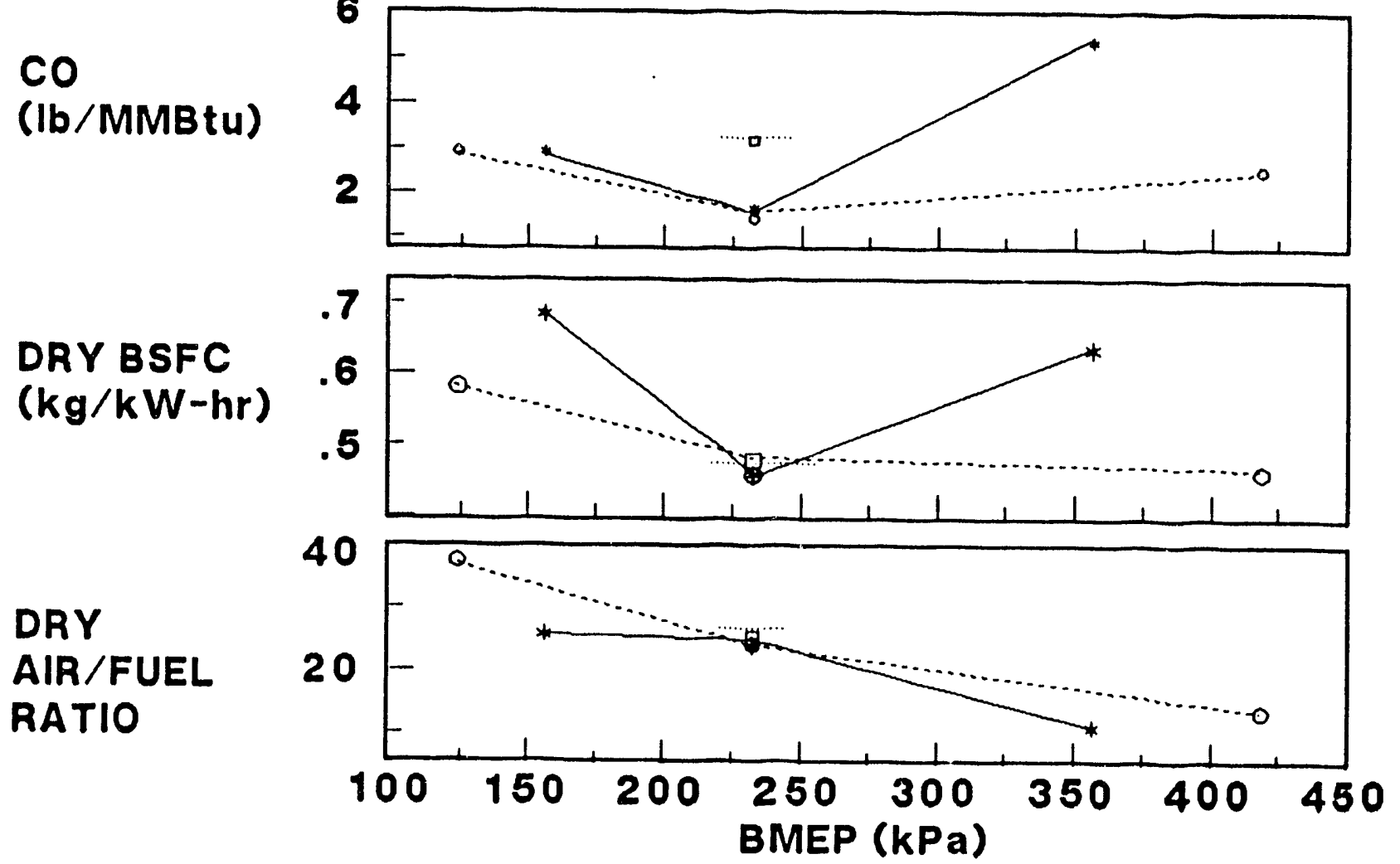

Figure 5.2.1-6 Innovative Coal-Fueled Diesel Engine at 1,800 RPM and 20.7 MPa Injection Pressure 
BRAKE

THERMAL

EFFICIENCY

(\%)

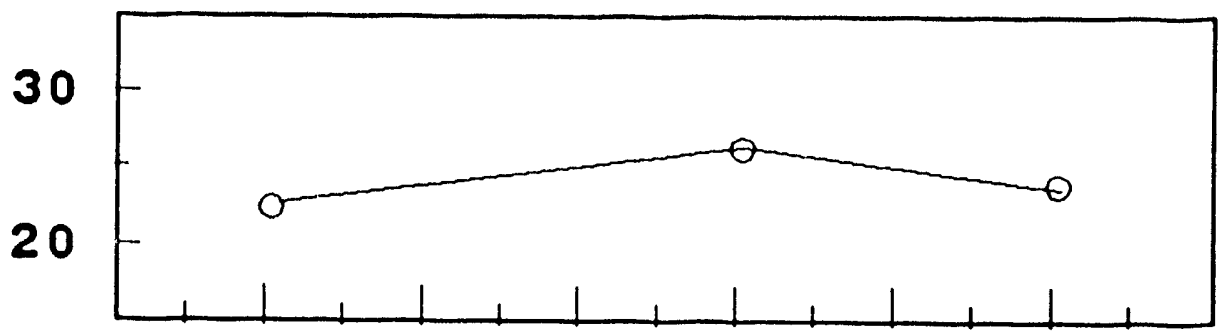

SMOKE

(bosch)

NOX

(lb/MMBtu)

Co

(lb/MMBtu)

DRY BSFC

(kg/kW-hr)
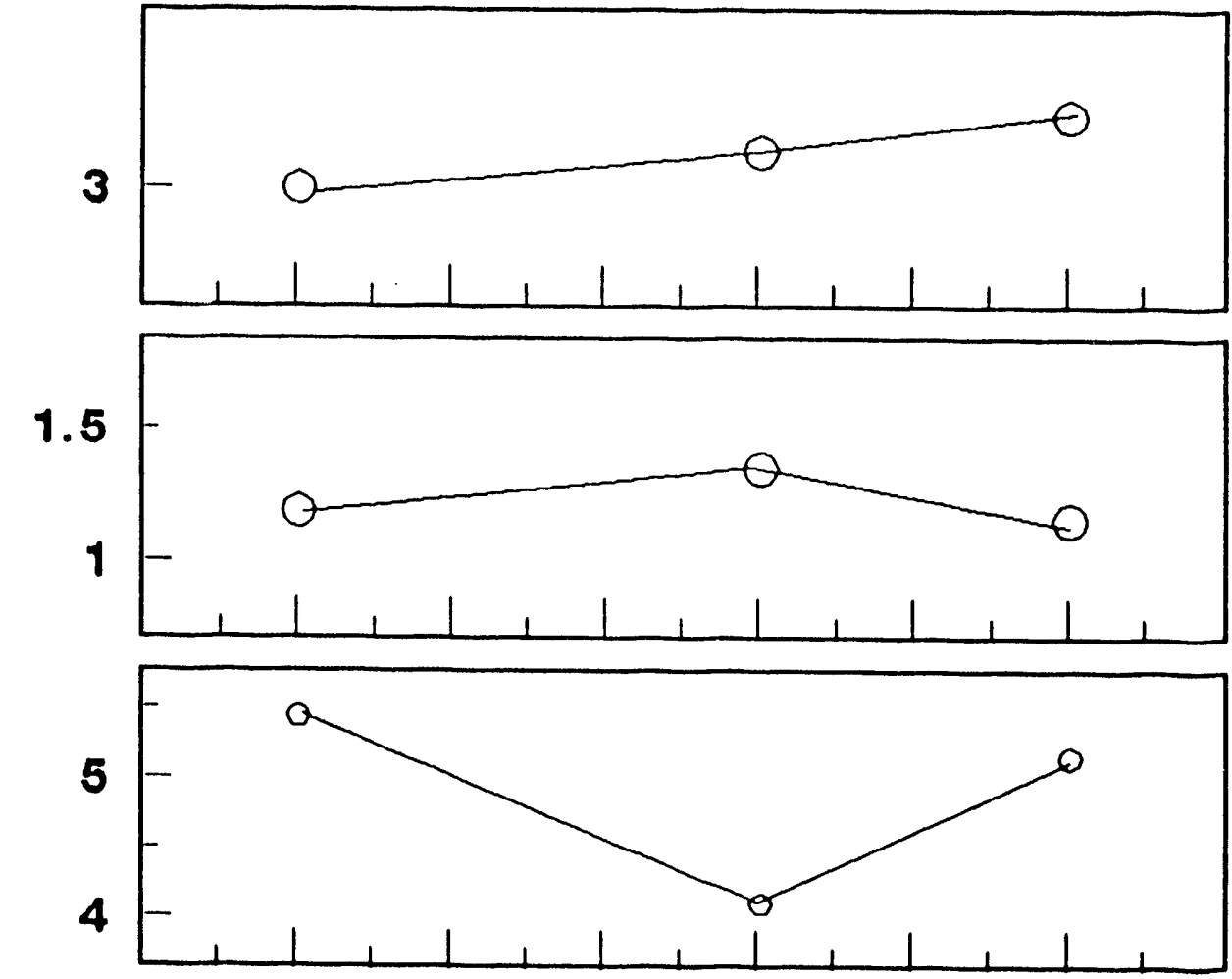

BMEP

(KPa)
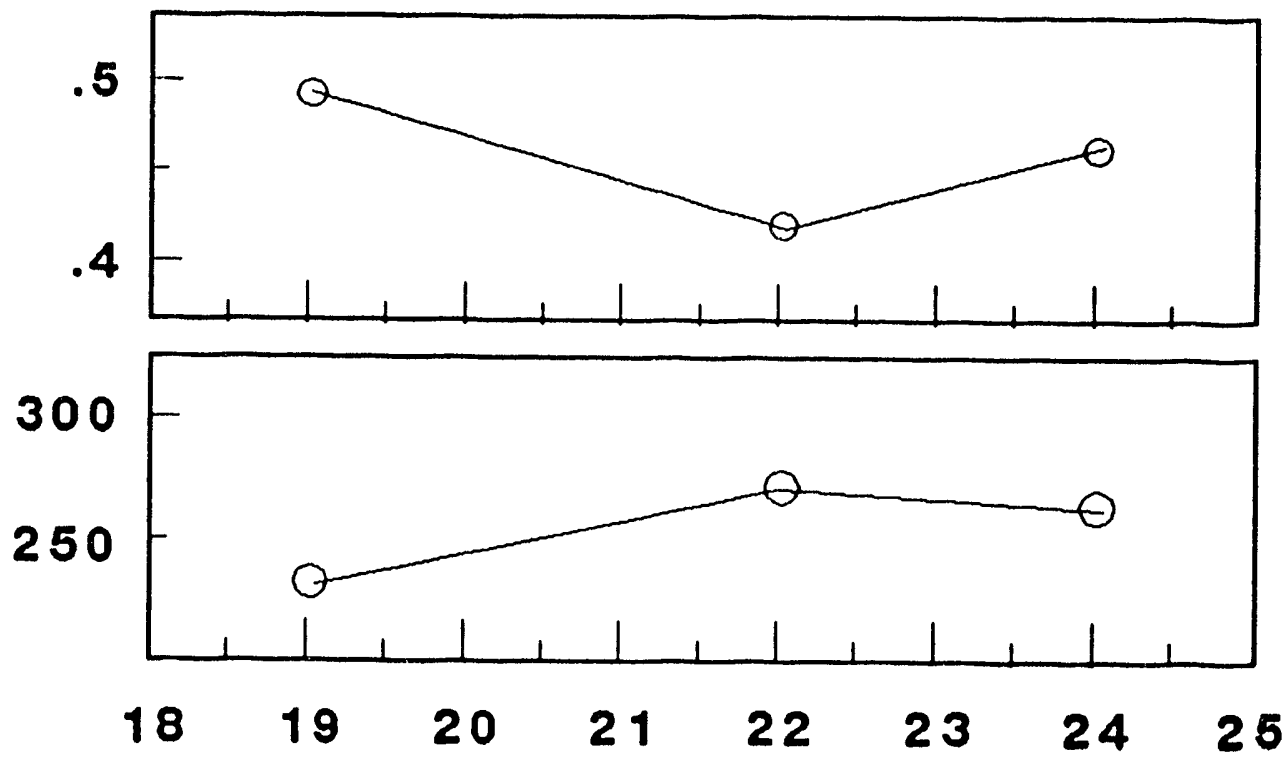

INJECTION TIMING (deg BTDC)

Figure 5.2.2-1 Effect of Injection Timing at 1,400 RPM 
swirl prechamber, a 40 cc prechamber volume and a $16.4: 1$ compression ratio. It can be seen that the effect of injection timing was significant. A variation of three degrees of infection timing significantly degrades engine performance. Figures 5.2.2-2 thru 5.2.2-3 shows injection timing for all of the tests run with each conflguration at 1,000 and $1,400 \mathrm{rpm}$. A nomenclature Table showing the Plot Legend for identifying each individual curve is shown as Table 5.2.2-1. This Table is used for additional plots in the following sections.

\section{2 .3 Effect of PCC Temperature}

The locations where PCC temperatures were measured were shown in Figure 4.4.1-3. Figures 5.2.3-1 thru 5.2.3-3 show plots of lower PCC temperature versus BMEP at each speed and encompassing all engine configurations. As a general rule, the higher the prechamber temperature was, the better the engine performed. It can be seen by examining these curves that lower PCC temperature is affected more by englne design configuration than by load or speed. Upper PCC temperature versus lower PCC temperature at the three speeds and all load points is shown in Figures 5.2.3-4 thru 5.2.3-6. Examination of these plots shows that upper chamber temperature is consistently lower than the lower PCC temperature and that the configuration uniformly affects the magnitude of this difference. The temperature contrast is the result of the upper chamber being in contact with the water cooled CWS injector.

\section{2 .4 Effect of PCC Volume}

The effect of the change in PCC volume on the performance was explored with the swirl type prechamber (since the swirl design performed best). Five variations of prechamber volumes were tried in which sleeves were either inserted inside the prechamber to reduce prechamber volume or a taller intermediate seal was installed to increase prechamber volume. All engine testing was with injection timing set at optimum. Table 5.2.4-1 is a summary of the prechamber volume configurations tested. Note that compression ratio did not remain constant. The compression ratio is increased when the PCC volume is decreased and vice versa. The comparative results are presented in Figure 5.2.4-1. It was Interesting to see that the total power output improved with the increase in PCC volume up to the second from the largest prectiamber volume. The largest $54 \mathrm{cc}$ prechamber volume produced high power output (though not the highest) with a low 15:1 compression ratio. An investigation into the effect of compression ratio on engine perfo mance was not performed but it is very possible that a higher compression ratio in conjunction with the larger prechamber volume could perform best. The perfcrmance improvement with larger volumes was reflected in the emisstons, namely, lower $H C, C O$ and smoke. The engine would not run on 100 percent CWS with the $20 \mathrm{cc}$ prechamber volume.

\section{2 .5 Effect of Injector Orifice Diameter}

Three different injector nozzle hole diameters were engine tested in an effort to determine the effect of hole diameter on CWS atomization, injection pressure requirement, ignition delay and ciWs combustion. Special effort was made to ensure that the length over diameter (L/D) rat1o was the same for all three nozzle hole diameters. For this testing, the swirl type prechamber was used in conjunction with a 47 cc prechamber volume and 15.7:1 compression ratio. Infection timing was optimized for maximum power output. A ceramic 


\section{Table 5.2.2-1 \\ PLOT LEGEND}

$\begin{array}{lccc} & \text { INJECTOR } & \text { PCC } \\ \text { PRECHAMBER } & \text { ORIFICE } & \text { VOLUME } & \\ \text { THROAT } & (\mathrm{mm}) & \text { (cc) SYMBOL }\end{array}$

BASELINE

0.96

47

将

SWIRL

1.00

47

0

- $-\infty$ PEPPER

POT 1.00

47

0.74

47

$\triangle$

SWIRL

0.91

47

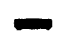

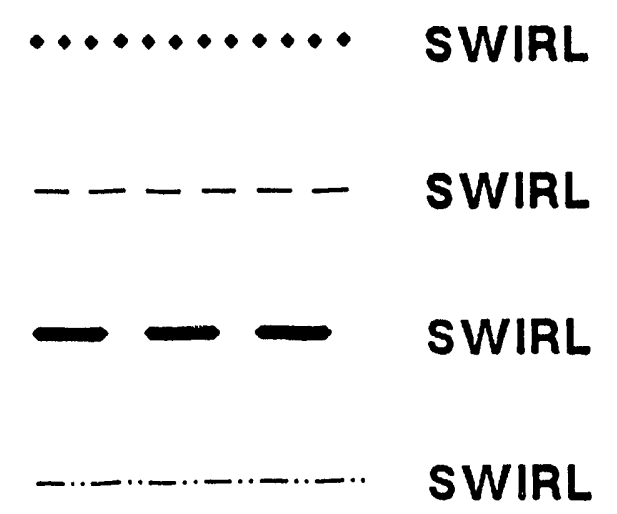

1.10

40

1.10

34

0.91

54

$\Delta$

0.91

47

$\diamond$ 


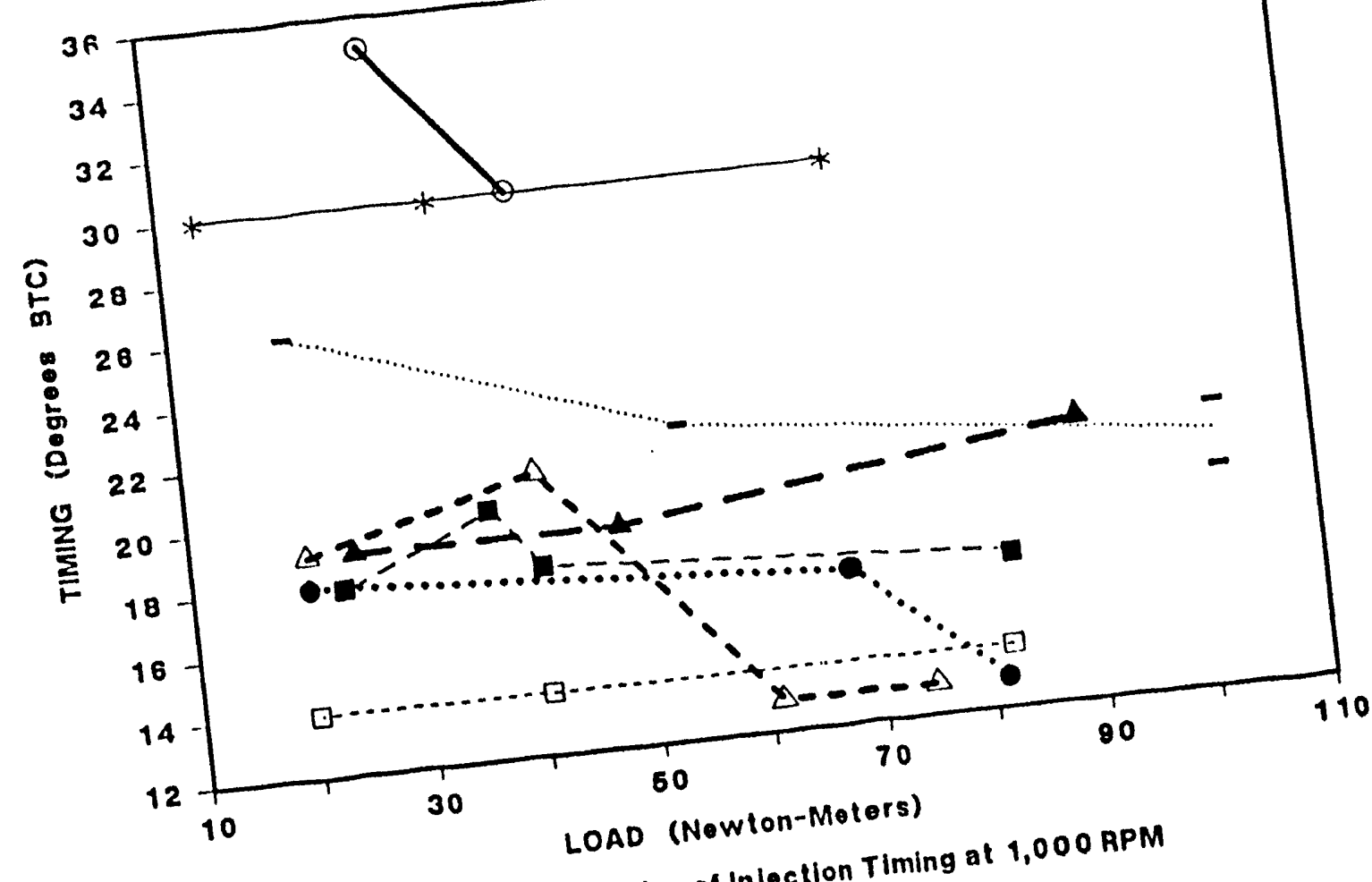

Figure 5.2.2-2 Beginning of injoction Timing at 1,000 APM

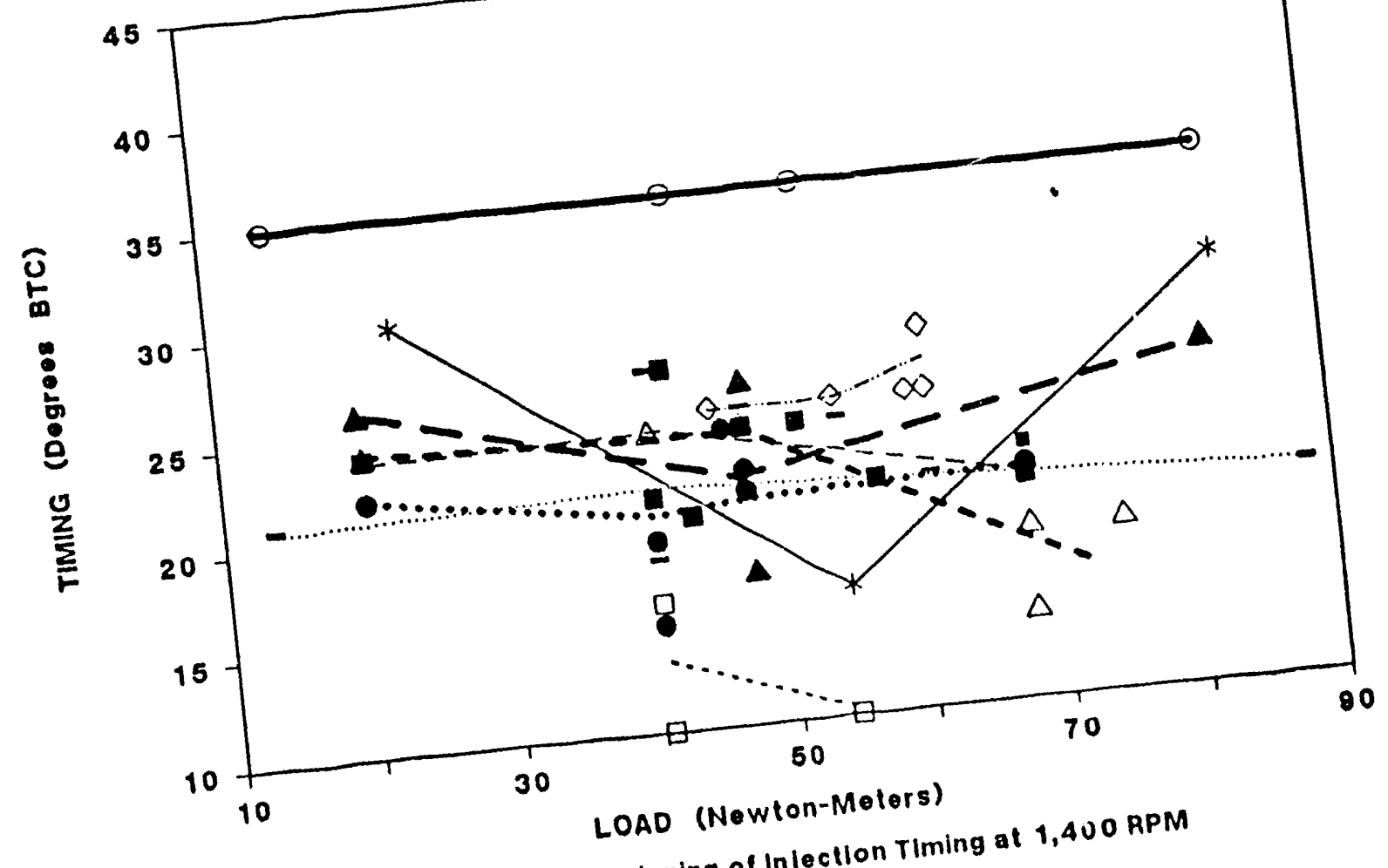

Figure 5.2.2-3 Beginning of Injectlon Timing at 1,400 RPM 


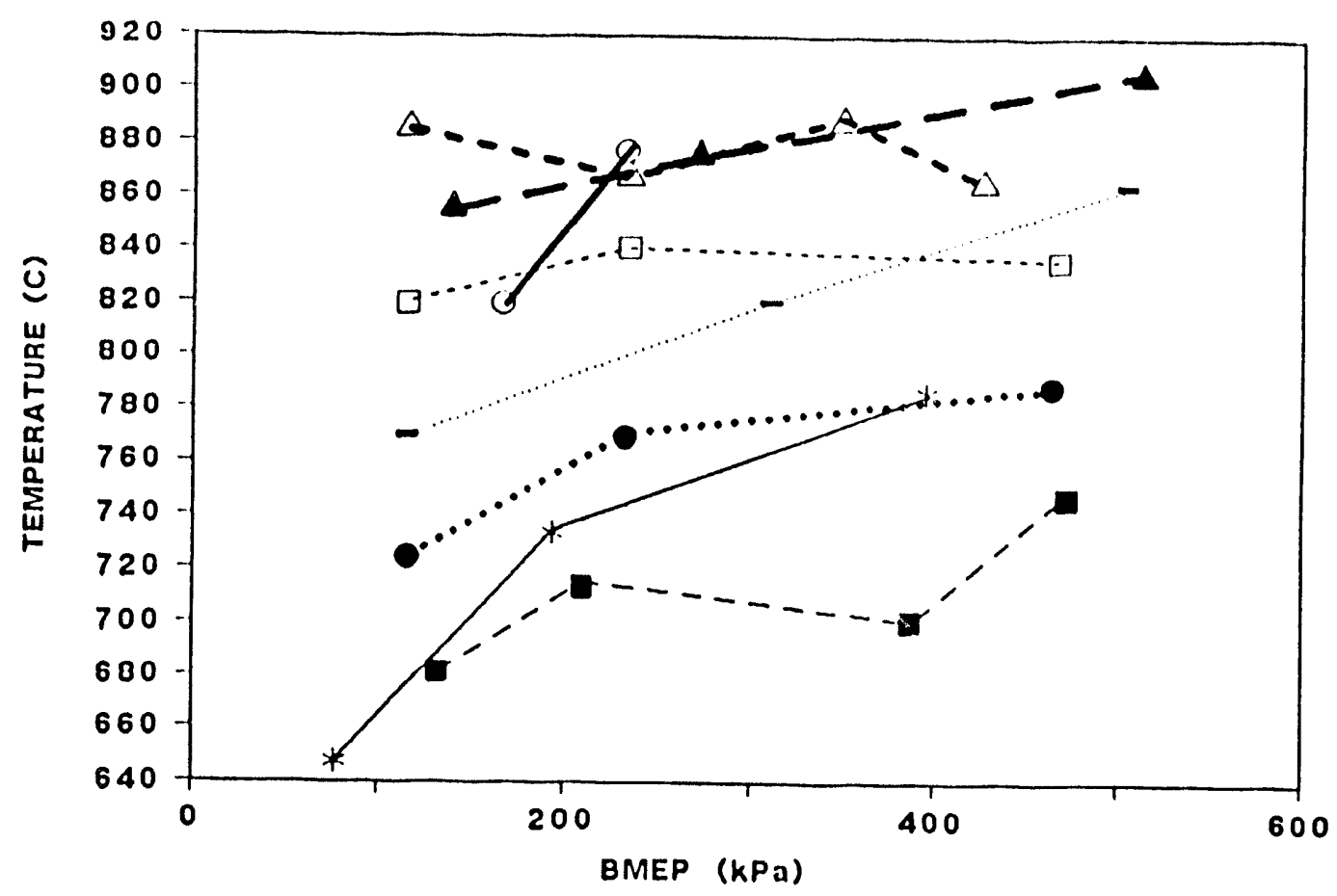

Figure 5.2.3-1 Lower Prechamber Temperature at 1,000 RPM

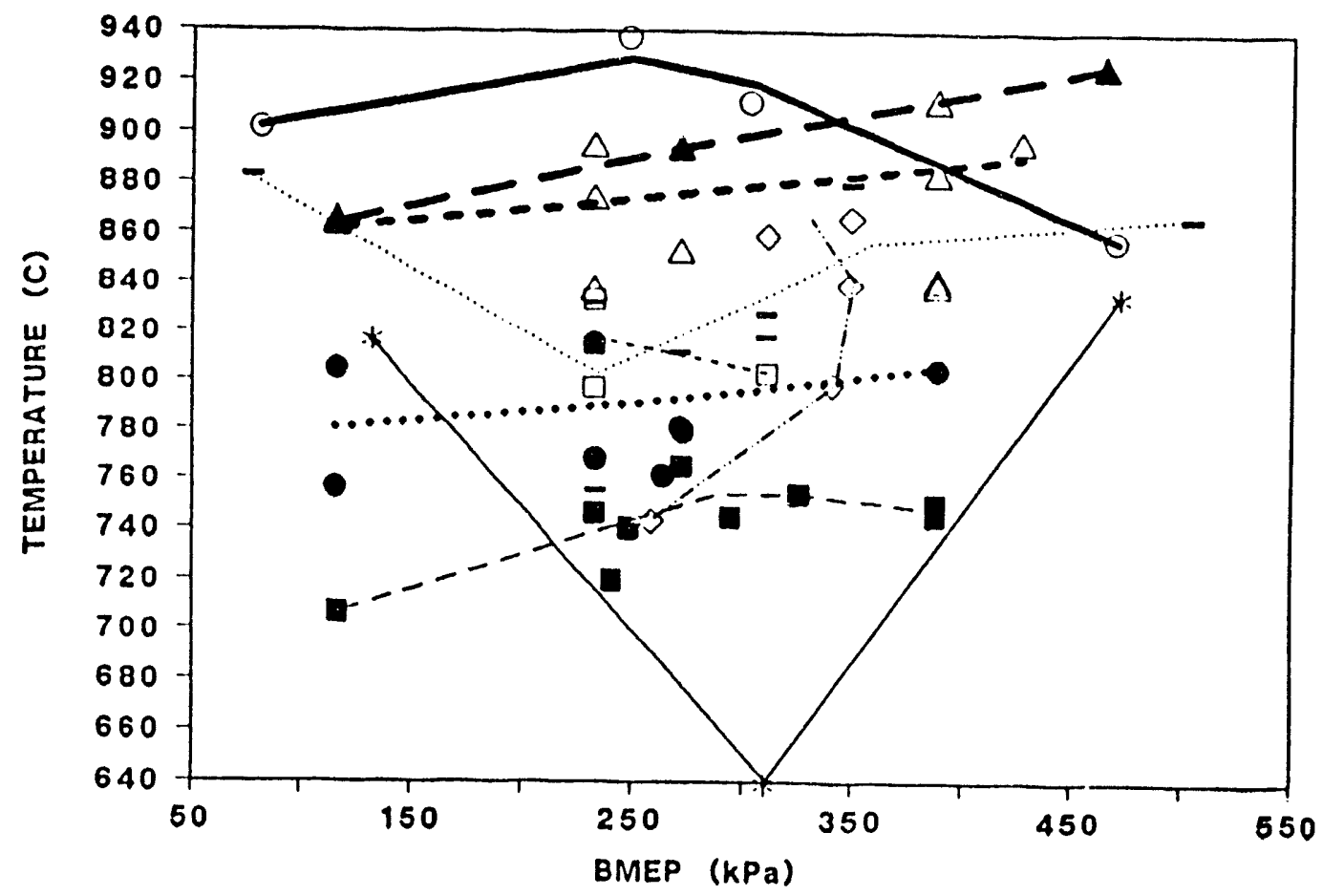

Figure 5.2.3-2 Lower Prechamber Temperature at 1,400 RPM 


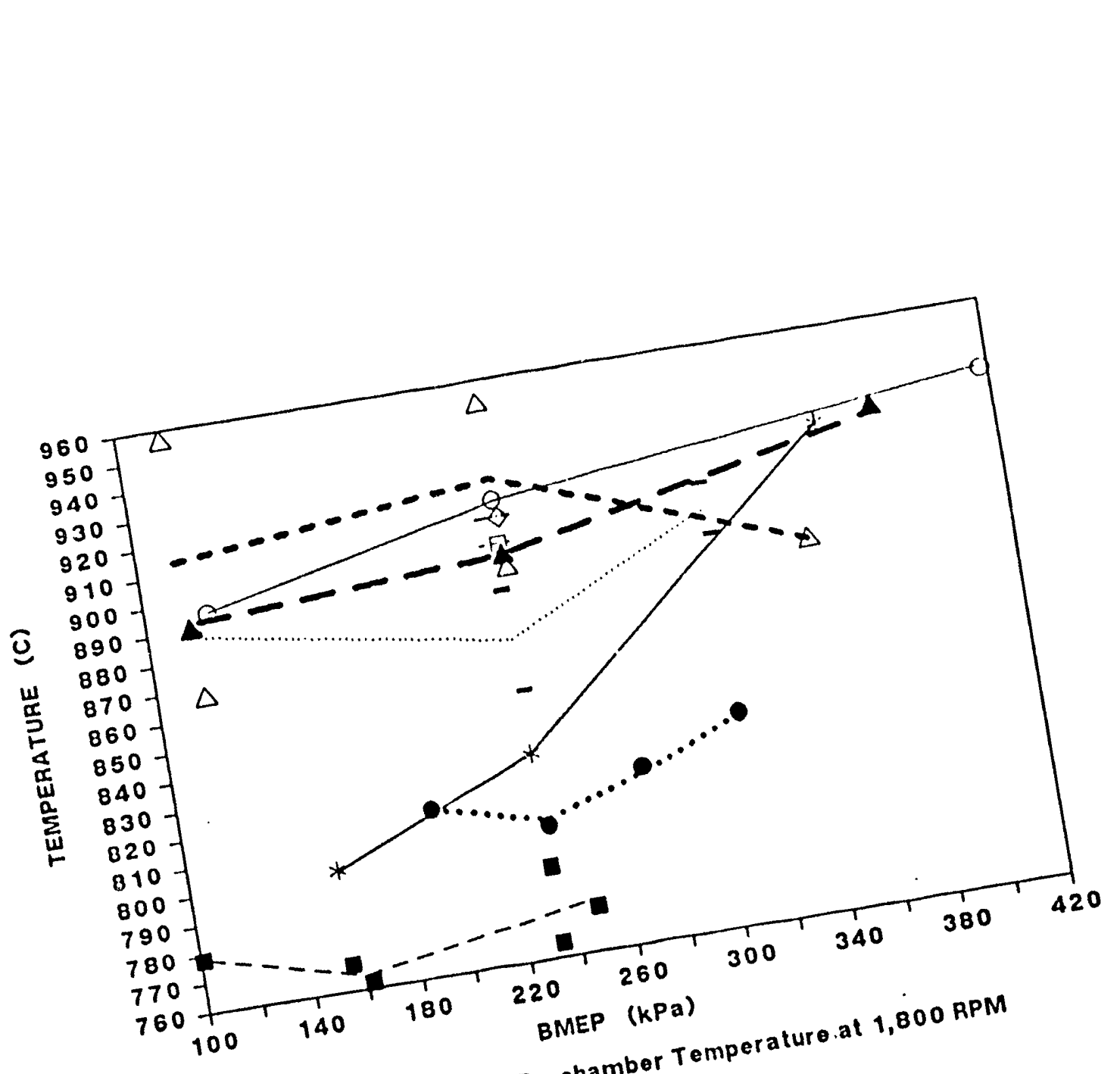

Figure 5.2.3-3 Low

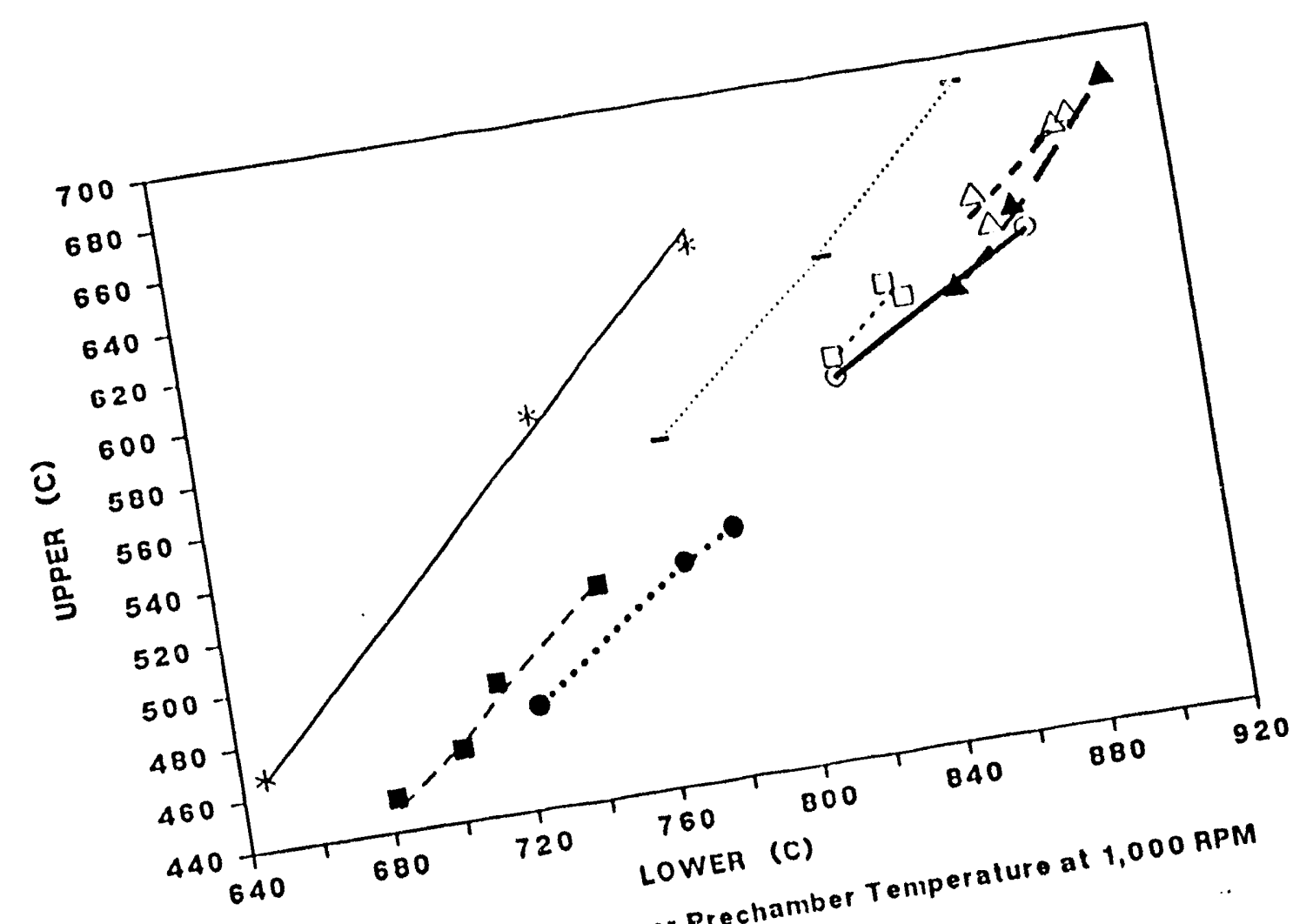

Figure 5.2.3-4 Upper VS. Lower prechamber Temperaluro 


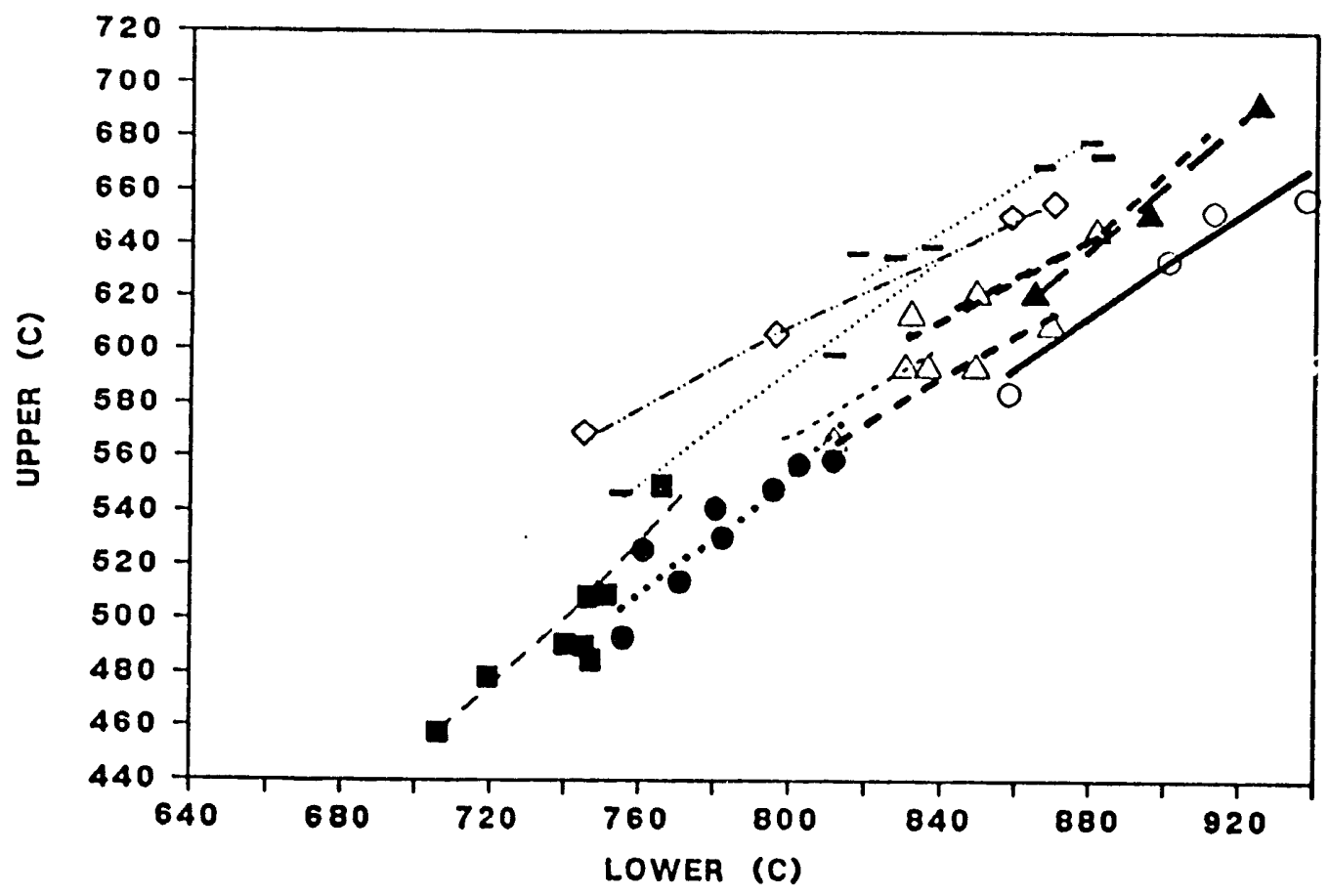

Figure 5.2.3-5 Upper VS. Lower Prechamber Tomperatt re at 1,400 RPM

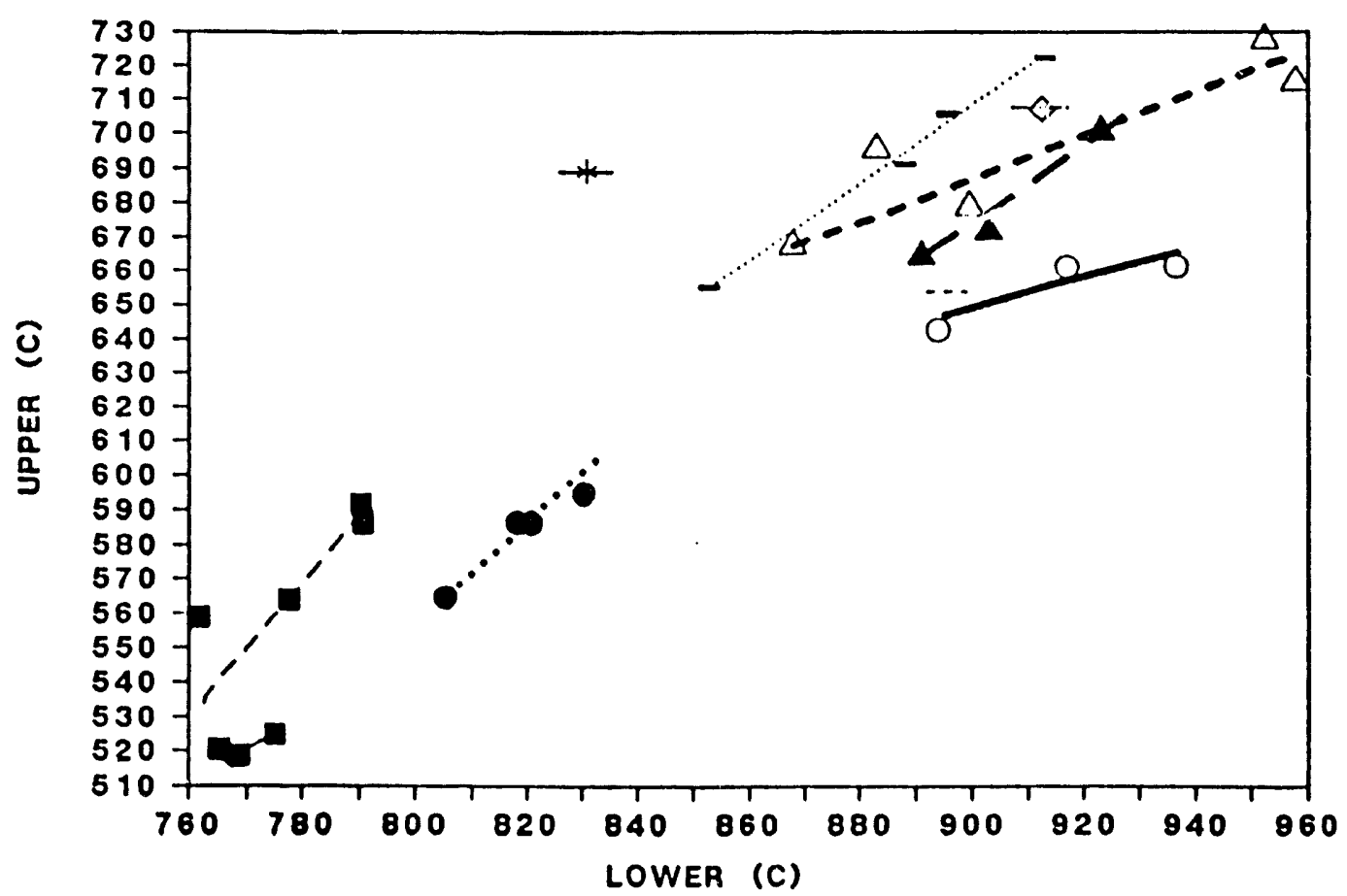

Figure 5.2.3-8 Upper VS. Lower Prechamber Temperature at 1,800 RPM 
Table 5.2.4-1

SUMMARY OF PRECHAMBER VOLUMES TESTED

INJECTOR

\begin{tabular}{lcccc}
$\begin{array}{l}\text { PEST } \\
\text { NUMBER }\end{array}$ & $\begin{array}{c}\text { PRECHAMBER } \\
\text { VOLUME } \\
(C C)\end{array}$ & $\begin{array}{c}\text { \% TOTAL } \\
\text { CLEARANCE } \\
\text { VOLUME }\end{array}$ & $\begin{array}{c}\text { COMPRESSION } \\
\text { RATIO }\end{array}$ & $\begin{array}{c}\text { NOZZLE } \\
\text { DIAMETER } \\
\text { (MM) }\end{array}$ \\
\hline 1 & 54 & 34.4 & $16: 1$ & 0.91 \\
2 & 47 & 31.4 & $16.7: 1$ & 1.0 \\
3 & 40 & 28.0 & $16.4: 1$ & 1.0 \\
4 & 34 & 24.8 & $17.1: 1$ & 1.0 \\
6 & 20 & 13.5 & $15.8: 1$ & 1.0
\end{tabular}

TEST \# 5 WOULD NOT RUN ON $100 \%$ CWS 
- 54 cc Prechamber Volume …... 40 cc Prechamber Volume … 47 cc Prechamber Volume -- 34 cc Prechamber Volume
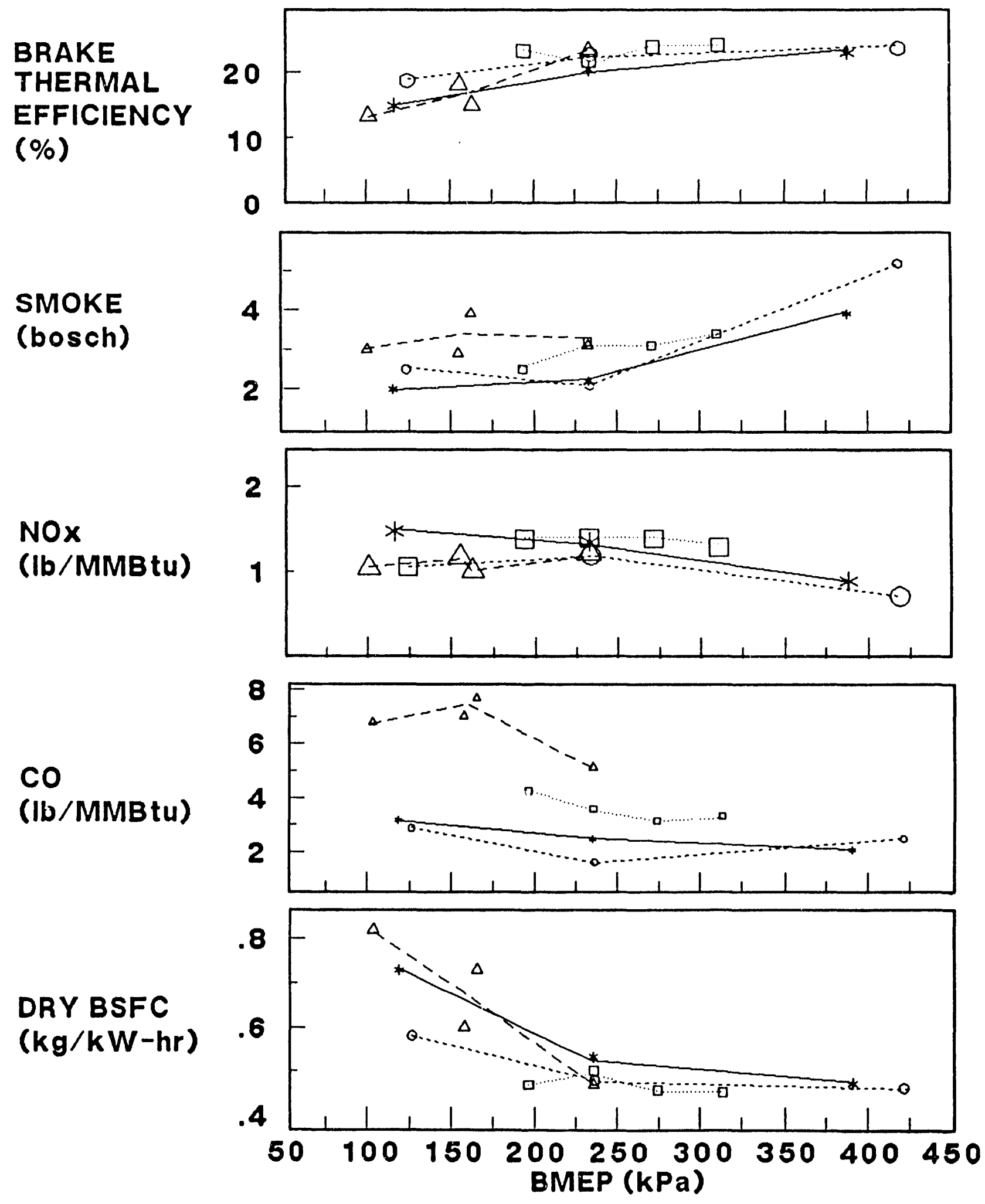

Figure 5.2.4-1 Effect of Prechamber Volume at 1,800 RPM 
thermal barrier washer was added between the cylinder head and the precombustion chamber to increase and stabilize the temperature of the precombustion chamber, during the tests. The effect of injector orifice for this configuration is shown in Figure 5.2.5-1 and 1 t can be seen that peak power was produced with the largest nozzle hole diameter.

\section{2 .6 Effect of CWS Injection Pressure}

Figure 5.2.6-1 is a plot of the test results using the swirl type prechamber at $1,400 \mathrm{rpm}$ comparing injection pressures of $13.8 \mathrm{MPa}(2,000 \mathrm{psi})$ and $20.7 \mathrm{MPa}(3,000 \mathrm{psi})$ Examination of this figure shows that the higher injection pressure results in improved engine performance in all aspects except NOx emissions (which was the result of hotter combustion).

\subsubsection{Effect of Exhaust Gas Recirculation}

The effect of exhaust gas recirculation (EGR) is depicted in Figure 5.2.7-1. In general, there is a significant reduction in NOx with increased EGR. However, the load could not be maintained beyond 15 percent EGR. As can be seen from the figure, there is a significant improvement in NOx ( 40 percent reduction at 5 percent EGR and 75 percent reduction at 10 percent without much deterioration in performance). Beyond 10 percent EGR diminishing returns are achieved in NOx reduction and drastic increases in $C O$ and smoke were observed.

\section{2 .8 Particulate Measurements}

A simple full flow system with a ceramic particulate filter has been used to measure the particulates. A photograph of the system is shown in Figure 5.2.8-1. The filter was made up of Lithium, Alumina Silicate ceramic foam with 2.56 pores per mm (from $\mathrm{Hi}$-Tech Ceramics, Inc.) and was capable of filtering particles as small as 5 microns. The particulate filter was installed in the exhaust manifold and the exhaust gas was made to flow through the filter for a specific periodic time ( 1 to 2 minutes) during steady state running. A high temperature valve system was used to divert the exhaust gas through the filter and the exhaust flow was diverted back through the regular manifold when the exhausc back pressure increased to $25.4 \mathrm{~cm}$ ( 10 inches) of water. The exhaust flow through the filter was controlled by the actuation of Dezurik pneumatic shut off valves. The particulate measurements were determined from the difference in weight of the dry filter (the filters were dried at $104^{\circ} \mathrm{C}$ in an oven) before and after the collection of the particulates.

The particulate tests were each conducted at $1,800 \mathrm{rpm}$ and are summarized in Table 5.2.8-1. This table shows the smoke reading, the smoke reading converted to soot concentration in $\mathrm{mg} / 1$ iter, the particulate reading in grams per hour and the particulate reading converted to a concentration in the exhaust flow also expressed in $\mathrm{mg} / \mathrm{liter}$. Quality control problems were encountered with the ceramic filters which resulted in a breakdown of some of the filters accompanied by loss of ceramic material. This was probably the reason for the low particulate reading for point 0121GCL. Examining the smoke and particulates concentration levels show there is a roughly linear correlation between the two measurements. The last column in the table lists the flow rate of ash for each test point. Comparing this rate to the particulate deposition rate, the particulate filter is collecting about 60 percent of the ash from the coal. 
- $1.00 \mathrm{~mm}$ Nozzle Hole Diameter

$0.91 \mathrm{~mm}$ Nozzle Hole Diameter

$0.76 \mathrm{~mm}$ Nozzle Hole Diameter

BRAKE

THERMAL

EFFICIENCY

(\%)

SMOKE

(bosch)

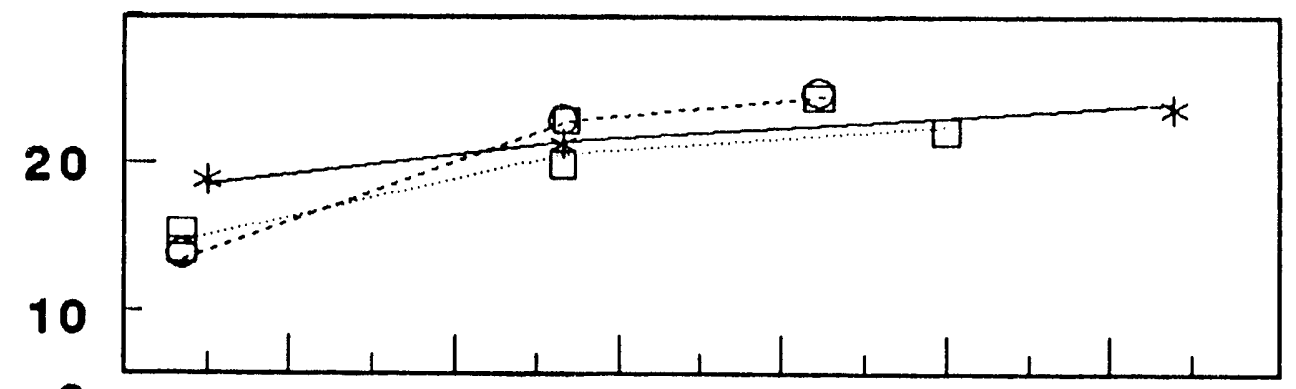

NOx

(Ib/MMBtu)

6
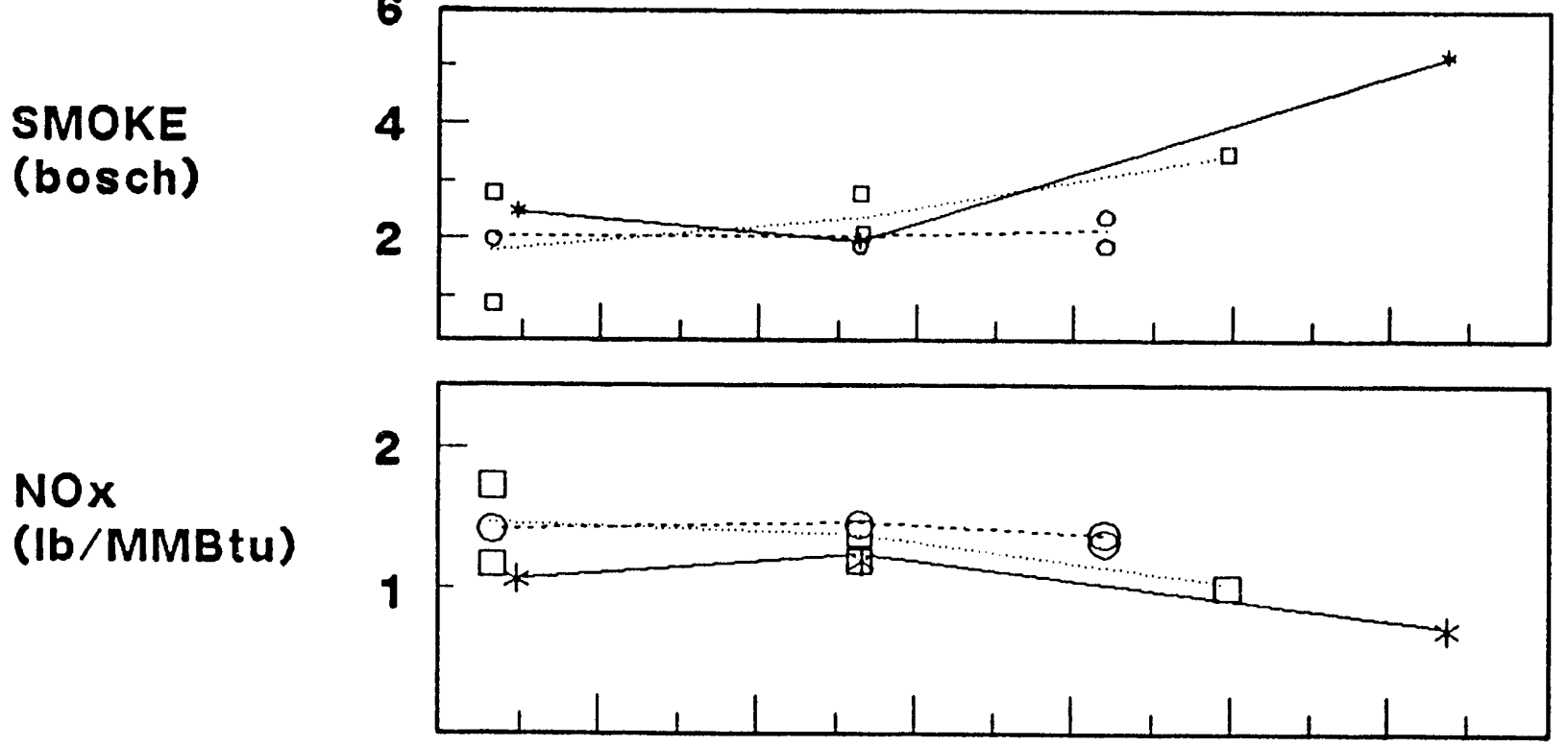

co

(lb/MMBtu)

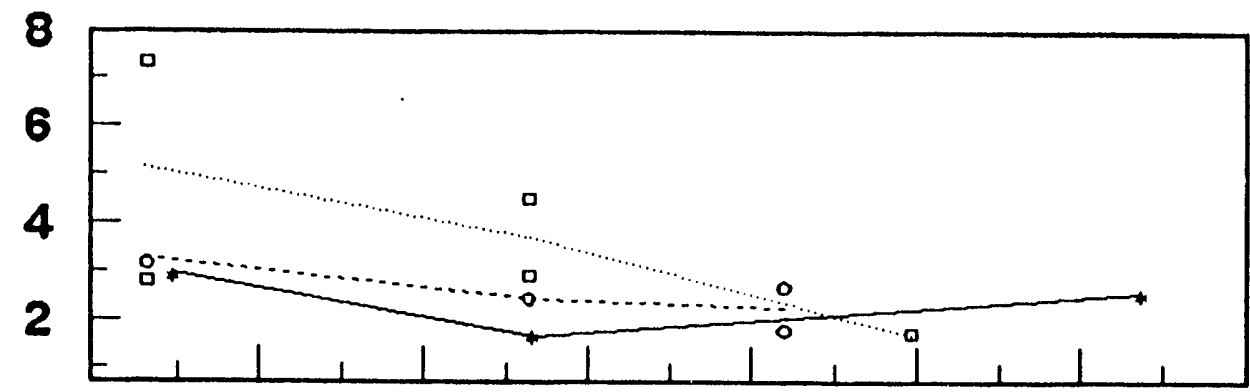

DRY BSFC (kg/kW-hr)

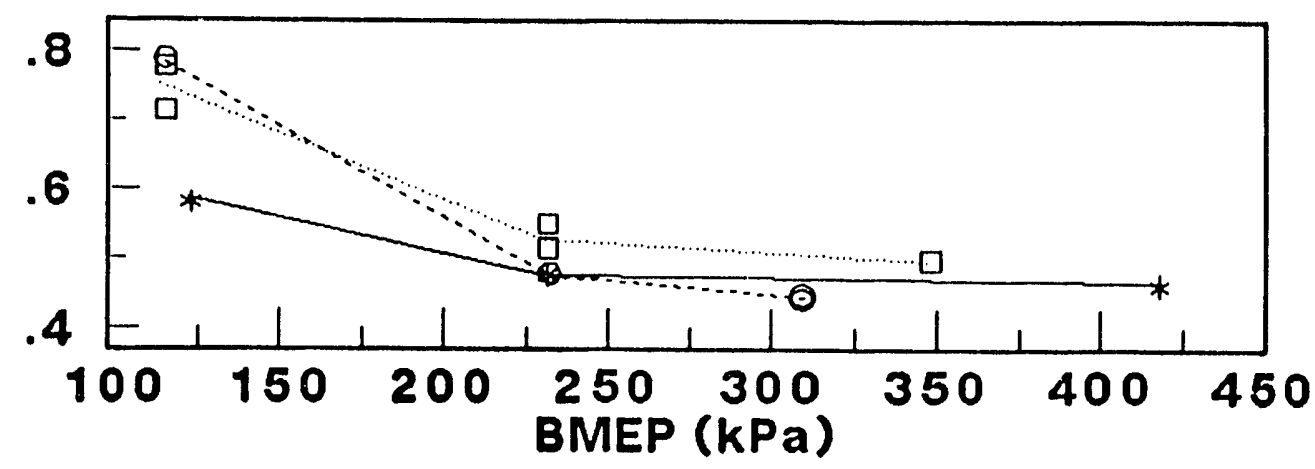

Figure 5.2.5-1 Effect of Nozzle Hole Diameter at 1,800 RPM 
BRAKE

THERMAL

EFFICIENCY

(\%)

40
20
0

- 20.7 MPa Injection Pressure

13.8 MPa Injection Pressure

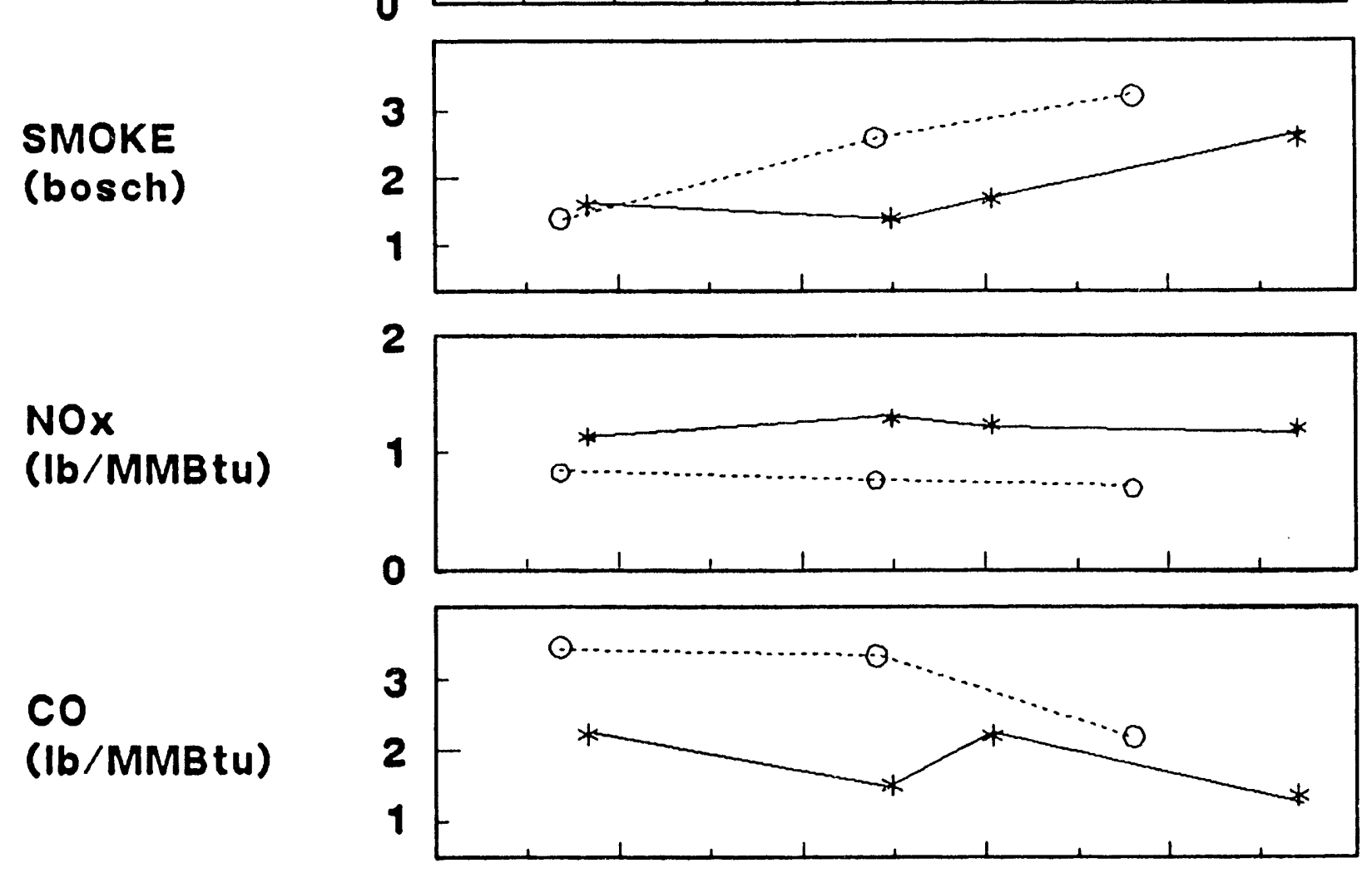

DRY BSFC

(kg/kW-hr)

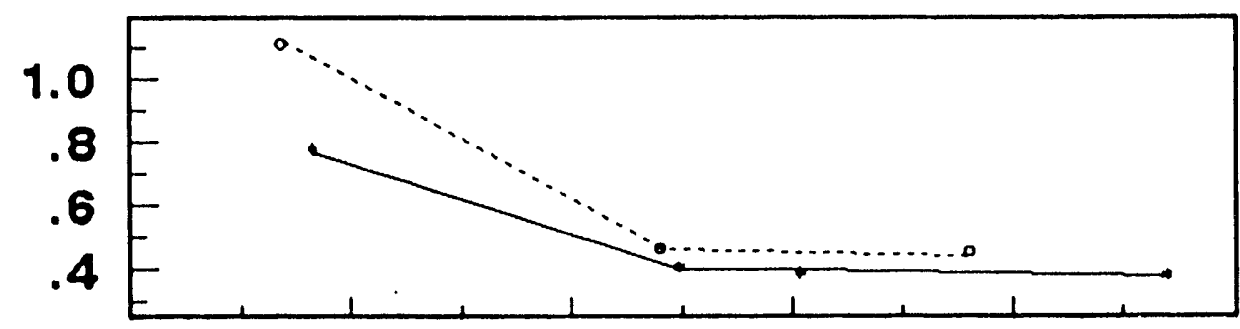

DRY

AIR/FUEL

RATIO

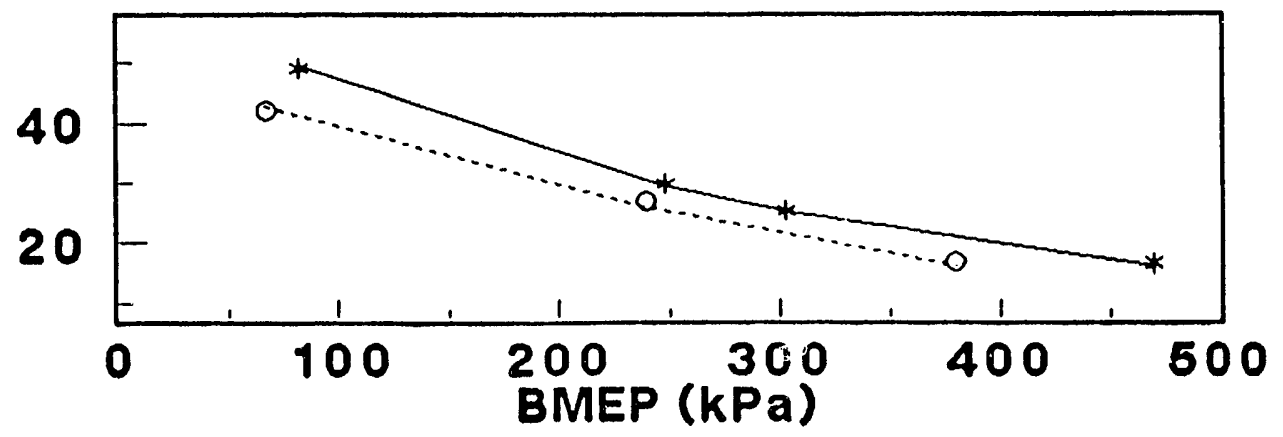

Figure 5.2.6-1 Effect of Injection Pressure at 1,400 RPM 
BRAKE

THERMAL

EFFICIENCY

(\%)

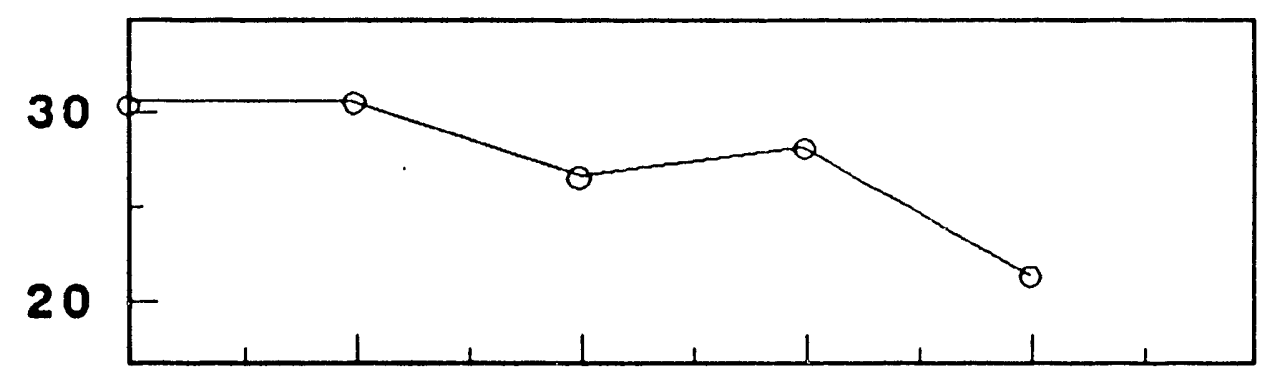

SMOKE

(bosch)

NOx

(lb/MMBtu)
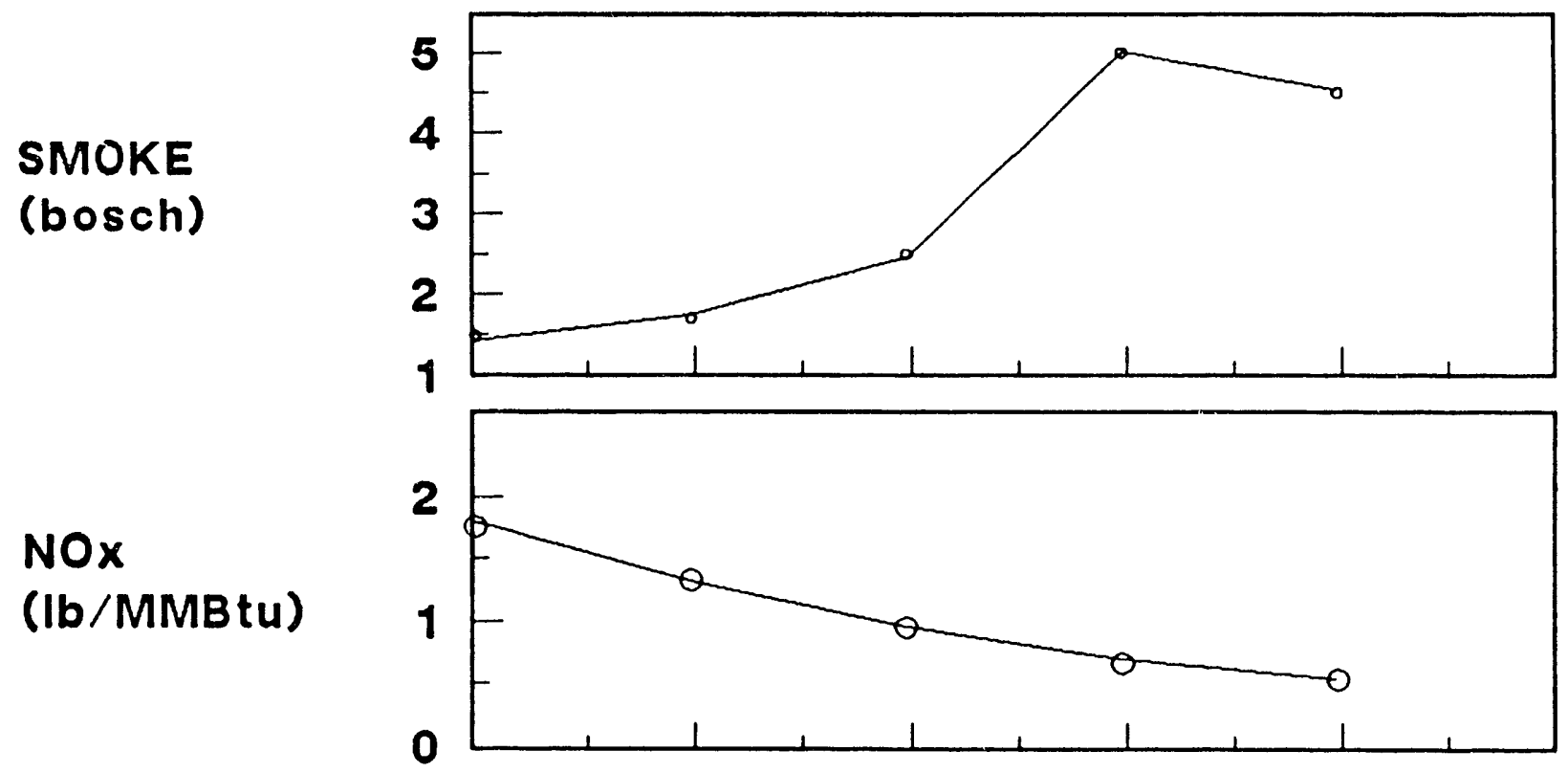

co

(Ib/MMBtu)

BMEP

(KPa)
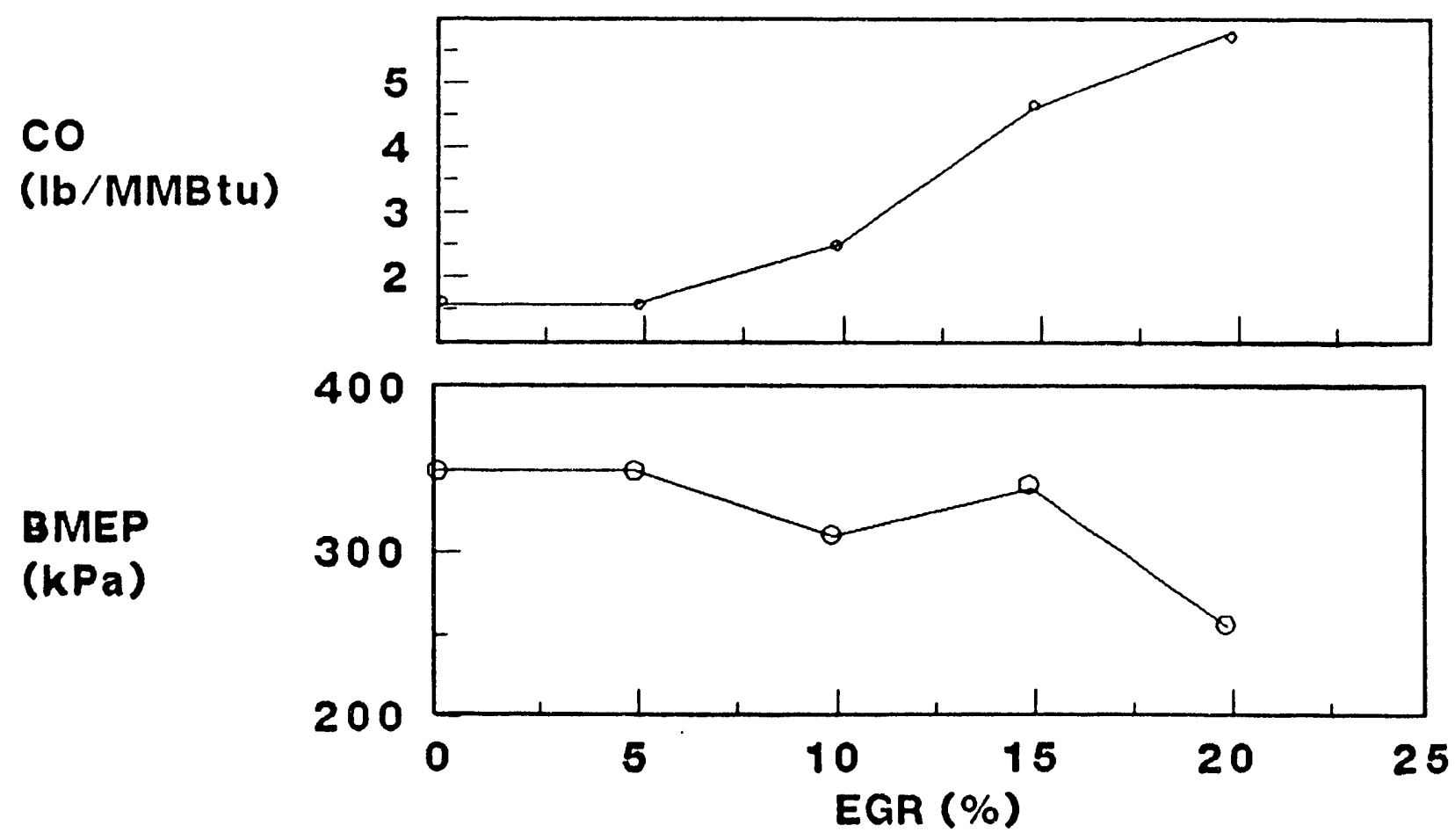

Figure 5.2.7-1 Effect of EGR at 1,400 RPM 


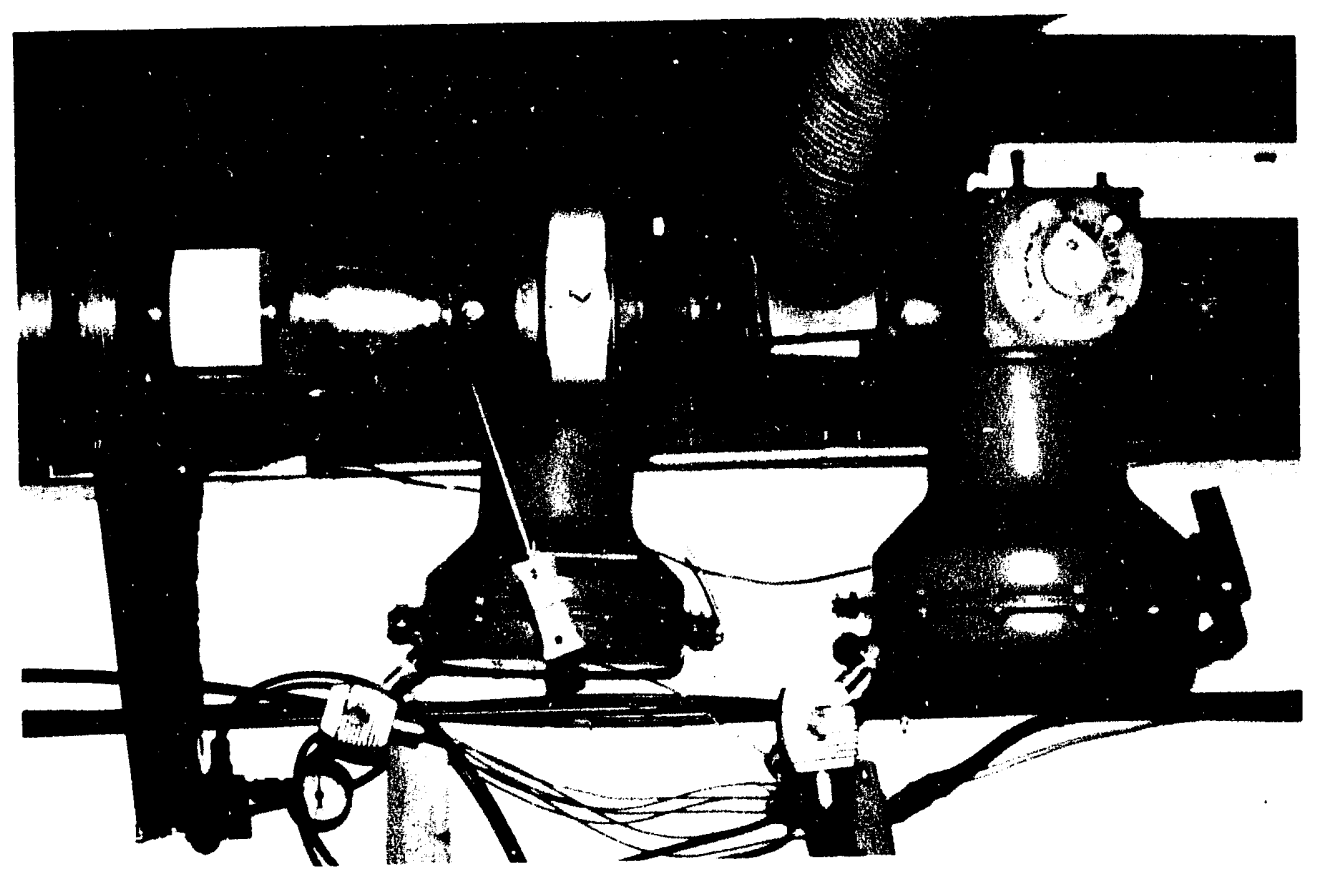

A I - $241-18$

Figure 5.2.8-1 Ceramic Particulate Sampling System 
Table 5.2.8-1

Correlation Between Smoke and Particulates

Smoke

\begin{tabular}{lll} 
Point & Bosch & Equivalent \\
Number & Soot \\
& & Concentration at \\
& $15.6^{\circ} \mathrm{C} \& 30 " \mathrm{HG}$ \\
& $(\mathrm{mg} /$ liter $)$ \\
\hline
\end{tabular}

$1211 \mathrm{FCL}$

$0103 \mathrm{CCL} \quad 3.6$

$0131 \mathrm{FCL} \quad 2.6$

O121GCL $\quad 1.4 \quad 0.053$

\section{Particulates}

Equivalent

Particulate

\begin{tabular}{lcc} 
Filter & Density at & Ash in \\
Loading & $15.6^{\circ} \mathrm{C} \& 30^{n} \mathrm{HG}$ & Fuel \\
$(\mathrm{gm} / \mathrm{hr})$ & $(\mathrm{mg} /$ liter $)$ & $(\mathrm{gm} / \mathrm{hr})$ \\
\hline
\end{tabular}

58.3

0.699

83.5

48.6

0.579

85.8

32.2

0.403

57.0

3.6

0.046

74.7 


\subsubsection{Emissions and Performance Summary}

In addition to the data presented in each of the above sections relating to single aspects of the engine design a series of summary graphs were prepared to show the engine performance and emissions results for all of the testing. These graphs utilize the plot legends described in Table 5.2.2.1 to identify each engine configuration. The graphs are as follows:

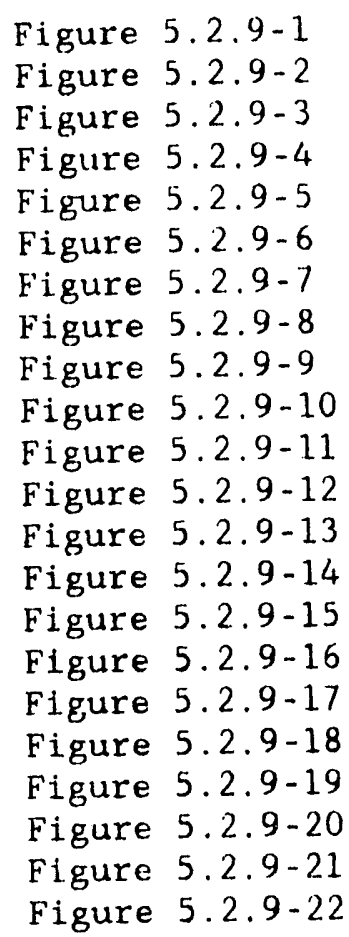

BSFC vs TORQUE
BSFC vs TORQUE
BSFC vs TORQUE
Brake Thermal Efficiency vs BMEP
Brake Thermal Efficiency vs BMEP
Brake Thermal Efficiency vs BMEP
Engine Temperature Rise vs A/F
Engine Temperature Rise vs A/F
Engine Temperature Rise vs A/F
Engine Temperature Rise vs A/F
Hydrocarbons vs Torque
Hydrocarbons vs Torque
Hydrocarbons vs Torque
NOx vs BMEP
NOx vs BMEP
NOx vs BMEP
CO vs BMEP
CO vs BMEP
CO vs BMEP
Smoke vs BMEP
Smoke vs BMEP
Smoke vs BMEP
$1,000 \mathrm{rpm}$
$1,400 \mathrm{rpm}$
$1,800 \mathrm{rpm}$
$1,000 \mathrm{rpm}$
$1,400 \mathrm{rpm}$
$1,800 \mathrm{rpm}$
$1,000 \mathrm{rpm}$
$1,400 \mathrm{rpm}$
$1,800 \mathrm{rpm}$
all speeds
$1,000 \mathrm{rpm}$
$1,400 \mathrm{rpm}$
$1,800 \mathrm{rpm}$
$1,000 \mathrm{rpm}$
$1,400 \mathrm{rpm}$
$1,800 \mathrm{rpm}$
$1,000 \mathrm{rpm}$
$1,400 \mathrm{rpm}$
$1,800 \mathrm{rpm}$
$1,000 \mathrm{rpm}$
$1,400 \mathrm{rpm}$
$1,800 \mathrm{rpm}$

\section{2 .10 Wear Data Summary}

During Phase II a total of 45 hours and 40 minutes of 100 percent CWS engine testing was performed. Wear data for the injector nozzle hole and piston rings are presented in Tables 5.2.10-1 and 5.2.10-2 respectively. From Table 5.2.10-1, it can be summarized that the M2 tool steel experienced wear throughout almost all the engine testing. Variations in the wear rate can be explained because Table 5.2.10-1 does not account for the time when both coal and diesel fuel were supplied to the engine. Table 5.2.10-2 shows that significant ring wear was experiened. Figure 5.2.10-1 shows a side view of the piston after 28.1 hours of 100 percent CWS engine testing. It can be seen from the photograph that the chrome carbide coated top ring had become too hot during engine testing and had allowed deposits to form below the top ring reversal area. The top ring has also lost its tension. The loss of ring tension is the likely cause for the excessive wear on the intermediate and oil rings since particles were allowed to pass the top ring.

Cylinder liner wear during all the Phase II CWS engine testing was never significant. One chrome oxide coated liner was used for all of the Phase II testing. The wear during the last 28.1 hours of testing, the liner diametral wear was less than $0.0013 \mathrm{~mm}(0.0005$ inch) and was still within the specifications required by the engine manufacturer. 


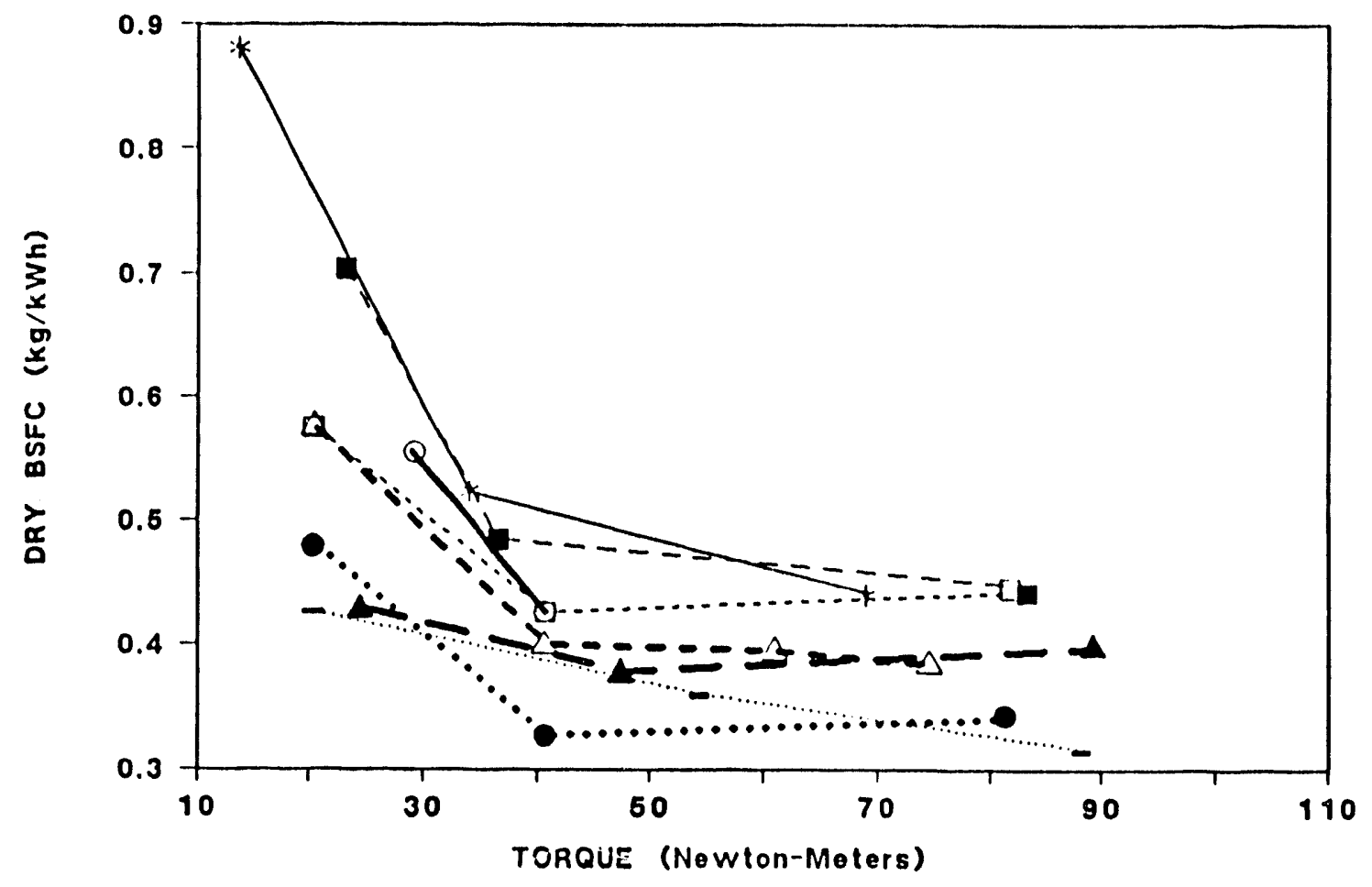

Figure 5.2.9-1 Brake Specific Fuel Consumption at 1,000 RPM

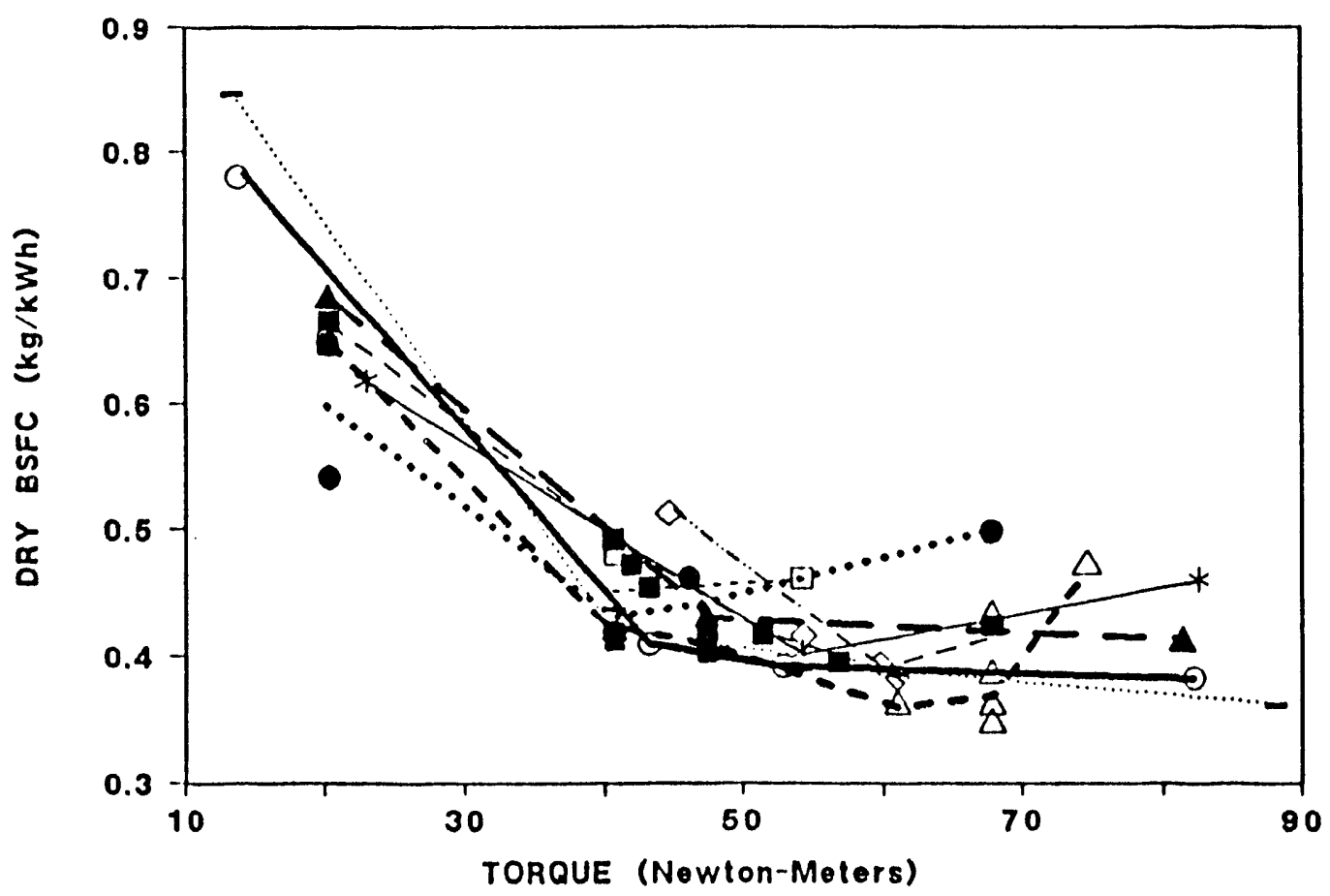

Figure 5.2.9-2 Brake Specific Fuel Consumplion at 1,400 RPM 


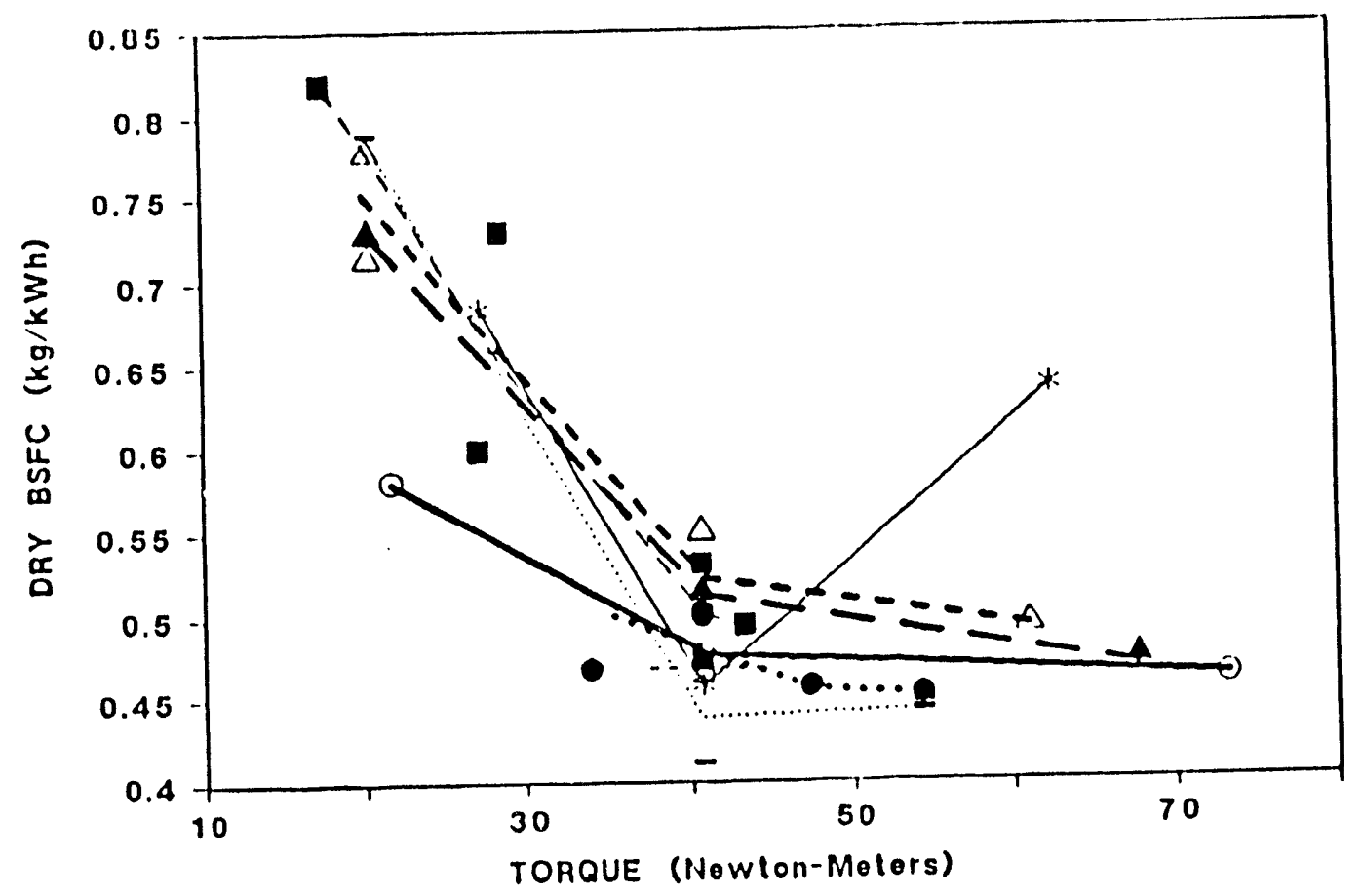

Figure 5.2.9-3 Brake Specific Fuel Consumption al 1,800 RPM

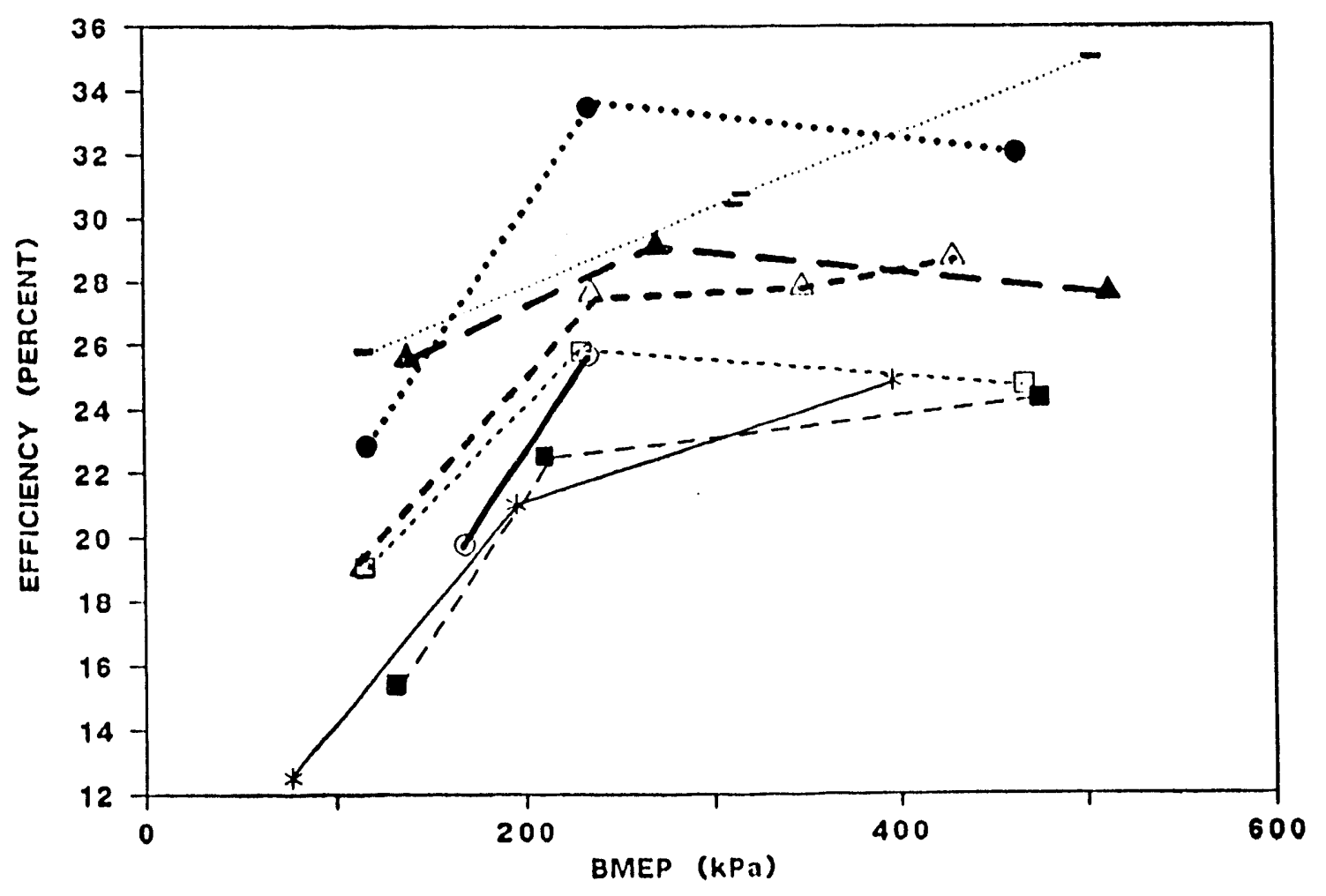

Figure 5.2.9-4 Brake Thermal Elficiency at 1,000 RPM 


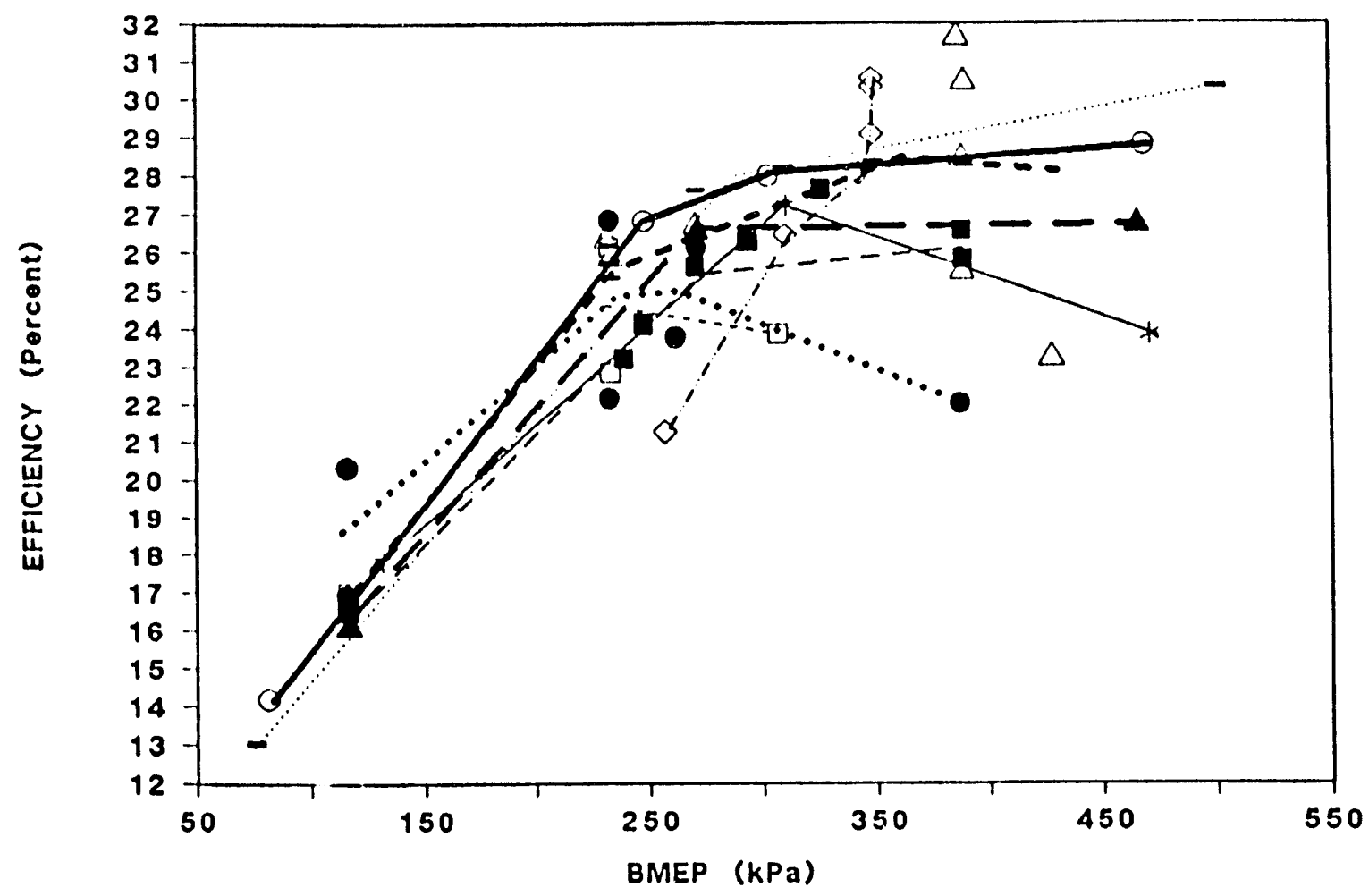

Figure 5.2.9-5 Brake Thermal Efficiency at 1,400 RPM

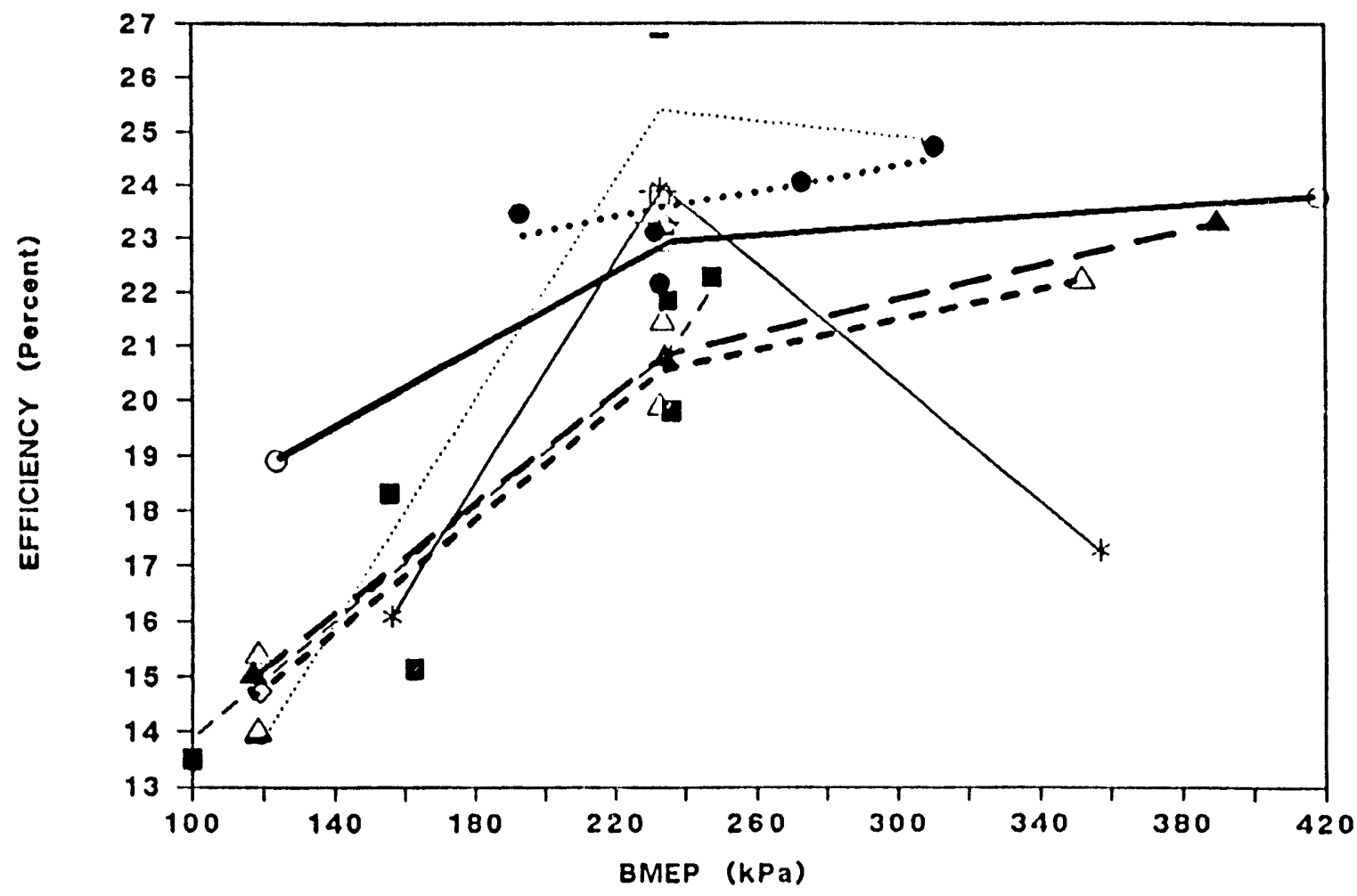

Figure 5.2.9-6 Brake Thermal Elliciency at 1,800 RPM 


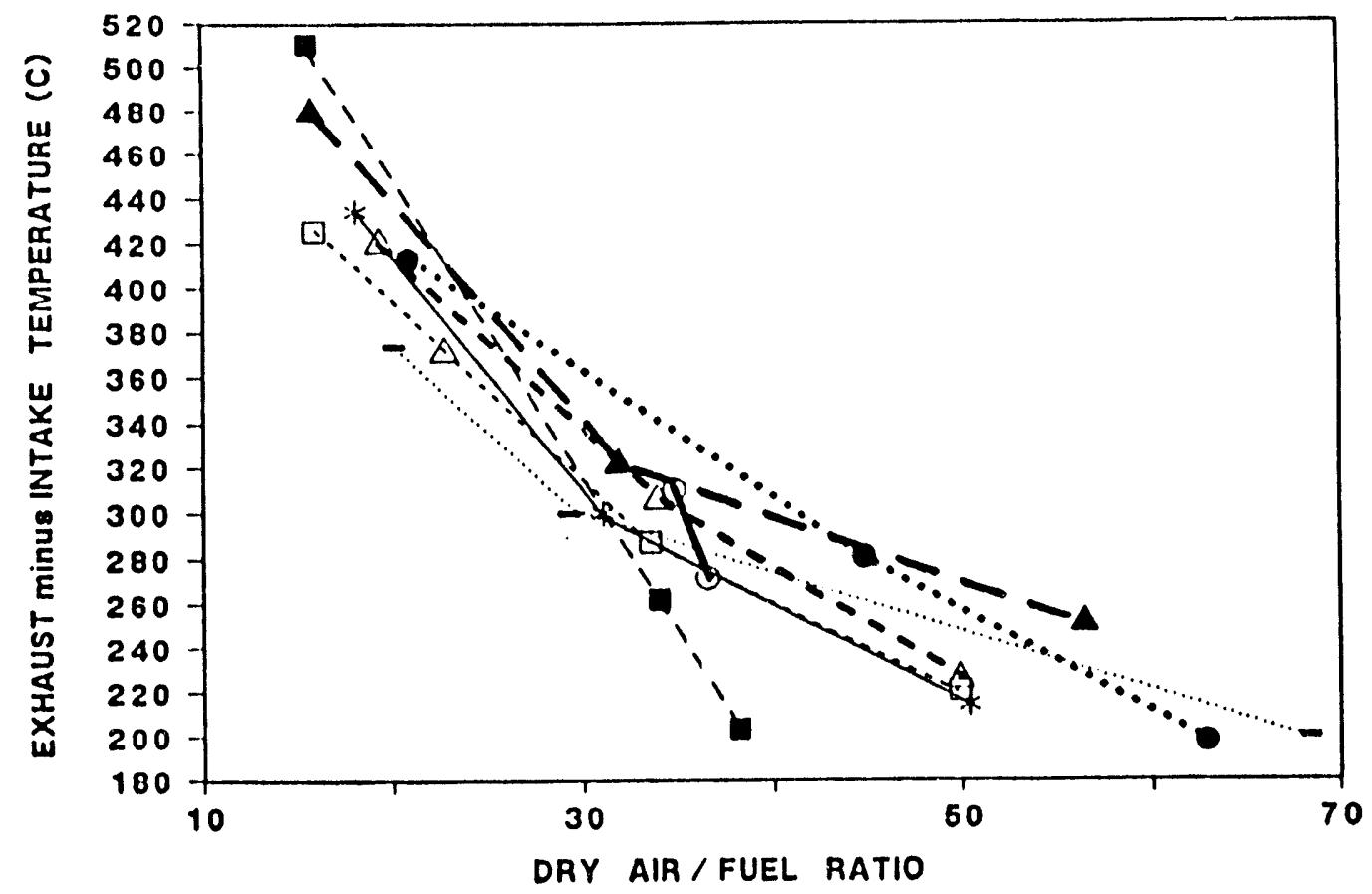

Figure 5.2.9-7 Engine Temperature Rise at 1,000 RPM

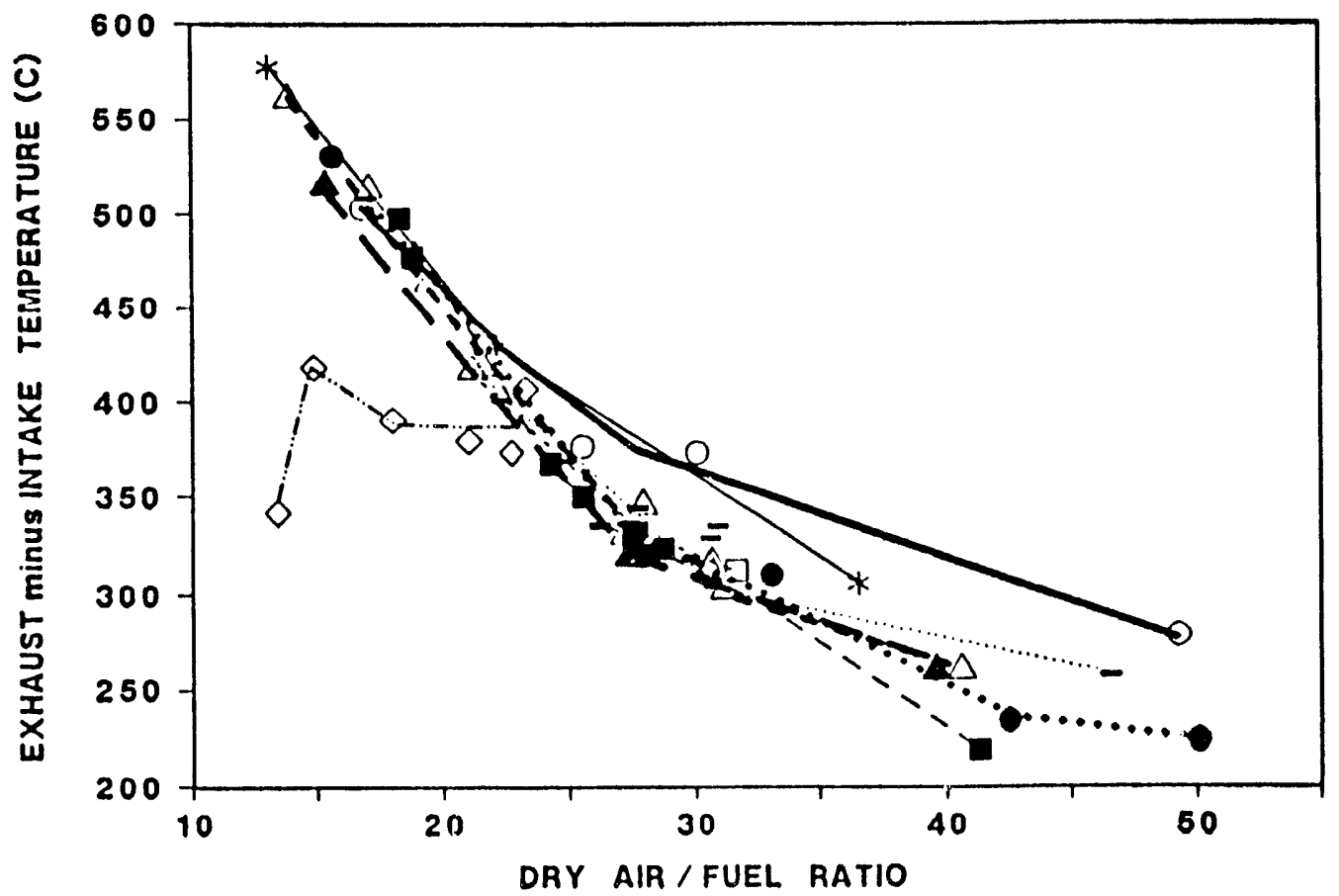

Figure 5.2.9-8 Engine Temperature Rise at 1,400 RPM 


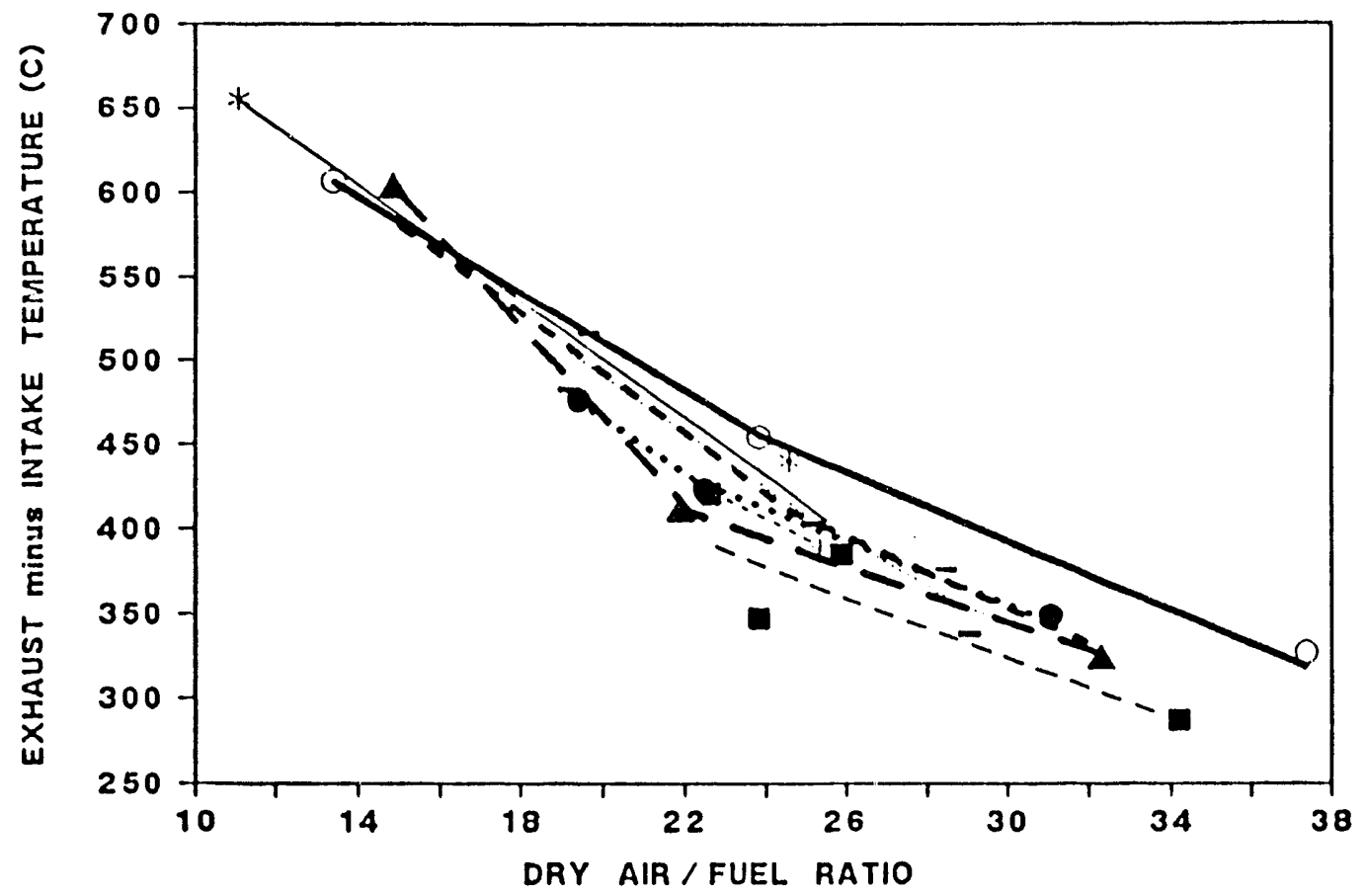

Figure 5.2.9-9 Engine Temperature Rise at 1,800 RPM

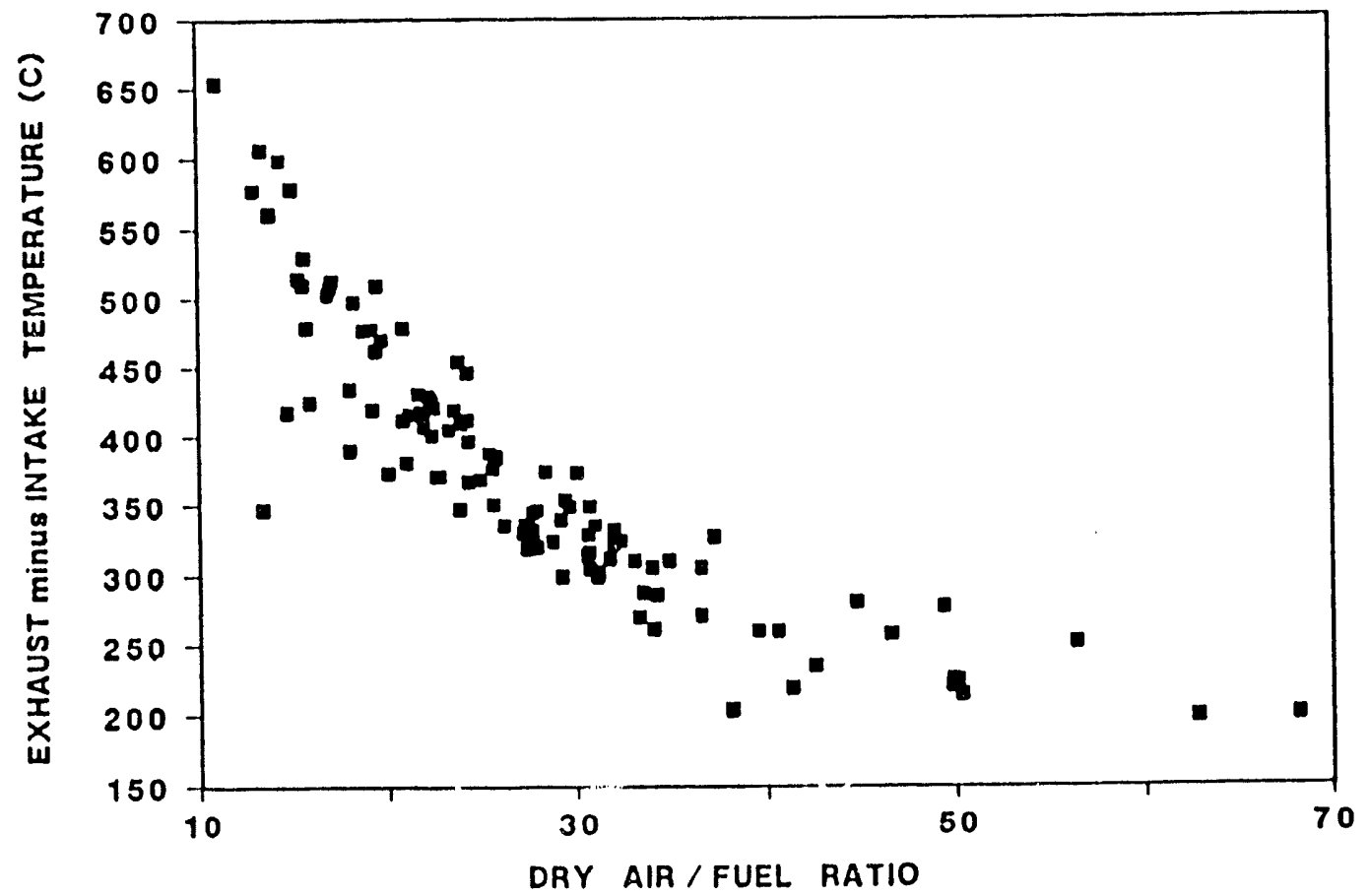

Figure 5.2.9-10 Engine Temperature Rise for All Speeds and All Loads 


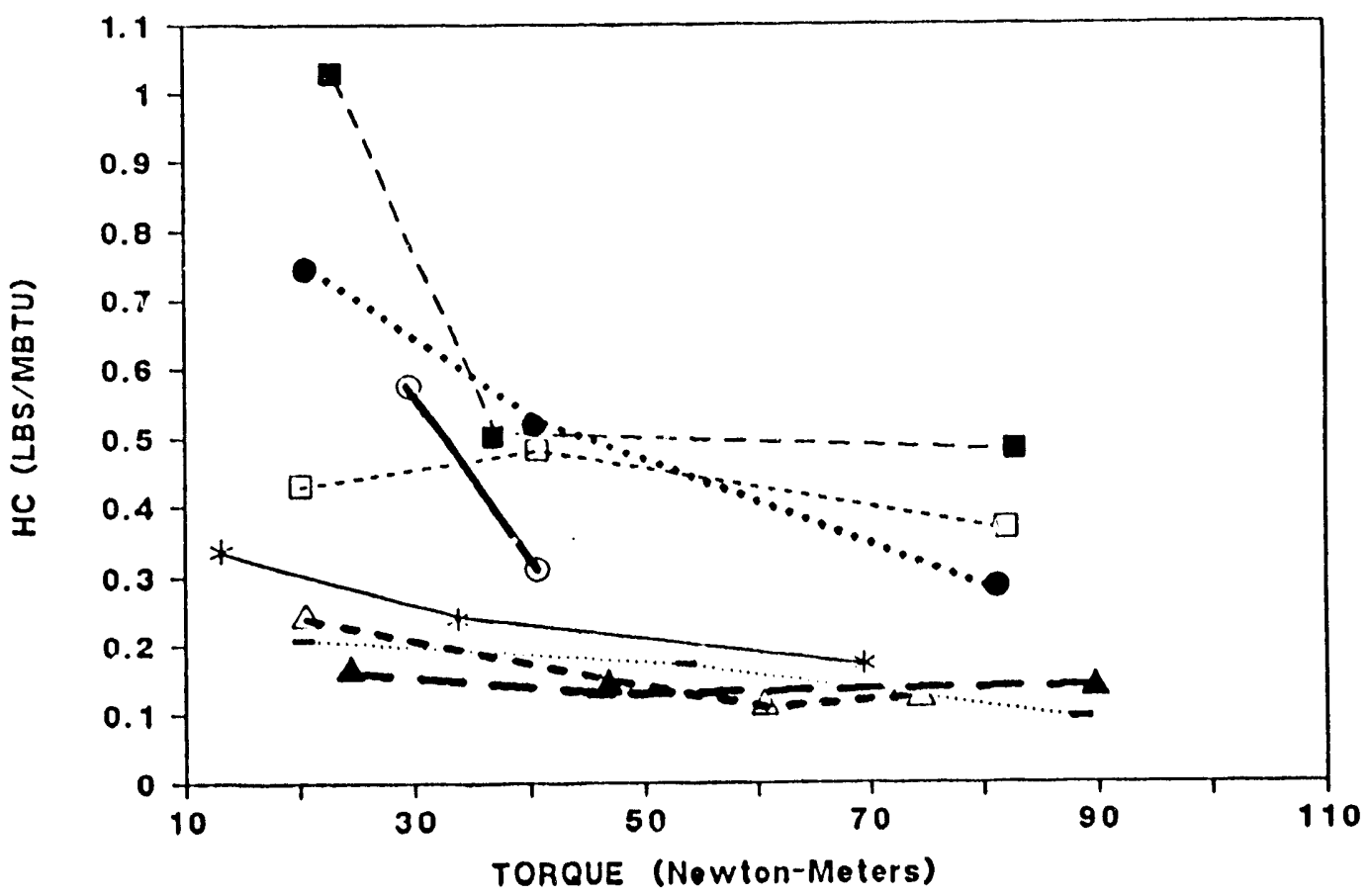

Figure 5.2.9-11 Hydrocarbon Emissions at 1,000 RPM

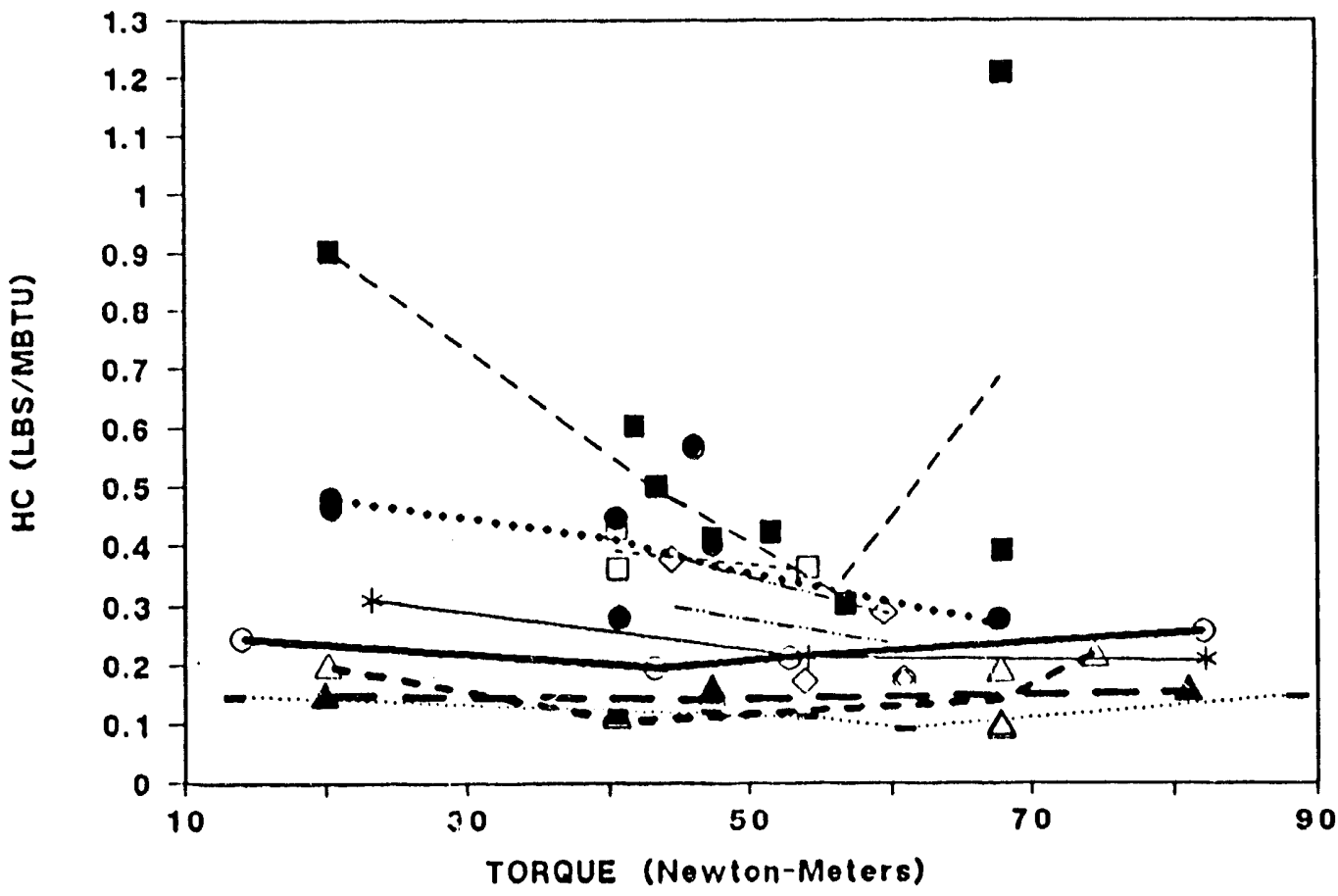

Figure 5.2.9-12 Hydrocabon Emissions at 1,400 RPM 


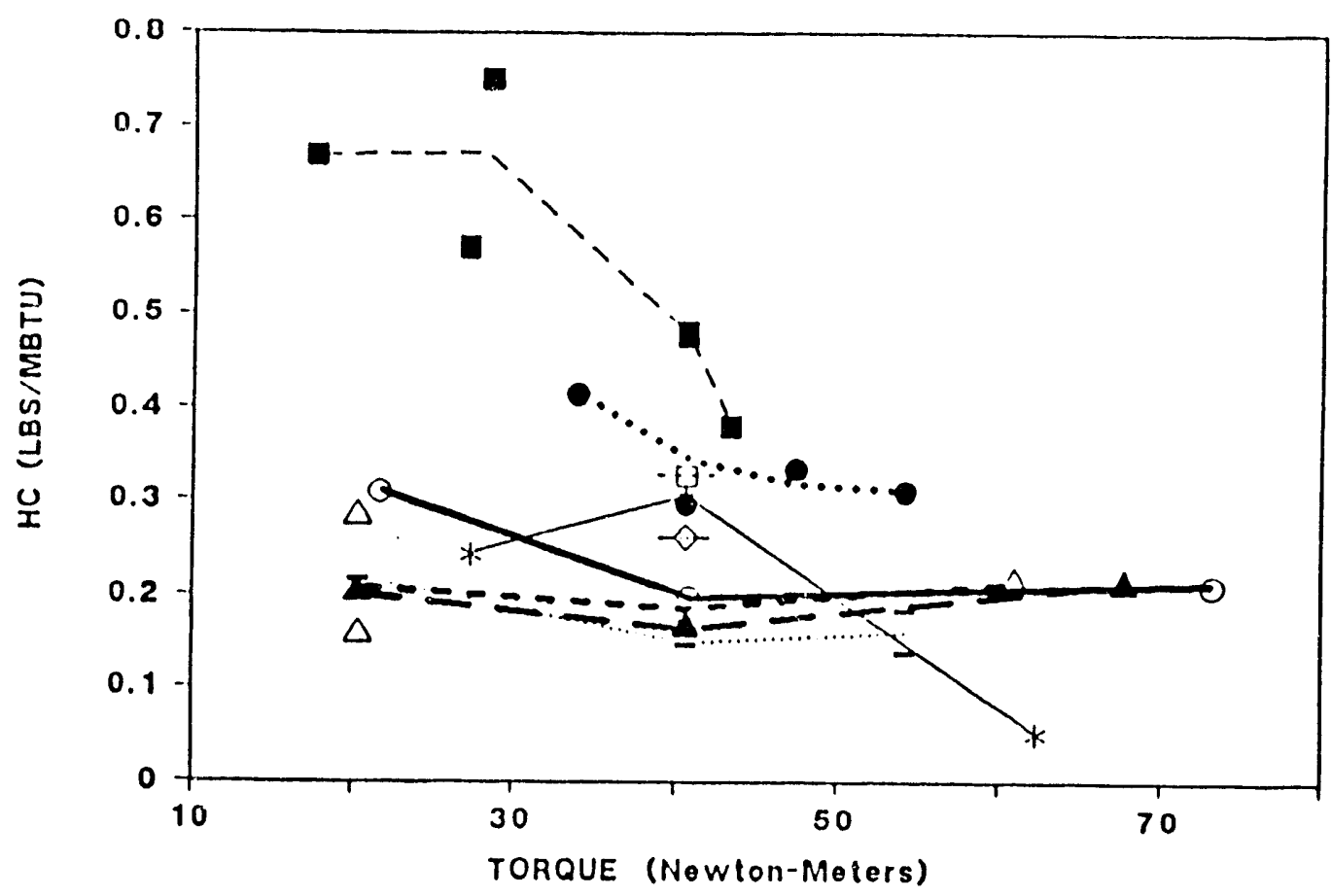

Figure 5.2.9-13 Hydrocarbon Emissions at 1,800 RPM

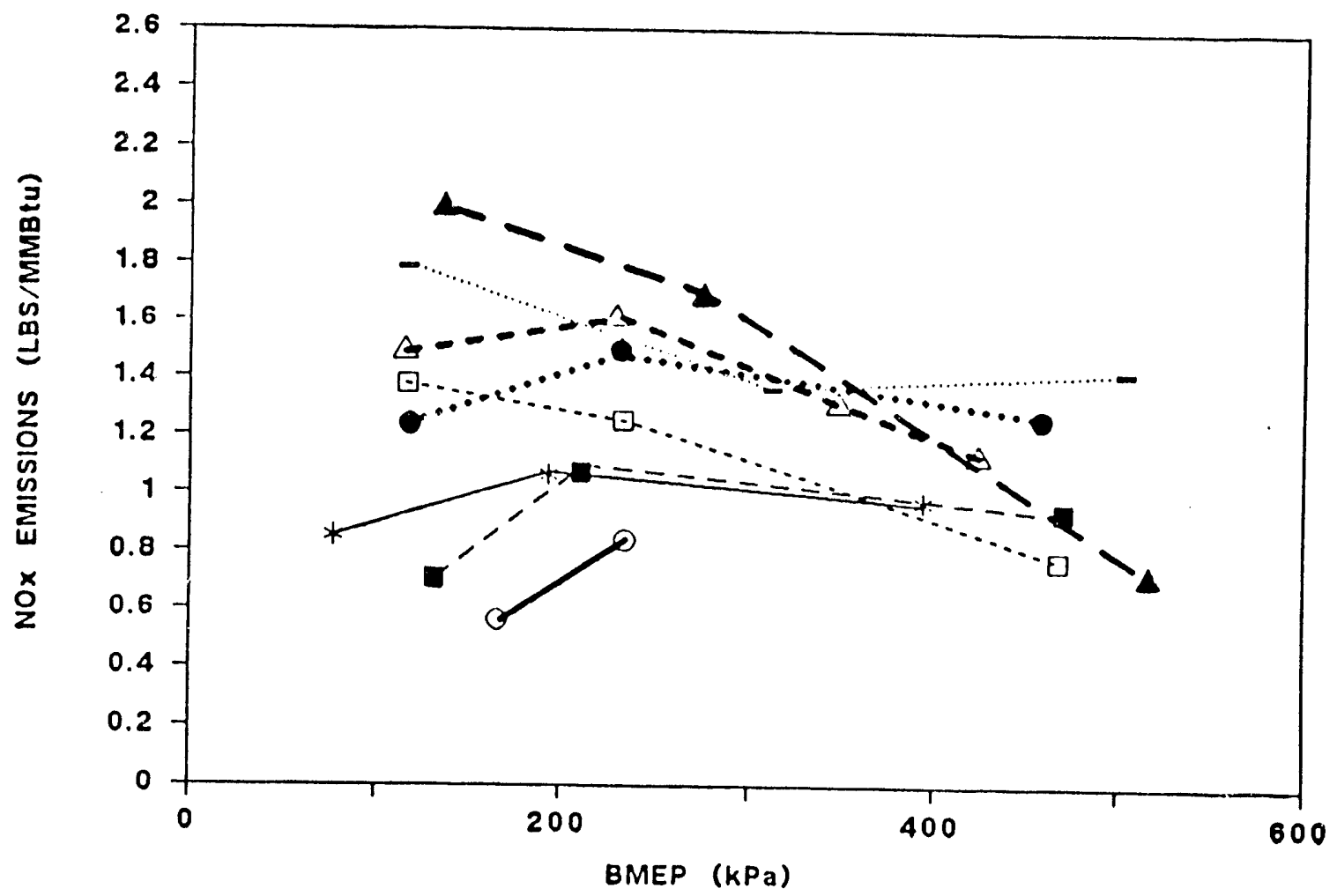

Figure 5.2.9-14 NOX Emissions at 1,000 RPM 


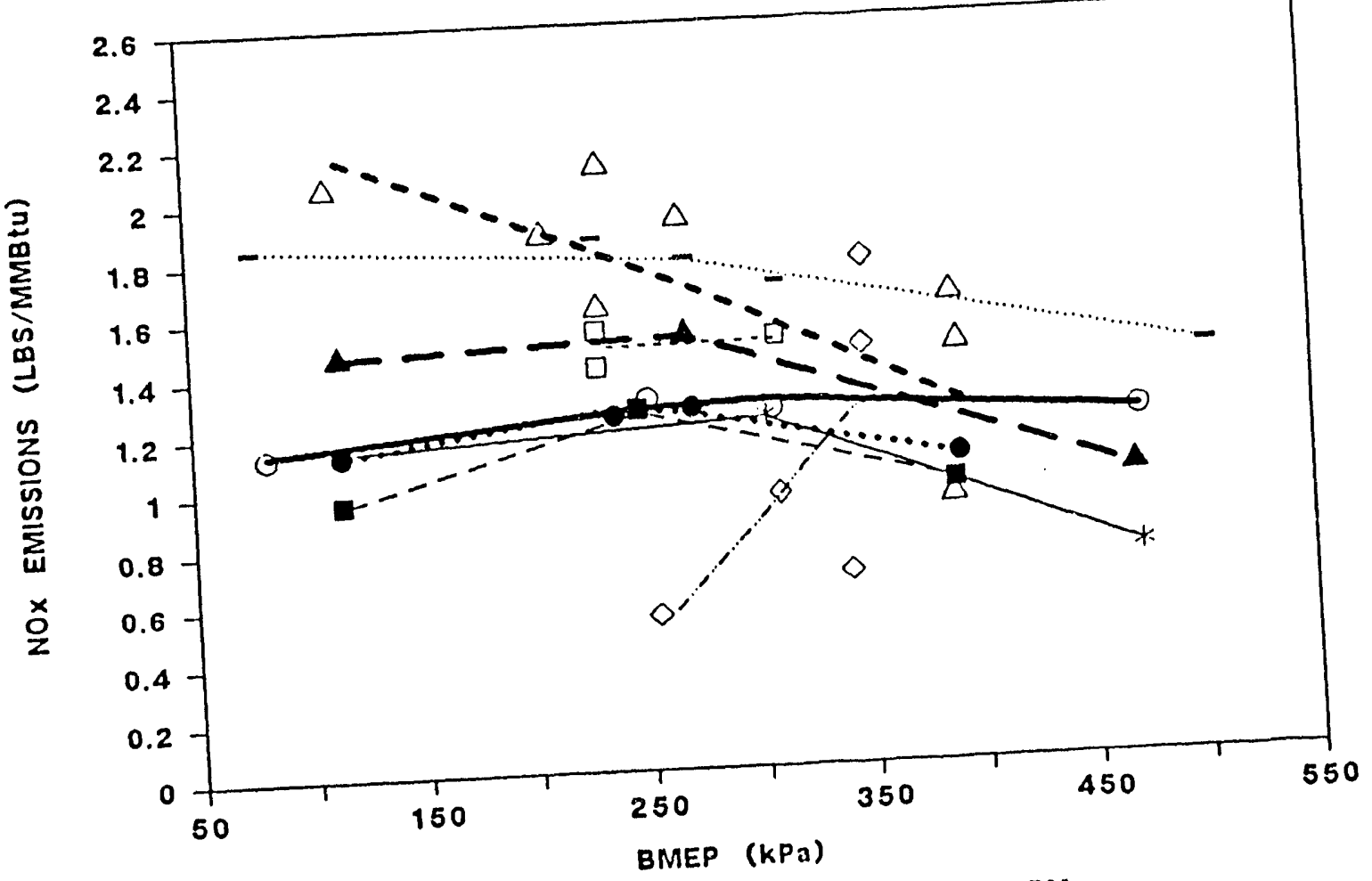

Figure 5.2.9-15 NOX Emissions at 1,400 RPM

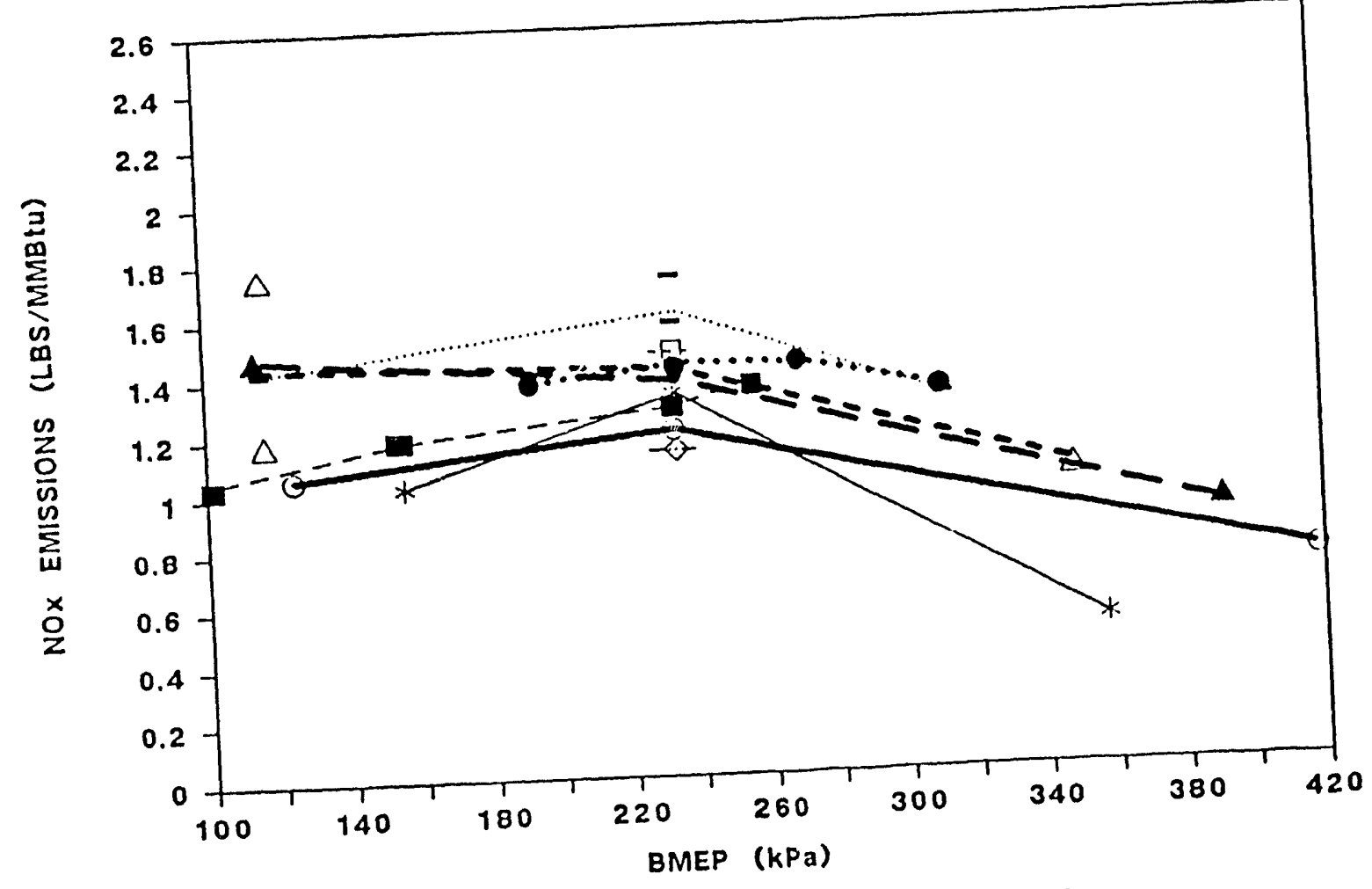

Figure 5.2.9-16 NOX Emissions at 1,800 RPM 


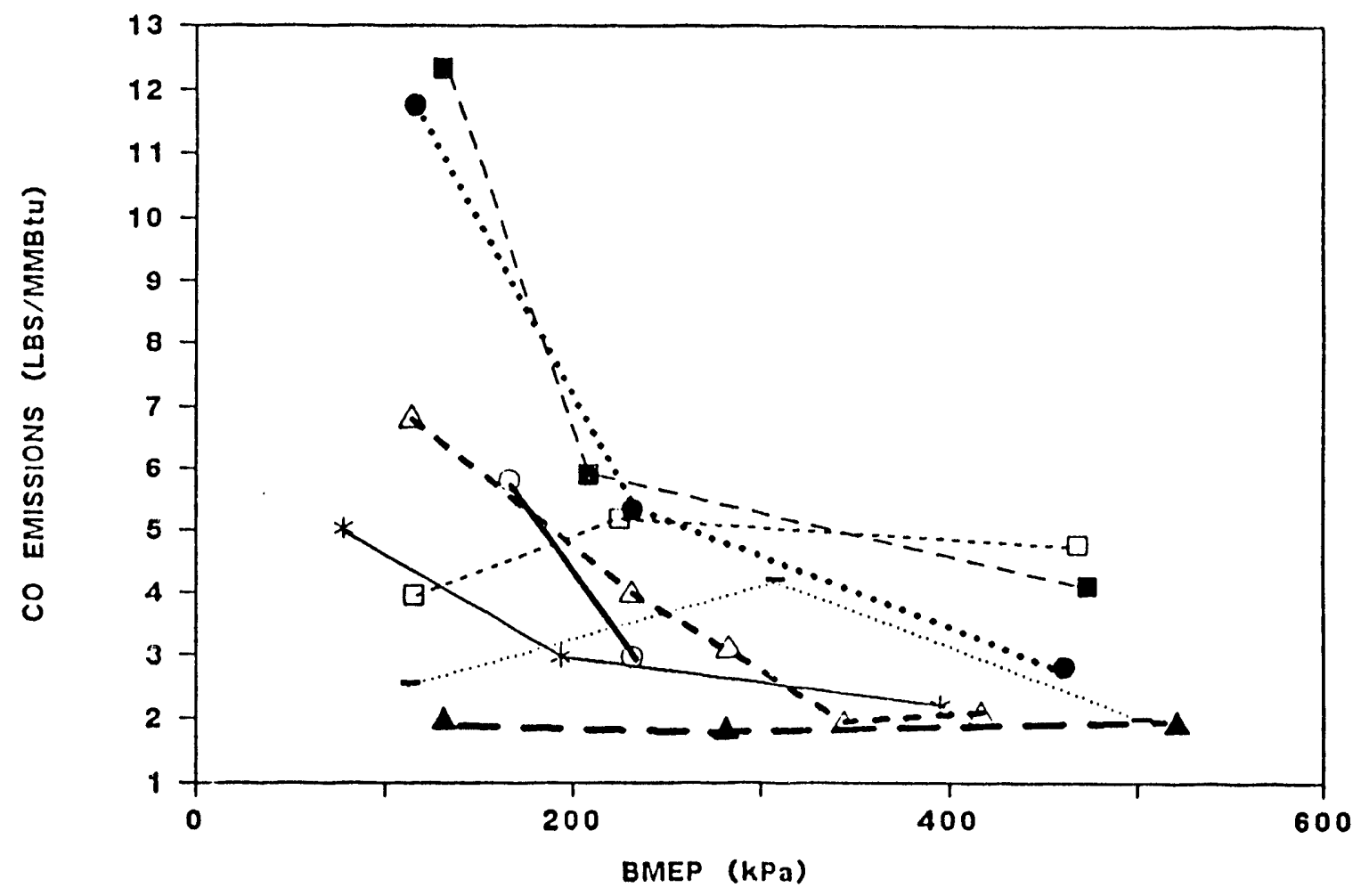

Figure 5.2.9-17 Carbon Monoxide Emissions at 1,000 RPM

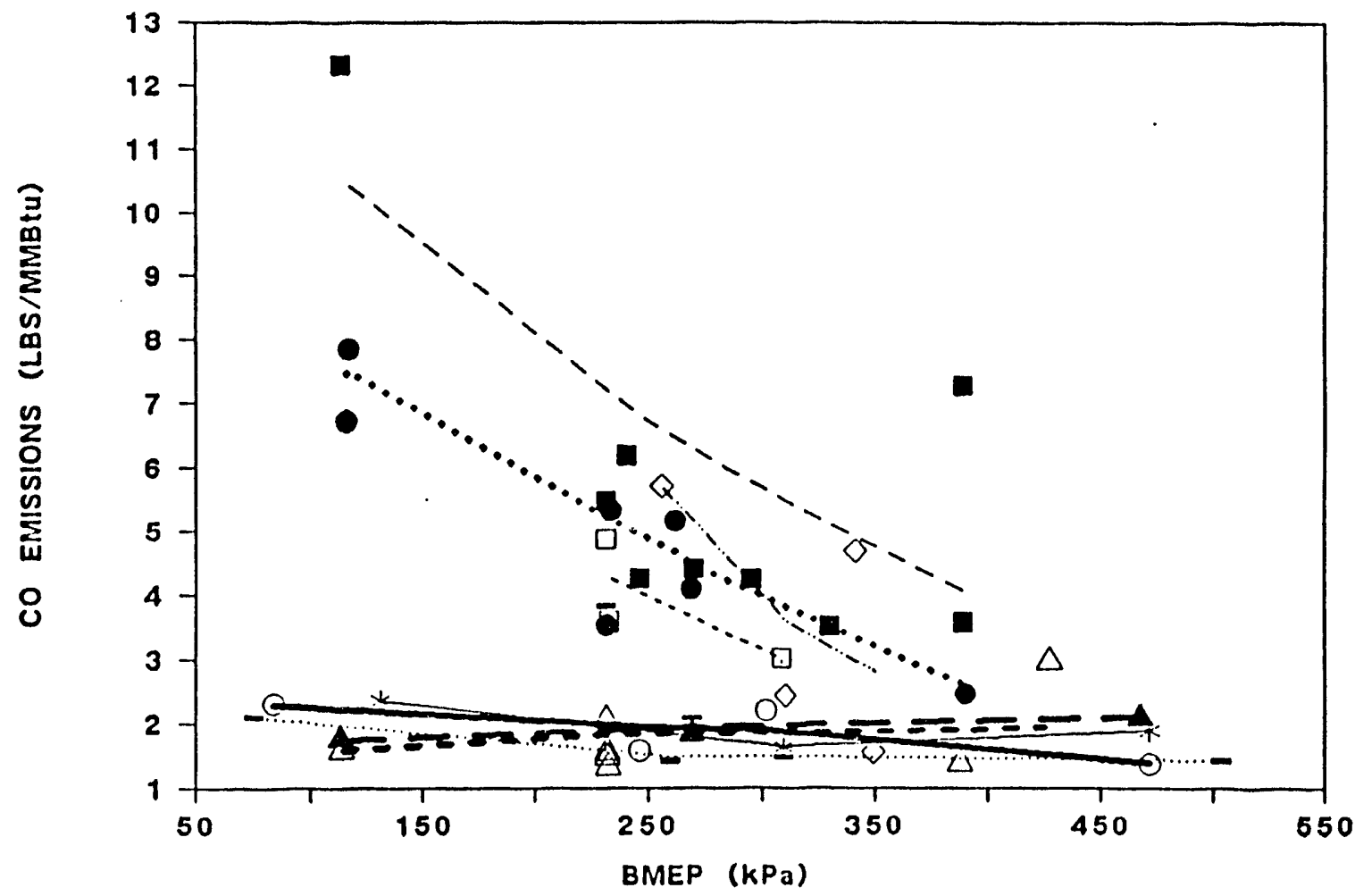

Figure 5.2.9-18 Carbon Monoxide Emissions at 1,400 RPM 


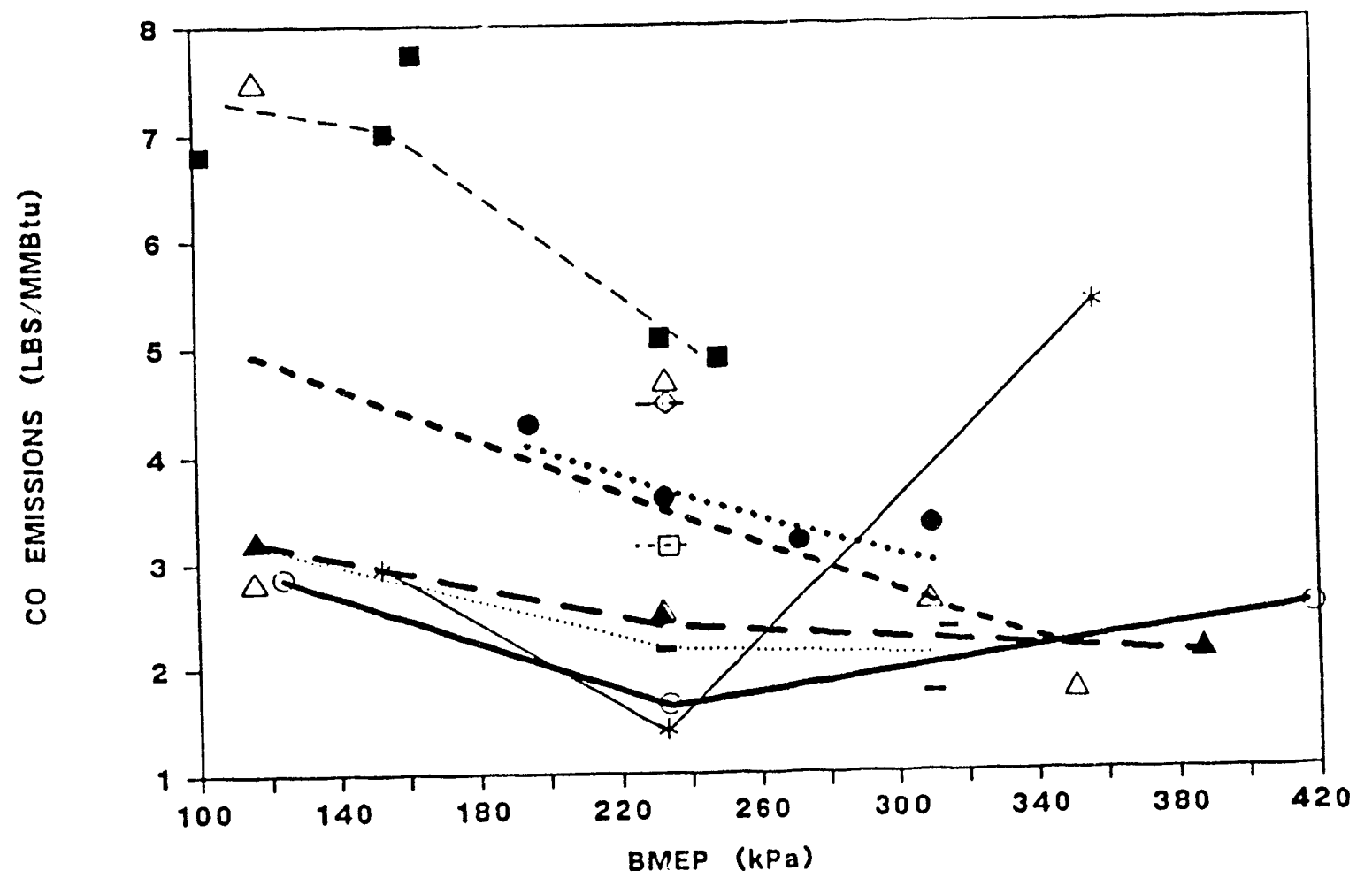

Figure 5.2.9-19 Carbon Monoxide Emissions at 1,800 RPM

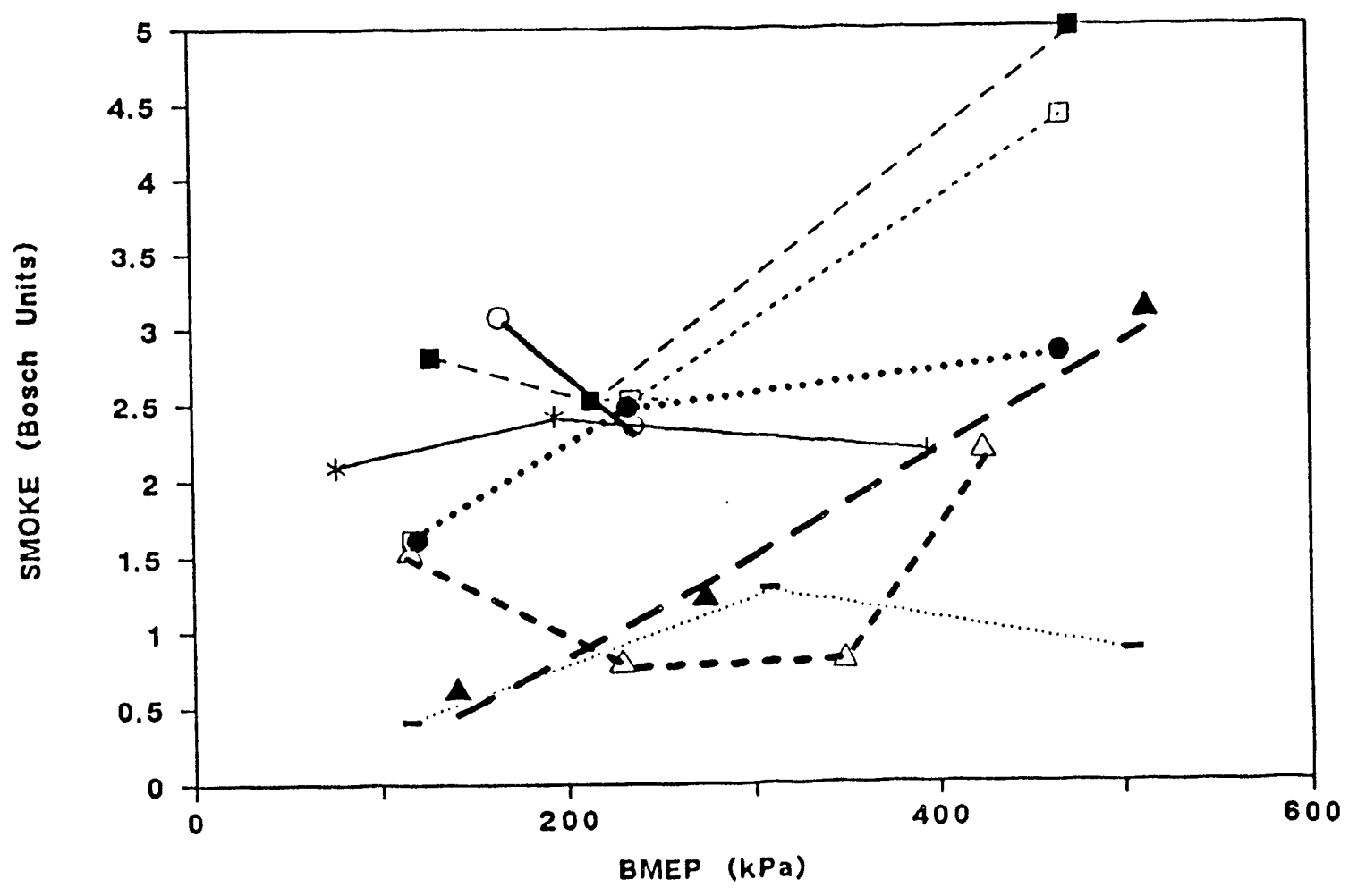

Figure 5.2.9-20 Exhaust Smoke at 1,000 RPM 


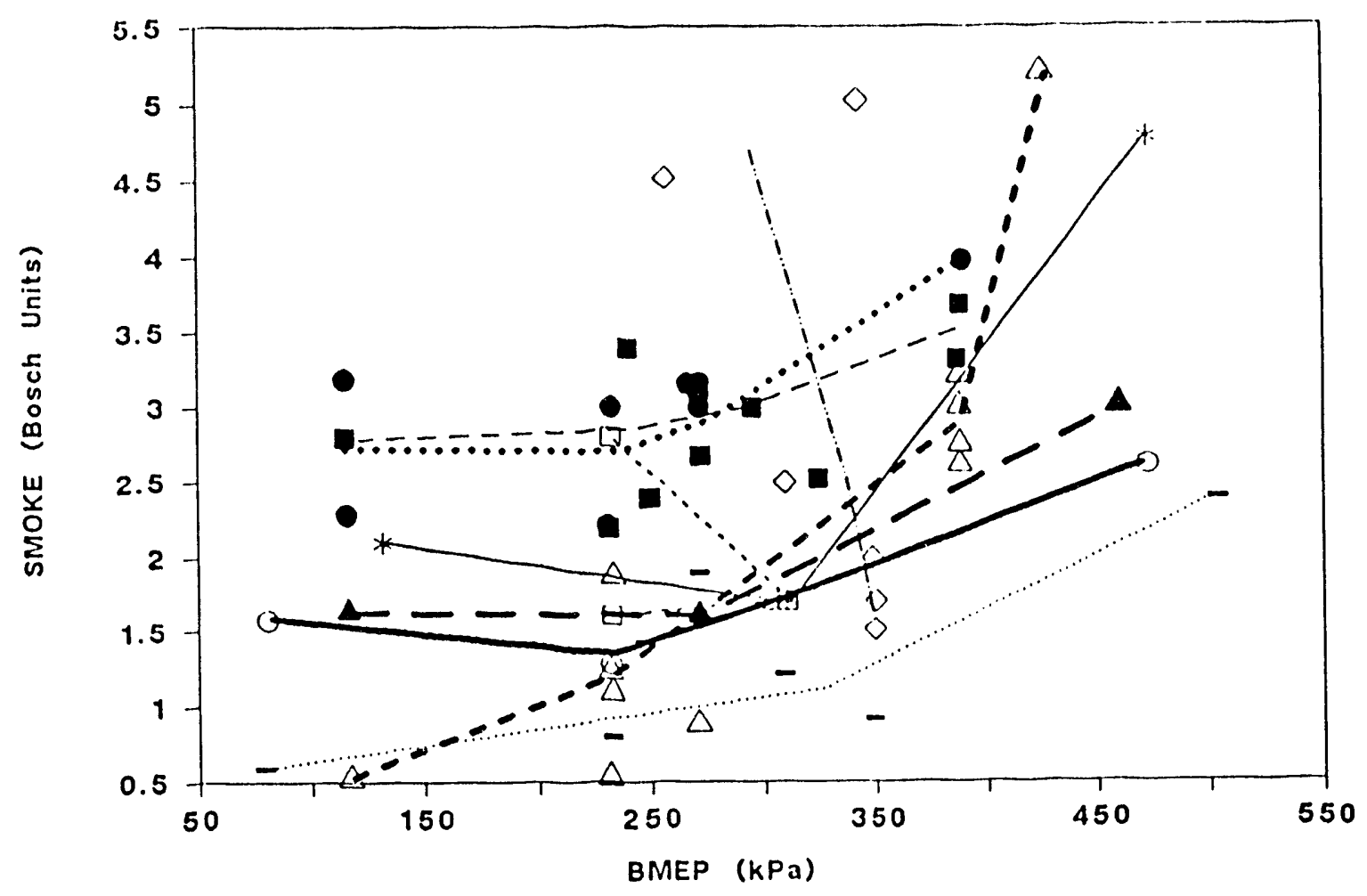

Figure 5.2.9-21 Ex!laust Smoke at 1,400 RPM

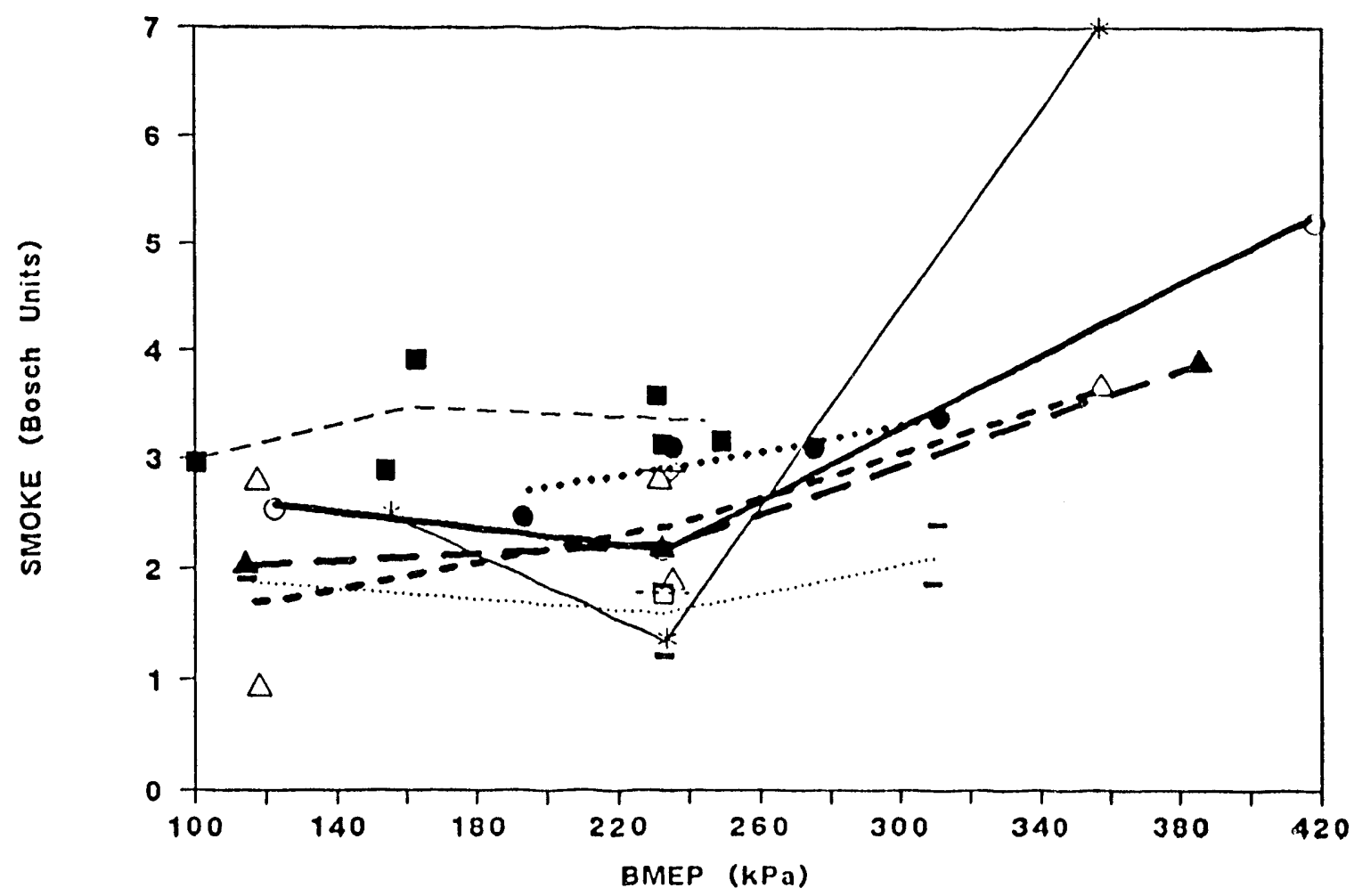

Figure 5.2.9-22 Exhaust Smoke at 1,800 RPM 


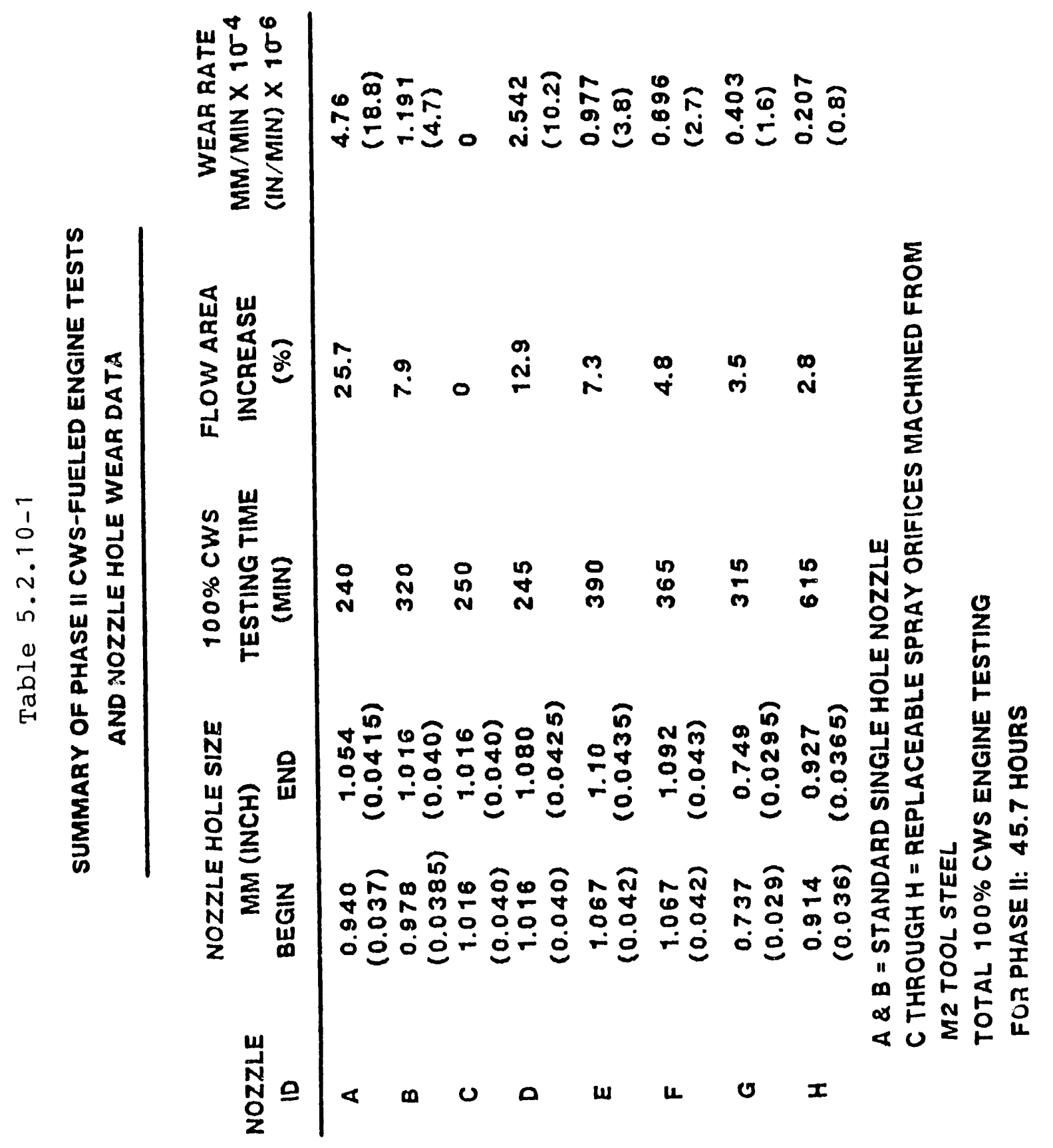




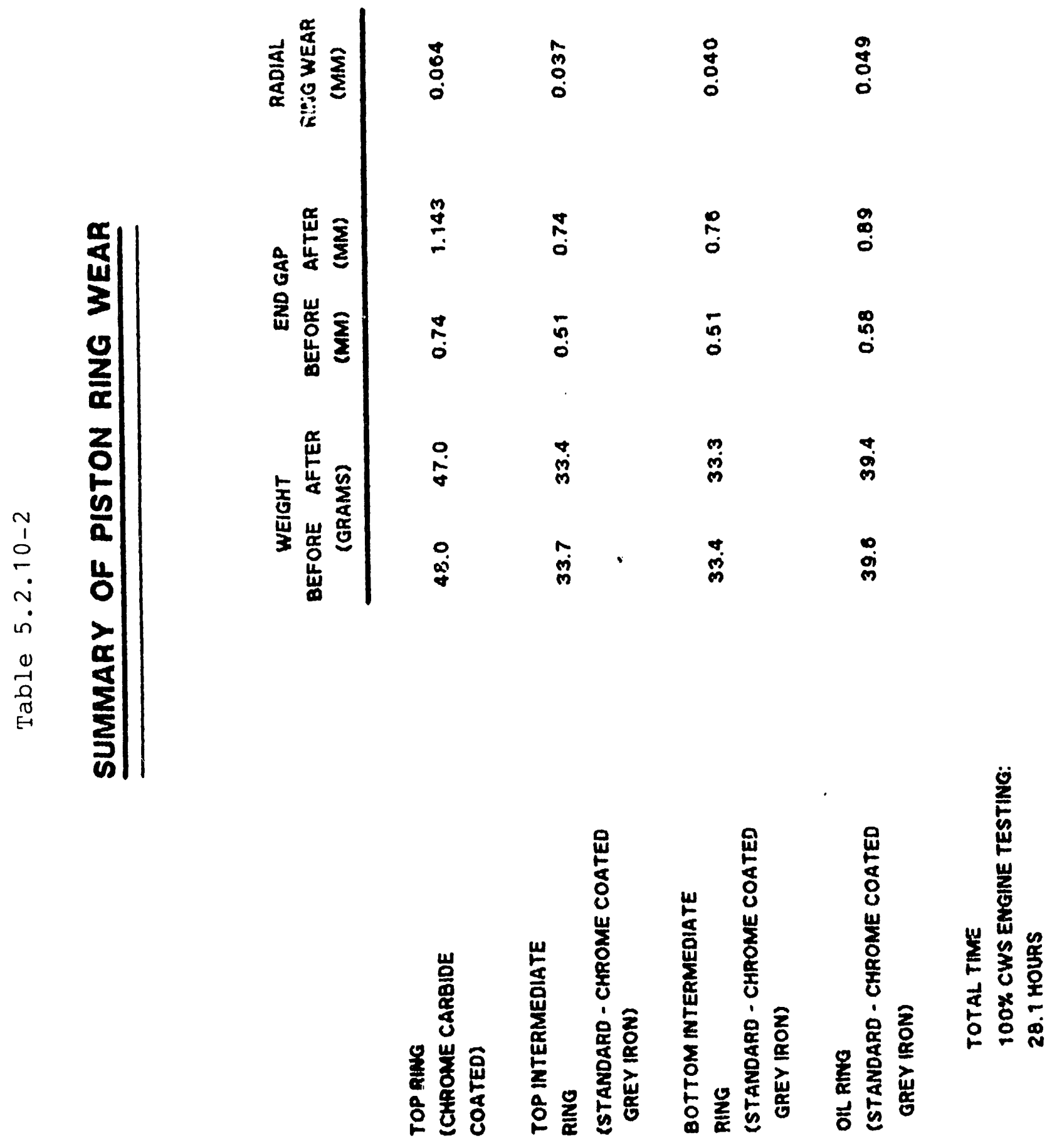




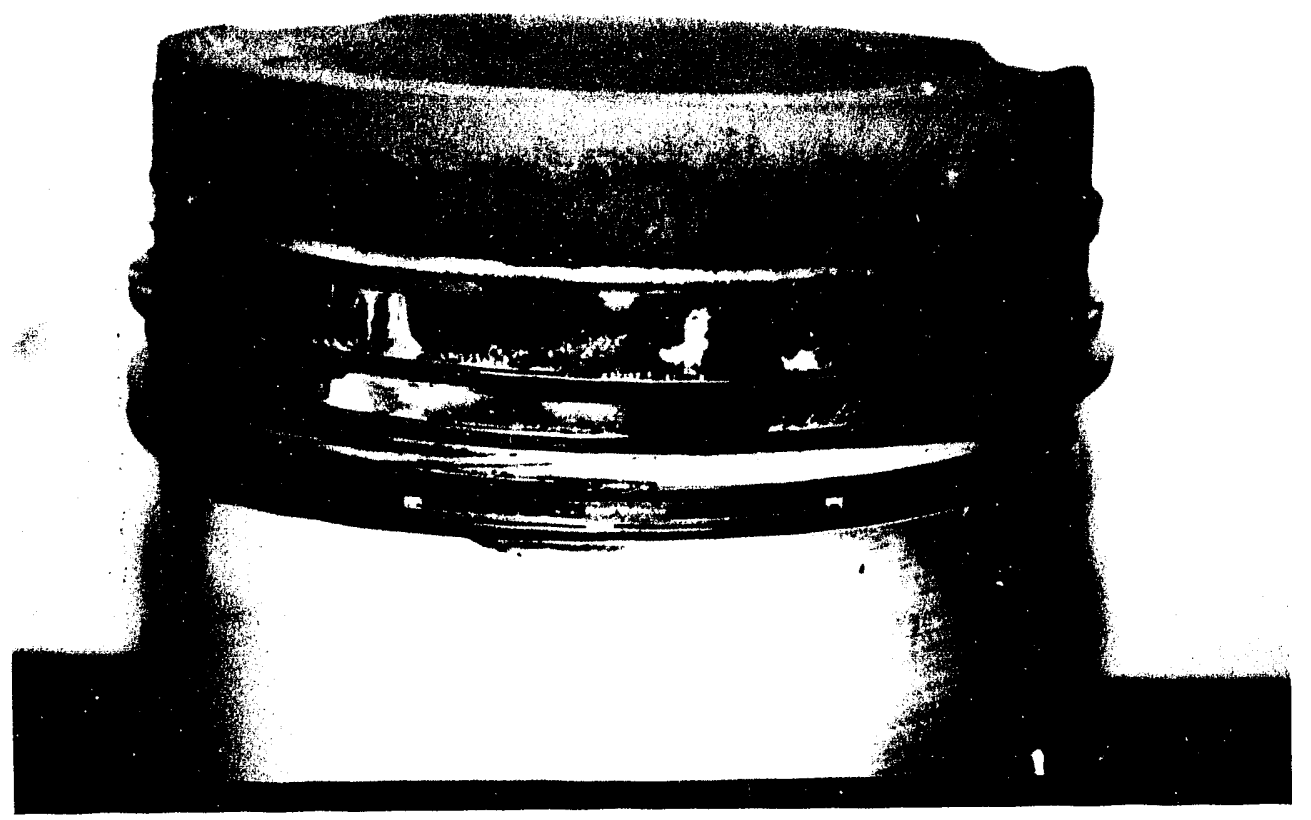

A I $-232-23$

Figure 5.2.10-1 Caterpillar Piston after 28.1 Hours of $100 \%$ CWS Engine Operation 


\subsection{TECHNICAL, CONCERNS}

Various operational and maintenance difficulties were encountered during this investigation and it is important to note these difficulties for the future.

\section{3 .1 C.al Water Slurcy Quality and Hasdling}

Despite the attempts to avoid problems which previous researchers have encountered with CWS, several additional severe problems were encountered during rhis program. The problems included non-recoverable setting during shipping and storage, agglomeration caused by contact with hydrocarbon liquids, and foreign particle contamination. other difficulties such as extreme property changes caused by small changes in the percentage of water in the slurry and clogging and plugging problems were experienced. Like other researchers, it was found that the slurry had to be kept in continuous motion to mintwize these problems. The presence of large particles (both foreign and coal based) resulted in the need to filter the fuel (Figure 5.3.1-1). Another real problem has been the disposal of contaminated CWS which must presently be treated as a hazardous waste.

\subsubsection{Engine Contamination}

Coal particles (both burnt and unburnt) were found in three different areas of the engine after testing. Ash particles were found on the exhaust valve rotators and springs. These particles had slipped through the clearance between the valve stem and the valve guide. At no time during testing did these deposits present any problem (such as valve sticking, failure to rotate, etc.). Ash and unburnt coal contacted the cylinder 1 iner causing ring wear. and large deposits above the top ring reversal srea. The last area of coal contamination was the product of the first two areas. The ash and unburnt coal that slipped past the valve guides and rings contaminated the ofl. Two centrifugal oil filteis were used to remove the coal contaminants (Figure 5.3 .2 .1 is a photograph of one filter after eight hours of 100 percent CWS testilg). During this time period the engine was run extensively at very high loads to determine maximum power output and was occasionally run in overfueled condition which aggravated the migration of coal into the oil. Therefore, the accumulation during this eight hour run was higher than normal.

\section{3 .3 Depesit Formation in PCC and on Piston}

Adiabatics, Inc., moved to a new facility during the middle of the Phase II program. The firgt tests at the new facdilty with 100 percent CWS fuel showed deposit formation at the throat of the prechamber. Figure 5.3.3-1 shows typical deposits including loose deposits collected on a magnet. Englne operation including efficiency and the power output were similar at the old and new facilities so long as the deposits were light.

Further investigation showed the deposit formation in both the swirl type and pepper pot type prechambers. These deposits deteriorated the engine performance. It was confirmed that the deposits form when burning, slurry from different batches, including that which was used at Adiabatic's former facility (where the deposit formation was minimal). It has bec $n$ also found that all the deposits can be attracted to a magnet. Samples fror two batches of slurry were analyzed and found to have an iron content betwer n 300 to 400 


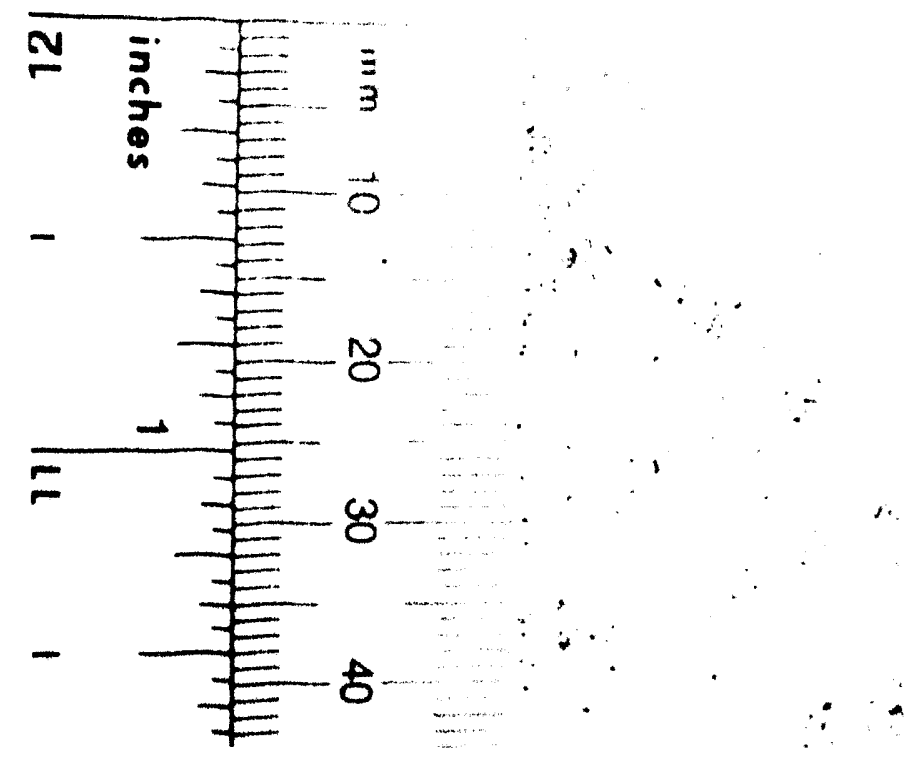

AI - 234-23

Figure 5.3.1-1 Large Particles Filtered Out of CWS Before Testing Began 


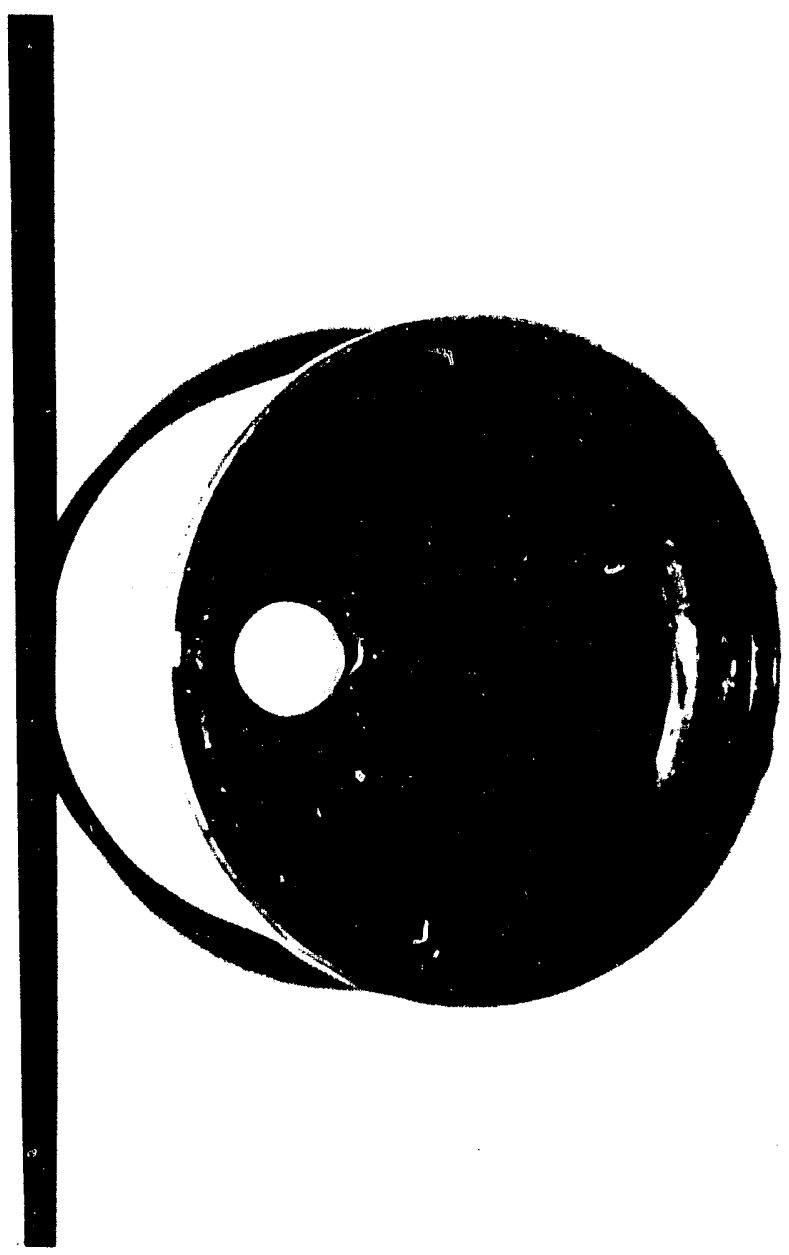

AI $-233-18 \mathrm{~A}$

Figure 5.3.2-1 Load Contaminants Collected in Centifugai Filter After 8 Hours of $100 \%$ CWS Engine Testing 


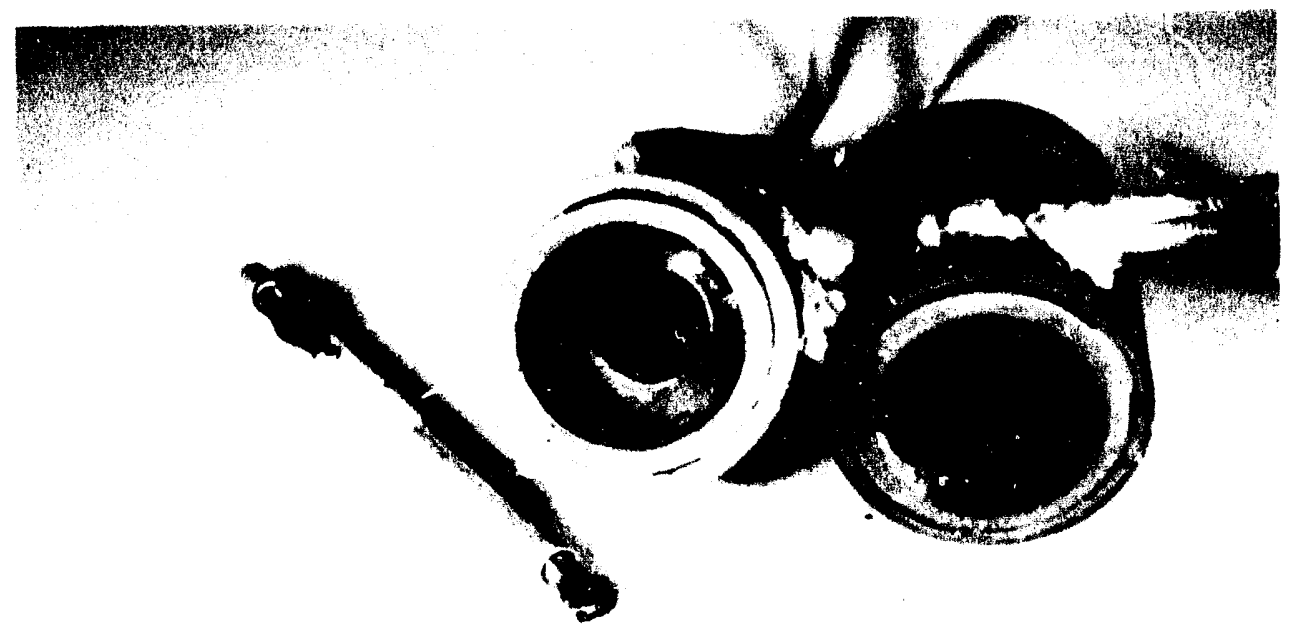

AI $-214-16 \mathrm{~A}$

Figure 5.3.3-1 Pepper Pot Type Prechamber After One Hour of $100 \%$ CWS Engine Testing With Blue Gem Seam Coal 
ppm. The analysis of the prechamber deposits has revealed a concentration of 20 percent iron and 0.13 percent nickel. The PCC material has been changed to Haynes allov no. 230 from Hastelloy $X$ as the 230 marerial has a significantly lower iron content and the same deposit formation has been experienced. Further, the deposit formation did not change with a change in PCC temperature from $871^{\circ} \mathrm{C}$ to $982^{\circ} \mathrm{C}\left(1.600\right.$ to $\left.1.800^{\circ} \mathrm{F}\right)$.

Precombustion chambers have been weighed before and afler testing to confirm that the deposit formation was not due to the corrosion of the Hastelloy $x$ or 230 alloy.

The location and appearance of the deposits suggests that the deposits are a slag formation which is deposited on the inner surface as a 1 iquid which then tuns down the walls until it reaches a cooler section of the prechamber near the throat where it solidifies. Examination of a paper [15] sent by Mr. Cary smith shows that a similar problem of scale deposit formation was experinced in the boiler tubes of fossil fueled utility systems. The deposits described in the paper were a form of iron oxide called magnetite which re created by a chemical reaction between the surface of the steel. tubes ind the steam flowing through them. It is possible that the deposits. formed in the engine testing, could be also a form of magnetite and needs to be contirmed. At this point, it is quite plausible to think that the deposits we:e coming from the burning of the CWS fuel. Based upon the amount of iron in the deposits and the amount of iron in the coal-fuel it is possible that all of the deposits are coming from the ash in the fuel.

\section{3 .4 vozzle oriflce and cylinder Head cracking}

Problems with cracking the spray insert orifice in the nozzle cap and crackin; of the cylinder head were encountered during the engine testing. The orifice was corrected by increasing the load bearing area of the orifice and providing two holes into the cooling passage of the injector nozzle to allow cooling water to contact the spray insert orifice.

The cylinder head cracking problem (Figure 5.3.4-1) was the result of a large thermal expansion mismatch between the Caterpillar cast iron head and the Hastelloy $X$ prechamber material. The problem was corrected by installing belleville washers in the prechamber hold-down system to allow the prechamber to grow rithout introducing additional loads into the head.

\subsection{CONLLUSIONS}

The work conducted during this program was successful in developing an electronically controlled, hydraulically actuated CWS-injection system operating at low injection pressures of 13.8 to $20.7 \mathrm{MPa}(2,000$ to 3.000 psi). Also, the program objectives of 100 percent CWS-fueled engine operation with the TICS concept without the use of external ignition assist sources up to $1.800 \mathrm{rpm}$ speed were achieved. The high level of ignition energy in TICS chamber enabled the unassisted combustion of CWS fuel at all speeds and loads in the test engine. The nozzle wear data showed less wear of the nozzle hole as compared to the wear data reported for other CWS injectors. Further, a wear-resistant coating or harder material for the nozzle hole extends the CWS injector nozzle life for operation with the CWS fuels. 


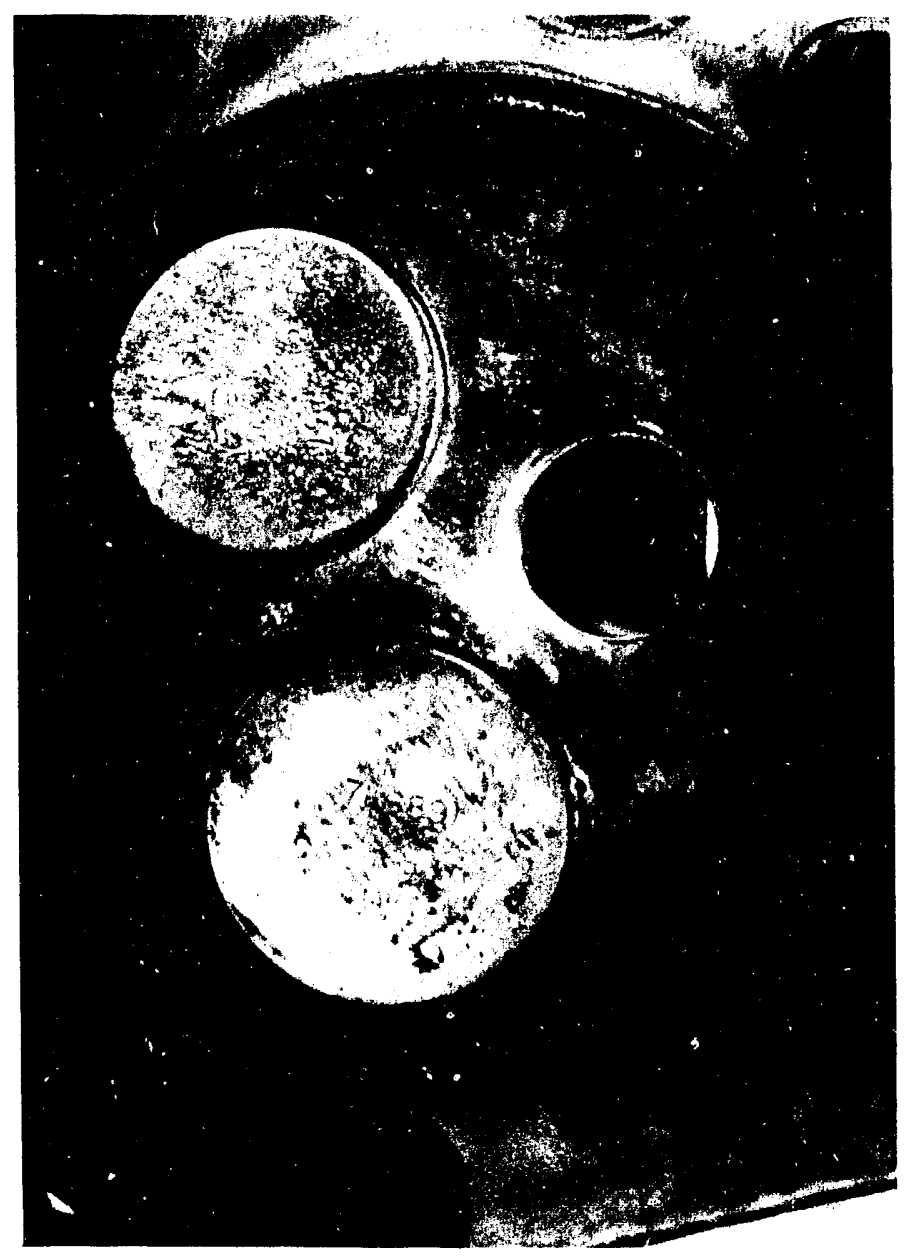

A I - 217-1A

Figure 5.3.4-1 Cracked Cylinder Head 
The Kentucky Blue Gem seam CWS-fueled engine test results show high heat release rates and short combustion duration. The heat release analysis shows a significant portion of the ChS fuel burning in the premixed combustion mode. An increase in CWS injection pressure from 13.8 to $20.7 \mathrm{MPa}$ s seen to increase the peak heat release rate. Performance data for coal powder. CWS and diesel-fueled engine tests show higlier cylinder pressure and heat release rates for coal powder and CWS as compared to diesel fuel. 100 percent CWS-fueled engine test data up to $1.800 \mathrm{rpm}$ speed range shows maximum brake thermal efficiency of 33.5 percent at $1,000 \mathrm{rpm}$. However. the brake thermal efficlency in a multi-cylinder CWS-fueled engine will be even higher. The test engine operation was optimized during the Phase II program with additional parametric optimization studies on the CWS injection and combustion. Amongst them includes: Improved performance with the swirl chamber PCC design and larger PCC volume. There exist optimum values of PCC temperature, nozzle orifice size. injection timing and percent EGR. Further. gaseous emissions, smoke and particulate measurements were made. There appears to be some correlation between smoke and particulates.

\subsection{RECOMMENDATIONS FOR FUTURE WORK}

Based on the results and Eindings of this program, the following recommendations are suggested for future work on the CWS injectors and engines:

- Evaluate CWS injection and combustion characteristics in a multi-cylinder engine with the TICS concept. For this purpose, a 4 or 6 cylinder engine can be modified with the CWS injection system and air gap insulated TICS chambers operating at high temperatures.

- Further investigate wear-resistant coatings and materials for the nozzle hole to increase its 1 ife.

- Improve CWS injector by making changes for its normally closed operation and direct solenoid actuation of the plunger. This will eliminate need for the servo-fluid (and servo-fluid pump and other accessorles) and make the CWS injector more compact and commercially viable. 


\section{REFERENCES}

1. McMillian, M.H. and Webb, H.A., 1989, "Coal-Fueled Diesels: Systems Development," ASME Publication ICE-Vol, 7, pp. 1-8, Houston, Texas.

2. Bendick, R.C., Dorchak, T.P., Rekos, N.F., and Webb, H.A., 1989, proceedings of the 6 th Annual Coal-Fueled Heat Engines and Gas Stream Cleanup Systems Contractors Review Meeting, Morgantown, West Virginia.

3. Leonard, G. et al., 1989 "Coal-Fueled Diesels: Technology Development," Einal Report Submitted by GE to the DOE, Contract No. DE-AC21-85MC22181.

4. Bendick, R.C., et al., 1989, Proceedings of the Sixth Annual Coal-Fueled Heat Engine and Gas Stream Cleanup Systems Contractors Review Meeting, Morgantown, West Virginia.

5. "Coal-Fueled Diesel Systems for Stationary Power Applications," Final Beport Submitted by A.D. Little. Inc. to the DOE, 1989, Contract No. $\mathrm{DE}-\mathrm{AC} 21-85 \mathrm{MC} 22182$.

6. Hsu, B.D., 1988, "Progress on the Investigation of the Coal Water Slurry Fuel Combustion in a Medium Speed Diesel Engine Part 1. Ignition Studies," Energy-Sources Technology Conference and Exhibjtion, ASME Paper No. 88-ICE-4, New Orleans, Louisiana.

7. Hsu, B.D., 1988, "Progress on the Investigation of the Coal Water Slurry Fuel Combustion in a Medium Speed Diesel Engine Part 2., "Energy-Sources Technology Conference and Exhibition, ASME Paper No. 88-ICE-5, New Orleans, Louisiana.

8. Flynn, P.L., and Hsu, B.D., "Coal-Fueled Diesel Developments," SAE Paper 881159,1988 .

9. Wilson, R.P. et al., 1988, Coal Fueled Diesel Systems Research, Coal Fueled Diesel Combustion: Cooper-Bessemer Test Results, "Proceedings of the Annual Coal Fuel Heat Engines and Gas Stream Cleanup Systems Contractors Review Meeting, Morgantown. West Virginia.

10. Kamo R., Kakwani, R.M., Woods, M.E., and Valdmants, E., 1986, "Combustion Characteristics of Coal Fuels in Adiabatic Diesel Engines, "Final Report Submitted to DOE. Contract No. DE-AC21-84MC21099.

11. Kamo R., Kakwani, R.M., Woods, M.E. and Carpenter, L.K. 1986b, Energy-Sources Technology Conference and Exhibition, ASME Paper No. 86-ICE-19, New Orleans, Louisiana.

1.2. Kakvani, R.M. Kamo, R., Cutlip, R.G., and Smith, W.C., 1989, "Combustion Characteristics of Dry-Coal-Powder-Fueled Adiabatic Diesel Engine," ASME Publication ICE-Vol. 7, pp. 27-34, Houston, Texas.

13. Kakwani, R.M., and Kamo, R., 1989, "Extending and Enhancing the Scientific Base for Advanced Coal-Fueled Power Systems Utilizing Heat Engines, "Einal Report Submitted to DQE, Contract No. DE-AC21-86MC23258. 
14. Heywood, J.B., 1988, "Internal Combustion Engine Fundamentals," McGraw-Hill Book Comapny, pp. 535.

15. "Solid Particle Erosion", EPRI Journal, October/November 1990. 

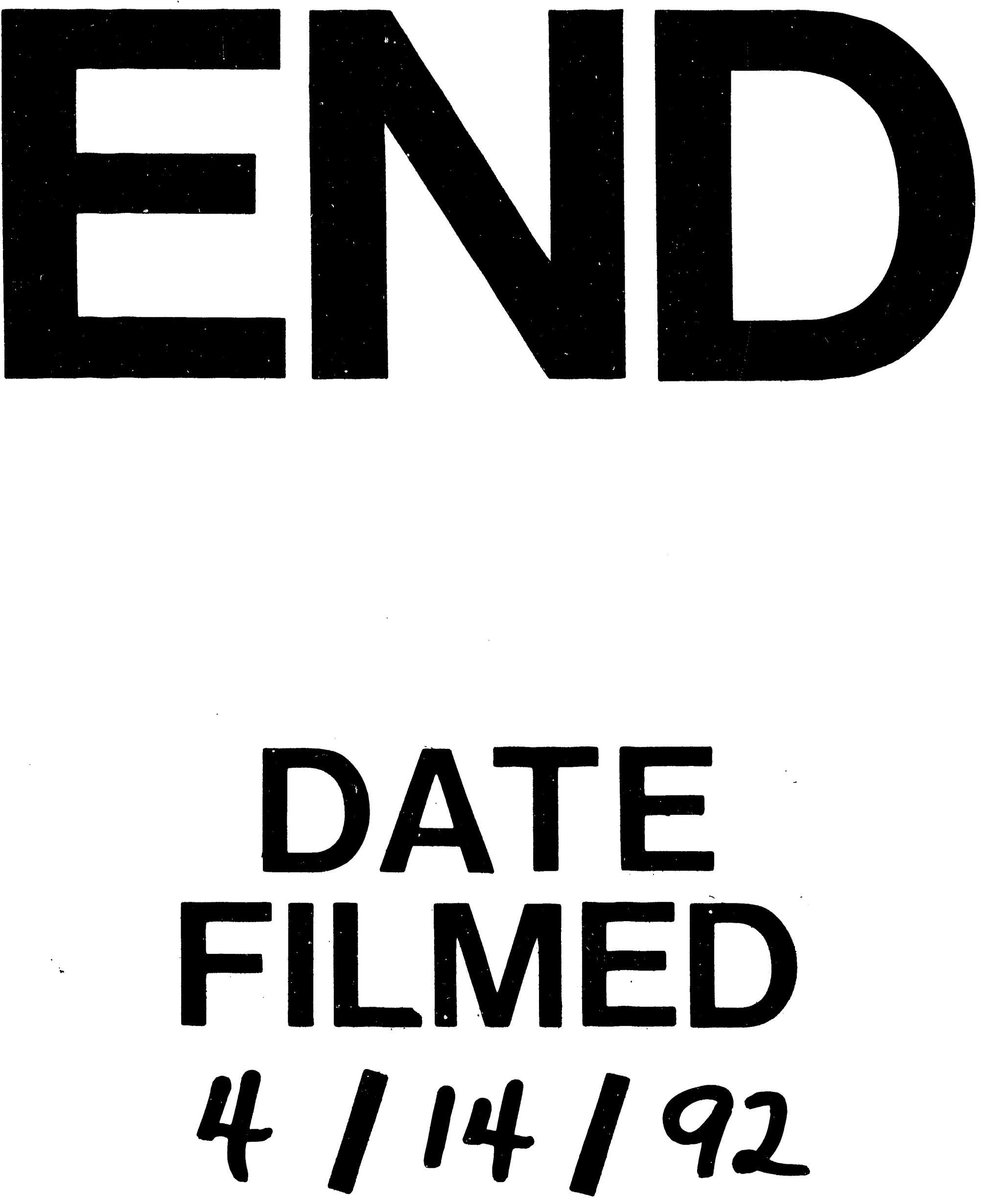
